\title{
Caracterización de la Alta Troposfera - Baja Estratosfera (UTLS) Subtropical: Tropopausa y Distribución Vertical de Ozono
}

Serie de notas técnicas digitales del Centro de Investigación Atmosférica de Izaña (CIAl)

Nota técnica digital 3 del CIAl

Juan José Rodríguez Franco 
(c) Ministerio de Medio Ambiente, y Medio Rural y Marino

Agencia Estatal de Meteorología

Madrid, 2009

Catálogo de Publicaciones de la Administración General del Estado:

https://cpage.mpr.gob.es/

NIPO: 784-09-013-8

https://doi.org/10.31978/784-09-013-8

Agencia Estatal de Meteorología (AEMET)

$\mathrm{C} /$ Leonardo Prieto Castro, 8

28040 Madrid

http://www.aemet.es/

@Aemet_Esp

f https://www.facebook.com/AgenciaEstataldeMeteorologia 


\section{Prólogo}

Con este trabajo, y bajo el mismo título de "Caracterización de la Alta Troposfera-Baja Estratosfera (UTLS) Subtropical: Tropopausa y Distribución Vertical de Ozono", Juan José Rodríguez Franco ha obtenido el Diploma de Estudios Avanzados (DEA) en el Departamento de Física Básica de la Facultad de Ciencias Físicas de la Universidad de La Laguna (ULL).

El DEA fue dirigido por los Doctores Emilio Cuevas Agulló (AEMET) y Juan Carlos Guerra (ULL), actuando este último como Tutor académico.

Juan José Rodríguez Franco ha realizado este trabajo como parte de su formación en el Tercer Ciclo de la Universidad de La Laguna. Esta investigación fue simultaneada con su formación en técnicas radiométricas del Centro Europeo de Calibración de Ozono (RBCCE), en el marco de una beca de formación de postgraduados de AEMET en 2008. 


\section{Índice general}

$\begin{array}{lr}\text { 1. Introducción } & 8\end{array}$

2. Técnicas instrumentales 11

2.1. Ozonosonda ECC. Descripción y Principios de Funcionamiento . . . . . . . 13

2.1.1. Descripción de la ozonosonda ECC . . . . . . . . . . . . . . . 13

2.1.2. Principio de medida del sensor de ozono . . . . . . . . . . . . 15

2.1.3. Factores que afectan al rendimiento de la ozonosonda . . . . . . . . . 17

2.1.4. Ecuación básica de la ozonosonda . . . . . . . . . . . . . . . 18

3. Metodología $\quad \mathbf{1 9}$

3.1. Depuración de los ozonosondeos. Implementación del método SLOM . . . . 19

3.1.1. Depuración de los sondeos . . . . . . . . . . . . . . . . . . 19

3.1.2. Detección de outliers . . . . . . . . . . . . . . . . . 20 20

3.1.3. Homogeneización . . . . . . . . . . . . . . . . . . . 24

3.2. Aspectos metodológicos . . . . . . . . . . . . . . . 25

3.2.1. Caracterización de la serie de sondeos meteorológicos . . . . . . . . 25

3.2.2. Determinación del nivel de la tropopausa. Definiciones . . . . . . . . 26

3.2.3. Climatologías. Cómputo y significancia . . . . . . . . . . . . 28

4. Climatología de la región UTLS subtropical 32

4.1. Caracterización de la Tropopausa sobre Tenerife . . . . . . . . . . . . . . . 33

4.2. Climatología de parámetros relativos al nivel de la tropopausa . . . . . . . . 36

4.2.1. Sistemas de tropopausa múltiple . . . . . . . . . . . . . . . . . 37

4.2.2. Sistemas de tropopausa simple . . . . . . . . . . . . . . . . 40

4.2.3. Perfiles de viento . . . . . . . . . . . . . . . . . . . . . 42

4.3. Estructura térmica en la región de la tropopausa . . . . . . . . . . . . . . . 46

4.4. Distribución de Ozono en la región UTLS subtropical . . . . . . . . . . . . 51

5. Conclusiones $\quad 63$ 


\section{Índice de figuras}

1.1. Diferencia entre tropopausa calculada y medida en función de la latitud . . 9

2.1. Esquema de un equipo de ozonosondeos . . . . . . . . . . . . . . . . . . 11

2.3. Ozonosonda ECC SPC-6A . . . . . . . . . . . . . . . . . . . . 14

2.4. Sección transversal de la ozonosonda ECC SPC-6A . . . . . . . . . . . . . 15

3.1. Errores de telemetría . . . . . . . . . . . . . . . . . . . . . 20

3.2. Ejemplos de perfiles de ozono típicos sobre Tenerife . . . . . . . . . . . . . 21

3.3. Ejemplos de aplicación del método SLOM . . . . . . . . . . . . . . . . 23

3.4. Interpolación de los perfiles . . . . . . . . . . . . . . . . . . . 24

3.5. Distribución mensual de ozonosondas lanzadas . . . . . . . . . . . . . 25

3.6. Altura máxima alcanzada por los sondeos individuales . . . . . . . . . . 26

3.7. Comparación de climatologías $\boldsymbol{T} \boldsymbol{L} \boldsymbol{B}$ vs $\boldsymbol{S} \boldsymbol{L} \boldsymbol{B} \ldots \ldots \ldots$. . . . . . . . . 29

3.8. Dependencia con el tamaño de la muestra del error estándar relativo . . . . 31

4.1. Altura observada de la tropopausa térmica desde Nov/1992 a Ago/2008 . . 33

4.2. Ejemplos de perfiles térmicos para todas las situaciones posibles . . . . . . . 33

4.3. Distribución de alturas de la tropopausa. Frecuencia de Brunt-Väisälä . . . 34

4.4. Relación entre la altura de la primera tropopausa térmica observada y la vorticidad relativa . . . . . . . . . . . . . . . 35

4.5. Porcentaje de sondeos con tropopausa simple, doble y triple . . . . . . . . . 36

4.6. Ciclo anual de la altura de la tropopausa para todos los tipos definidos. Tropopausa múltiple . . . . . . . . . . . . . . . . . . . 38

4.7. Idem a figura 4.6 , temperatura potencial . . . . . . . . . . . . . . . . 38

4.8. Ciclo anual de la altura de la tropopausa para todos los tipos definidos. Tropopausa simple . . . . . . . . . . . . . . . . . . . 4 41

4.9. Idem a figura 4.8 , temperatura potencial . . . . . . . . . . . . . . . 41

4.10. Climatología del viento para situaciones de tropopausa múltiple y de tropo-

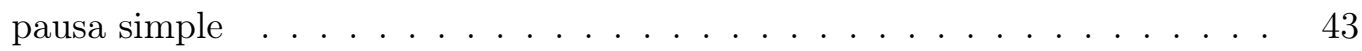

4.11. Situación correspondiente a una única tropopausa térmica detectada con chorro intenso, el 25 de Marzo de 1999 . . . . . . . . . . . . . . . . . 45

4.12. Comparación de perfil promedio SLB vs TLB para $N^{2} \ldots \ldots \ldots$. . . . . 46

4.13. Climatología de la frecuencia de Brunt-Väisälä . . . . . . . . . . . . . . 47

4.14. Climatología de la frecuencia de Brunt-Väisälä. Segunda tropopausa como

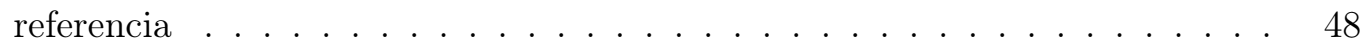

4.15. Variación estacional de la capa de inversión asociada a la tropopausa . . . . 49

4.16. Anomalías climatológicas mensuales para los perfiles de ozono . . . . . . . . 51

4.17. Distribución de frecuencias de las diferencias $\mathbf{T T 1}-\boldsymbol{O} 3 \boldsymbol{T} \ldots \ldots \ldots$ 
4.18. Idem a figura 4.1 , añadiendo la diferencia $\mathbf{Z}_{\mathbf{O 3 T}}-\mathbf{Z}_{\mathbf{T T} \mathbf{T}} \ldots \ldots \ldots \ldots$

4.19. Dos ejemplos mostrando la posición relativa de la tropopausa química respecto de la tropopausa térmica . . . . . . . . . . . . . . . . . . . 55

4.20. Ciclo anual observado en el ozono, y en la frecuencia de Brunt-Väisälä para situaciones de tropopausa múltiple . . . . . . . . . . . . . 56

4.21. Idem a figura 4.20, salvo que los valores climatológicos están referenciados a TT2 .

4.22. Ciclo anual observado en el ozono, y en la frecuencia de Brunt-Väisälä para situaciones con $\mathbf{Z}_{\mathbf{S i n g} \mathbf{T}} \geq \mathbf{1 4 , 5} \mathrm{km} \ldots \ldots \ldots \ldots . \ldots \ldots$

4.23. Máximos valores de viento en función de la longitud sobre Tenerife . . . . . 60

4.25. Esquema de la circulación ageostrófica asociada a un Jet Stream . . . . . . 61

4.26. Modelo conceptual sugerido para dar cuenta de los resultados obtenidos . . 62 


\section{Índice de tablas}

2.1. Composición de la solución (sensing solution type) al $1 \%$ para la ozonosonda SPC-6A . . . . . . . . . . . . . . . . . 15

2.2. Factores de corrección por eficiencia de la bomba para el sensor de ozono tipo ECC . . . . . . . . . . . . . . . . . . . 18

4.1. Número de sondeos para los que se detecta una única o múltiple tropopausa 38

4.2. Número de ozonosondeos con una única tropopausa térmica cuya altura es mayor o menor que el valor umbral $\sim 14,5 \mathrm{~km} \ldots \ldots . \ldots . \ldots 45$

4.3. Error estándar relativo $(\times 2)$ para el ozono en diferentes regiones atmosféricas 52

4.4. Porcentaje de ozonosondeos con el nivel de latropopausa térmica hallada por encima de la tropopausa química y viceversa, junto con la diferencia media de altura de ambos niveles . . . . . . . . . . . . . . . . . . 54 


\section{Capítulo 1}

\section{Introducción}

En los últimos años se ha prestado un gran interés a la región atmosférica en torno a la tropopausa, conocida también por sus siglas en inglés UTLS (Upper Troposphere-Lower Stratosphere. En gran parte, este resurgimiento de los estudios sobre la tropopausa ha sido motivado por el reconocimiento del importante papel que la tropopausa desempeña en un buen número de tópicos. Así, por ejemplo, aparece estrechamente relacionada con cambios en el ozono estratosférico [Hoerling et al., 1991, Steinbrecht et al., 1998], parece ser un buen indicador del cambio climático [Sausen and Santer, 2003] y aparece como un elemento activo en el intercambio de varias especies químicas entre la estratosfera y la troposfera [Danielsen, 1968, Wirth, 1995, Pan et al., 2004]. Es deseable por tanto un conocimiento preciso de la estructura espacial y temporal de la tropopausa con el fin de mejorar nuestra comprensión sobre una serie de fenómenos relacionados con el clima y la química atmosférica global.

El descubrimiento de la tropopausa se debe conjuntamente a Leòn Teisserenc de Bort, en Francia, y a Richard Assman, en Alemania, quienes simultáneamente advirtieron una inversión térmica en torno a $10-15 \mathrm{~km}$ de altura [Hoinka, 1997]. Sin embargo, a pesar de conocerse su existencia hace más de 100 años, el origen de la tropopausa es un problema aún no esclarecido del todo. Por ejemplo, no se sabe con exactitud qué factores son los que determinan la altura de la tropopausa. En la atmósfera tropical la tropopausa aparece como la consecuencia de una transición desde un equilibrio radiativoconvectivo en la troposfera hasta el equilibrio radiativo en la estratosfera. En la atmósfera de latitudes medias la influencia de perturbaciones baroclinas se traduce en una situación de mayor complejidad, dando origen a una tropopausa que presenta una gran variabilidad temporal y espacial. Son muchos los estudios que tratan de explicar la existencia de la tropopausa centrándose en algunos de los mecanismos relevantes, como pueden ser la influencia de los fenómenos radiativos, la dinámica de ondas baroclinas etc. [Thuburn and Craig, 1997, Ambaum, 1997, Haynes et al., 2001, Schneider, 2004].

Por lo tanto, a falta de un conocimiento unificado de los procesos físicos responsables de la formación de la tropopausa, las definiciones vigentes podríamos denominarlas empíricas, en el sentido de que se basan en el comportamiento de ciertos parámetros meteorológicos. En efecto, la tropopausa a menudo define una región donde tiene lugar una abrupta transición en los valores de propiedades atmosféricas y en la concentración de especies químicas [Pan et al., 2004, WMO, 1986]. Esta discontinuidad asociada a la tropopausa ha servido como base para una serie de definiciones formales, siendo la más usada la propuesta por la Organización Meteorológica Mundial [WMO, 1957], referida en la literatura como tropo- 
pausa térmica. Otra definición, utilizada habitualmente en latitudes tropicales, identifica la tropopausa con el nivel en el cual la temperatura es mínima. Es la tropopausa del punto frío, siendo especialmente relevante en el transporte de vapor de agua hacia la estratosfera en las regiones tropicales [Holton et al., 1995]. Una definición alternativa basada en la vorticidad potencial de Rossby-Ertel es reconocida como más apropiada para latitudes medias, identificando el nivel de la tropopausa con una determinada isosuperficie de vorticidad potencial (tropopausa dinámica). La ventaja de esta definición es su naturaleza material bajo condiciones conservativas, lo que la convierte en especialmente útil en estudios de STE (Stratosphere-Troposphere Exchange) [Wei, 1987]. Otra definición de la tropopausa más o menos extendida está basada en la distribución vertical de ozono [Bethan et al., 1996], ó tropopausa química, si bien estudios recientes apuntan hacia una redefinición de la misma basada en la relación entre marcadores típicamente estratosféricos y troposféricos en dicha región [Zahn et al., 2004, Pan et al., 2004]. Evidentemente, tal multitud de definiciones convierten a la región de la tropopausa en un objeto de estudio complejo, del cual se tiene un conocimiento incompleto.

Como se ha dicho al comienzo de esta introdución, especialmente durante la última década se han intensificado los esfuerzos dirigidos a mejorar el conocimiento que actualmente tenemos de la tropopausa. En particular se han llevado a cabo numerosos estudios observacionales, tanto a escala global como local [Seidel et al., 2001], [Gettelman and de Forster, 2002, Birner, 2006]. Una conclusión a destacar de dichos estudios, entre otras, ha sido el reconocimiento de la tropopausa como un estrato, más que una superficie, siendo cada vez más usuales los términos tropical tropopause layer (TTL) y extratropical tropopause layer (eXTTL). Sin embargo, es preciso destacar que la mayoría de estos estudios se han centrado bien en la región tropical o bien en latitudes medias. Son muy pocos los trabajos dedi-

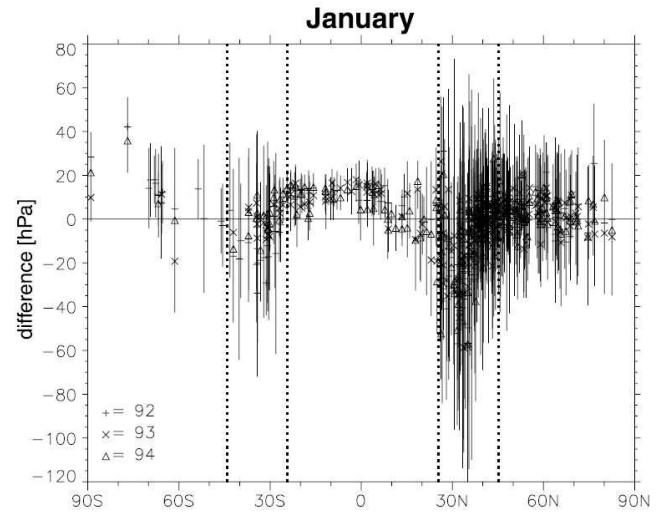

Figura 1.1 - Diferencia entre la tropopausa calculada a partir de datos de reanálisis y la hallada con datos de radiosondeo para el mes de Enero en función de la latitud (reproducida aqui con el permiso del autor, Dr. Thomas Reichler) cados al análisis de la región de transición desde la atmósfera tropical a la de latitudes medias, donde a menudo se observa una discontinuidad en la tropopausa, más que una transición continua desde la tropopausa tropical a la extratropical [Kochanski, 1955, Folkins and Appenzeller, 1996]. En contra de la visión tradicional que relaciona múltiples tropopausas con episodios de desdoblamiento de la tropopausa asociados a bajas profundas y DANAS (Depresiones Aisladas en Niveles Altos), en la región subtropical este fenómeno está íntimamente relacionado con una corriente de fuertes vientos en niveles altos, conocida como Chorro Subtropical ("Subtropical Jetstream"), lo que la hace especialmente interesante.

Estudios recientes atribuyen un papel decisivo al Chorro Subtropical en la distribución de especies químicas en la UTLS [Baray et al., 1998, Pan et al., 2004, Ray et al., 2004], mientra que por otra parte está documentada la dificultad inherente a los datos meteorológicos de cobertura global para resolver adecuadamente el nivel de la tropopausa en el rango de latitudes comprendidas entre $\sim 25^{\circ}$ a $\sim 45^{\circ}$ (ver figura 1.1) [Reichler et al., 2003]. En el caso 
de que, tal y como apuntan los estudios mencionados, la región subtropical desempeñara un papel fundamental en la composición química de la atmósfera a escala global, y si se tiene en cuenta que el análisis de los procesos de intercambio entre la troposfera y la estratosfera depende esencialmente de una correcta determinación del nivel de la tropopausa, podremos afirmar que resulta necesaria una revisión del marco conceptual vigente aplicado a la cuantificación del intercambio STE global, en el que se trabaja sobre la base de promedios zonales, además de una mejora cualitativa en los campos de datos de cobertura global, en el sentido de que éstos no son capaces de resolver adecuadamente las estructuras observadas en latitudes subtropicales.

Estas consideraciones han motivado la realización del siguiente estudio, organizado como sigue: el capítulo 2 se dedica a la descripción de la instrumentación utilizada, detallando los componentes básicos y los principios en los que se basa el funcionamiento de la ozonosonda. A continuación, capítulo 3, sección 3.1, se describe el proceso de depuración de los ozonosondeos: depuración de registros en los ficheros fuente, filtrado de outliers y homogeneización de la escala vertical. En particular, se describe el método empleado con el fin de eliminar posibles outliers en los perfiles verticales (técnica SLOM). En la sección 3.2 se caracteriza brevemente la serie de ozonosondeos en los que hemos basado este estudio, justificando su validez para la tarea que nos ocupa. También se introducen las diferentes definiciones de tropopausa empleadas, y se describe con detalle el cálculo de los valores climatológicos, introduciendo los parámetros que utilizaremos como "control de calidad" de los resultados. En el capítulo 4 se exponen los resultados logrados, abordando el estudio de la región UTLS subtropical desde una doble perspectiva: en primer lugar se caracteriza la región en torno a la tropopausa, tanto desde el punto de vista de una climatología de parámetros propios del nivel de la tropopausa (altura y temperatura potencial), como de las propiedades termodinámicas de la región adyacente. Se emplean todas las definiciones de tropopausa vigentes, como aproximación a la complejidad que le es propia. En segundo lugar se explora esta región desde una perspectiva dinámica, basando el análisis en los perfiles de ozono y en el estudio de la interacción con el Chorro Subtropical. Se propone al final de este capítulo un modelo conceptual que dé cuenta de los resultados obtenidos. Para acabar, dedicamos el capítulo 5 a exponer las conclusiones del estudio, sugiriendo futuras líneas de trabajo cuando proceda. 


\section{Capítulo 2}

\section{Técnicas instrumentales}

Un ozonosondeo consiste en el lanzamiento de un sensor de ozono que envía continuamente a un receptor en tierra información acerca de la cantidad de ozono en cada nivel de la atmósfera. Usualmente el sensor de ozono se halla acoplado por medio de una interfaz electrónica a una radiosonda estándar, que además de los datos de ozono, envía al receptor en tierra datos de temperatura, presión, humedad relativa del aire y datos sobre dirección y módulo del vector viento obtenidos a partir de un sistema de posicionamiento GPS. Dados el tamaño y peso del conjunto ozonosonda-radiosonda, típicamente con dimensiones $19 \mathrm{x} 19 \mathrm{x}$ $25 \mathrm{~cm}$ y peso aproximado de $1200 \mathrm{gr}$, el lanzamiento se realiza utilizando un pequeño globo meteorológico lleno de Helio. En la figura 2.1 se muestra el esquema básico correspondiente a un equipo de ozonosondeo

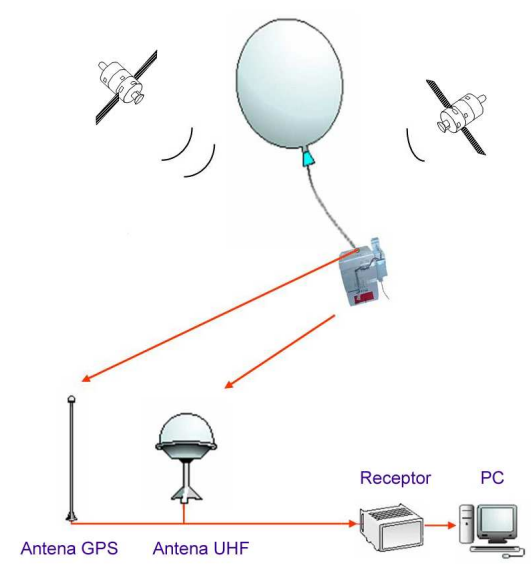

Figura 2.1 - Esquema correspondiente a un equipo de ozonosondeos

La figura 2.2 (a) ilustra el conjunto ozonosonda-radiosonda preparado para el lanzamiento. La conexión de la ozonosonda con la radiosonda tiene lugar a través de una tarjeta electrónica (Väisäla RSA11) dedicada a transferir los datos de corriente y temperatura del 


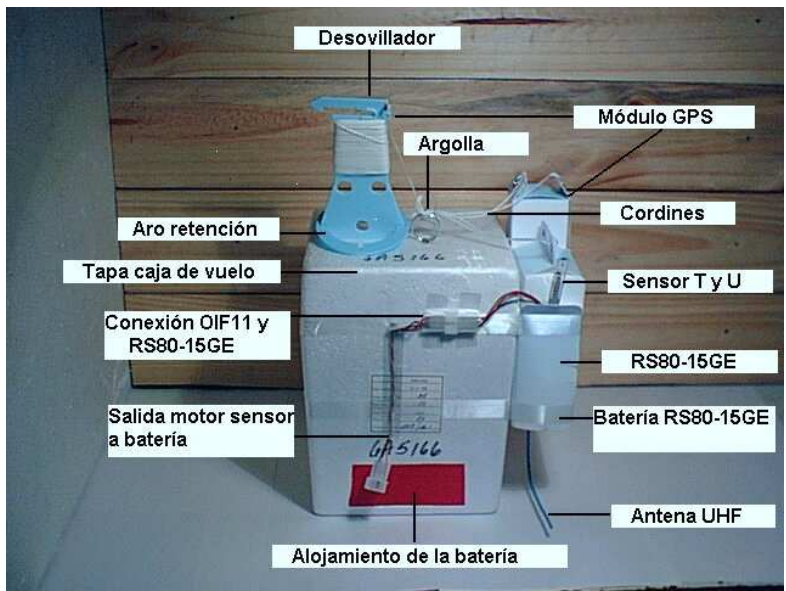

(a)

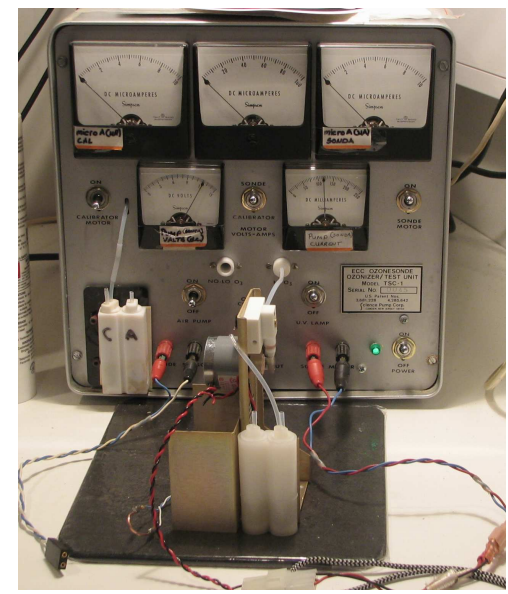

(b)

Figura 2.2 - En (a) se muestra el conjunto ozonosonda-radiosonda ya preparado para el lanzamiento. La figura (b) corresponde a la unidad ozonizadora utilizada para el acondicionamiento de la ozonosonda

sensor necesarios para el cálculo de de la cantidad de ozono a la radiosonda, la cual reenvía esta información junto con la que ella misma obtiene con sus sensores de temperatura, presión y humedad al equipo receptor en tierra vía radio. Desde comienzos del programa de ozonosondeos en Noviembre de 1992 hasta Octubre de 1997 se usaron radiosondas RS80. A partir de este momento y hasta el año 2005 se actualizó al modelo RS80-15GE, cambiándose nuevamente en el año 2005 y hasta la actualidad por el modelo RS92. Las características de los sensores con los que está equipada la radiosonda $R S 92$ son las siguientes:

- Temperatura: termistor con rango de medida de $+60^{\circ}$ a $-90^{\circ}$ y resolución de $0,1^{\circ}$.

- Presión: barómetro con rango de medida de 1080 a $3 \mathrm{hPa}$ y resolución de $0,1 \mathrm{hPa}$.

- Humedad: capacitor de película fina con rango de medida de $0 \%$ a 100 \% y resolución $1 \%$.

El equipo de recepción utilizado en tierra es un Digi-Cora Marwin-11 de Väisäla conectado a una antena multipolar de telemetría que recibe los datos de la radiosonda y a un ordenador PC en el que se ejecuta el programa de adquisición de radiosondeos (METGRAPH). Este programa presenta los datos de forma gráfica y crea y almacena los ficheros de datos después de depurar previamente la información recibida.

Para la preparación de la ozonosonda antes del lanzamiento se utiliza una unidad ozonizadora y de comprobación (figura 2.2 (b)) y un fluxómetro. La unidad ozonizadora se utiliza para acondicionar el sensor de ozono y para comprobar su funcionamiento. Esto se hace generando una cantidad fija de ozono gracias a un generador de ozono incorporado y comparando la corriente debida al sensor en pruebas con la producida por el sensor calibrador incluido en la unidad. Tambien se utiliza este equipo para obtener la corriente de fondo, medida con un polímetro de alta precisión. El fluxómetro es necesario para el cálculo del flujo de aire que aspira la bomba de la ozonosonda. 


\subsection{Ozonosonda ECC. Descripción y Principios de Funciona- miento}

La ozonosonda es un instrumento diseñado para el estudio de la distribución vertical de ozono atmosférico hasta una altitud aproximada de $30-35 \mathrm{~km}$, constituyendo la principal fuente de datos a la hora de obtener series temporales de ozono lo suficientemente extensas y con óptima resolución vertical, especialmente en la región UTLS. Su funcionamiento se basa en técnicas de análisis químico,

En la actualidad tres son los tipos de ozonosonda más usados:

- Brewer-Mast (BM)

- Electrochemical Concentration Cell (ECC)

- Carbon-Iodine (KC96)

El principio de funcionamiento es similar para todas, a saber, la generación de la molécula $I_{2}$ a partir del ozono según la reacción redox ${ }^{1}$

$$
2 \mathrm{KI}+\mathrm{O}_{3}+\mathrm{H}_{2} \mathrm{O} \rightarrow 2 \mathrm{KOH}+\mathrm{I}_{2}+\mathrm{O}_{2}
$$

si bien existen diferencias instrumentales notables entre ellas.

Se proporciona a continuación una descripción detallada de la ozonosonda del tipo ECC (Electrochemical Concentration Cell), siendo ésta la utilizada por el Centro de Investigación Atmósferica de Izaña desde Noviembre de 1992.

\subsubsection{Descripción de la ozonosonda ECC}

La ozonosonda ECC fue inicialmente desarrollada por Komhyr con el objetivo de proporcionar un dispositivo adecuado para el análisis continuo durante periodos de tiempo relativamente extensos de componentes químicos que, o bien liberan, o bien consumen halógenos según reacciones químicas conocidas, a la vez que se superaban las deficiencias presentes en los métodos similares existentes [Komhyr, 1969, Komhyr and Harris, 1971].

Los componentes principales de la ozonosonda ECC se muestran en la figura 2.3, destacando como principales los siguientes:

- Sensor de ozono

- Bomba, conectada a una batería, utilizada para obtener la muestra del gas a analizar

- Interfaz electrónica que conecta el sensor de ozono con la radiosonda meteorológica responsable de la telemetría

\footnotetext{
${ }^{1}$ Una excepción la constituye la ozonosonda japonesa KC79, pues con esta se usa KBr en vez de KI. Sin embargo, la reacción de reducción en el cátodo sigue siendo $I_{2}+2 e^{-} \rightarrow 2 I^{-}$
} 


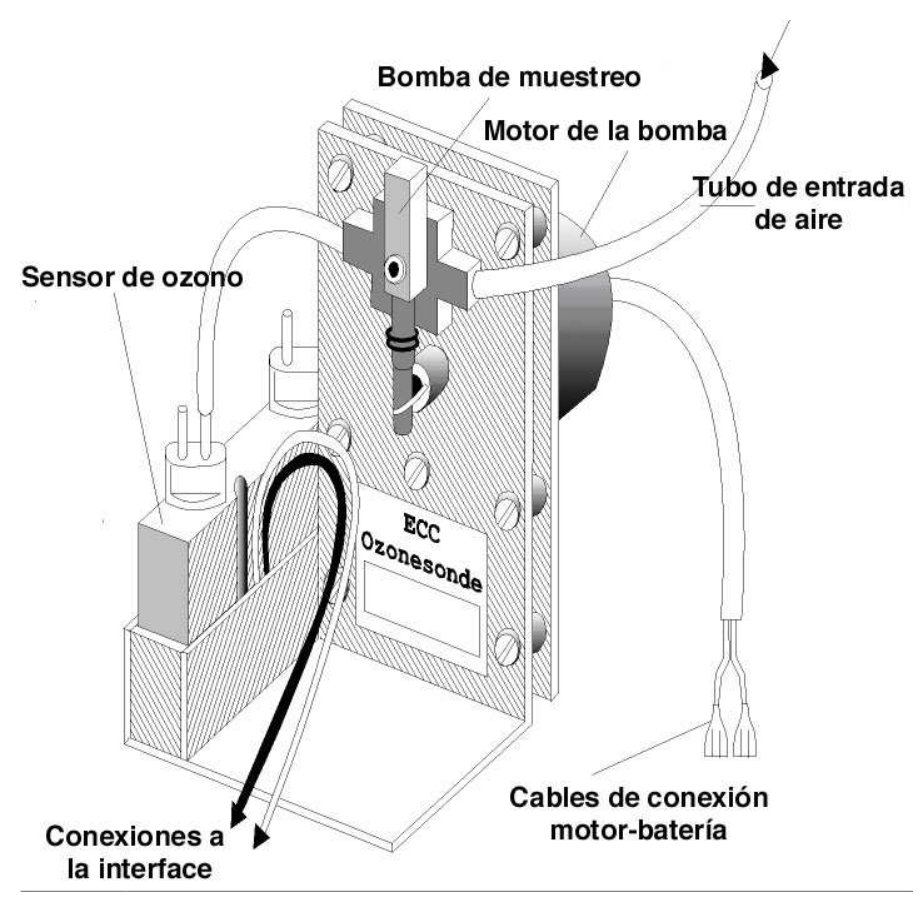

Figura 2.3 - Ozonosonda $E C C S P C-6 A$

La figura 2.4 muestra con más detalle la estructura del sensor de ozono, el cual no es más que una celda electroquímica compuesta por dos medias celdas. Cada una de las cavidades destinadas a albergar el cátodo y el ánodo está fabricada con un material inerte, en este caso resina de teflón, estando ambos compartimentos comunicados en la base por medio de un pequeño orificio cilíndrico, en el cual se ubica un puente iónico. La función de este último es permitir la transferencia iónica entre las soluciones de cada media celda a la vez que se conserva la concentración en cada una de ellas. Se muestran también en la figura 2.4 los electrodos de cada media celda, así como los hilos conductores que partiendo de ellos son accesibles desde el exterior para su posterior conexión a un microamperímetro. El electrodo que hace la función de cátodo (reductor) presenta una mayor superficie que el correspondiente al ánodo (oxidante).

En la cavidad del cátodo se incluyen dos tubos: uno de ellos, el de mayor longitud, conduce la muestra de aire a analizar hasta la solución y el otro, más corto, funciona como conducto de ventilación, de modo que el aire introducido para el análisis pueda regresar nuevamente al exterior, evitando así el aumento de presión en el interior de la celda. Desde la semicelda del ánodo sólo surge un tubo corto con idéntica función.

El volumen de aire cuyo contenido en ozono se desea determinar se introduce en el sensor de la ozonosonda por medio de la bomba mostrada en la figura 2.3, fabricada con igual material que la celda. Es preciso señalar que dada la altísima reactividad del ozono, es fundamental que el instrumento diseñado para su análisis esté fabricado a partir de un material inerte al mismo. Este es el caso del politetrafluoroetileno, o resina de teflón. 


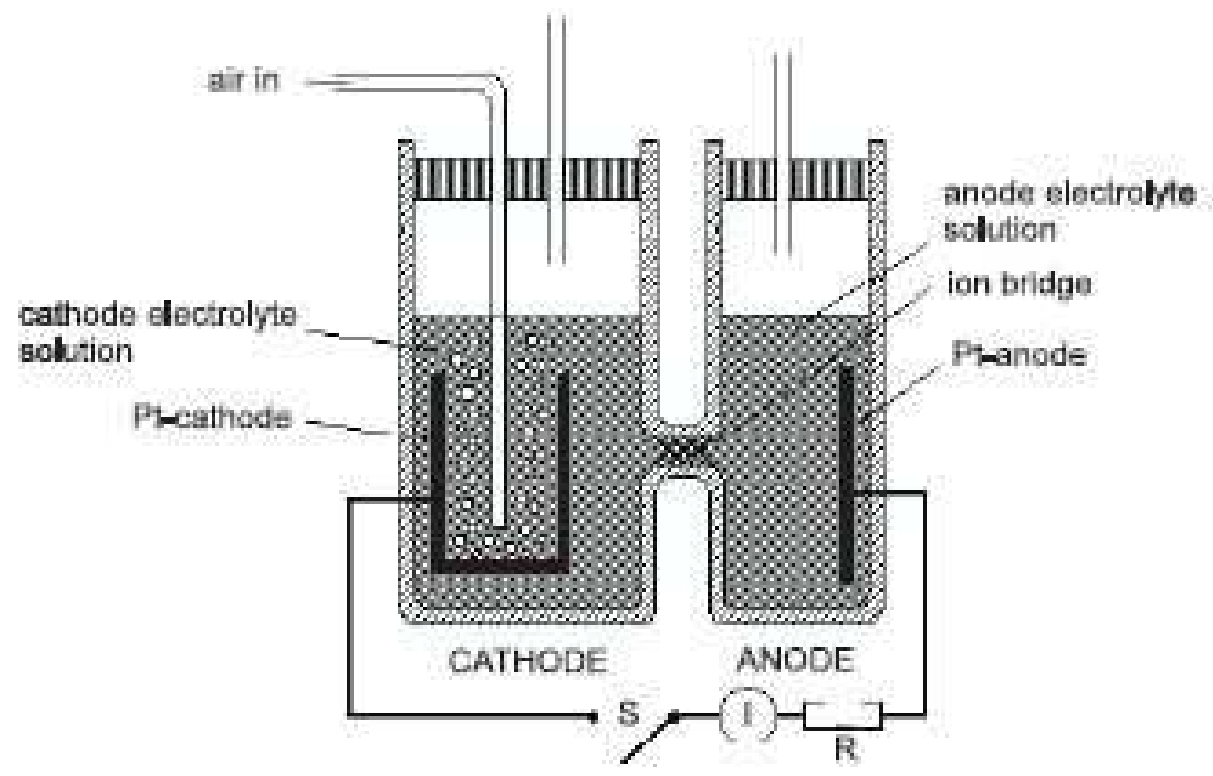

Figura 2.4 - Sección transversal de la ozonosonda ECC SPC-6A

\subsubsection{Principio de medida del sensor de ozono}

Los dos electrodos de la celda electroquímica se hallan inmersos en una solución de ioduro de potasio (KI) con diferentes concentraciones para el ánodo y el cátodo. Además, y con el fin de mantener el $p h$ de la solución igual a 7 (solución neutra), se añaden también otros compuestos que actúan como "buffer". La solución electrolítica contiene además KBr. Como ejemplo, en la tabla 2.1 se muestran los componentes y los pesos correspondientes necesarios para obtener una solución al $1 \%$ de KI.

Para la preparación de la solución se procede como sigue: tras disolver completamente los compuestos en $500 \mathrm{ml}$ de agua bidestilada, añadimos agua hasta conseguir $1000 \mathrm{ml}$ de solución. Para el cátodo utilizaremos la solución así obtenida, y para el ánodo añadiremos 90 gr de KI a $50 \mathrm{ml}$ de la solución anterior (el resultado será una solución saturada de KI). Como consecuencia de las diferentes concentraciones de KI en ambas semiceldas se genera espontáneamente una fuerza electromotriz, que de acuerdo a las semirreacciones

$$
\begin{aligned}
& I_{2}+2 e^{-} \rightarrow 2 I^{-} \\
& 3 I^{-} \rightarrow I_{3}^{-}+2 e^{-}
\end{aligned}
$$

\begin{tabular}{cc}
\hline Tipo SST & Descripción de SST (Sensing Solution Type) \\
\hline \multirow{2}{*}{ 1A } & $10.00 \mathrm{gr}$ de KI \\
& $25.00 \mathrm{gr} \mathrm{de} \mathrm{KBr}$ \\
& $1.25 \mathrm{gr} \mathrm{de} \mathrm{NaH}_{2} \mathrm{PO}_{4} \cdot \mathrm{H}_{2} \mathrm{O}$ \\
$5.00 \mathrm{gr}$ de $\mathrm{Na}_{2} \mathrm{HPO}_{4} \cdot 12 \mathrm{H}_{2} \mathrm{O}$ \\
\hline
\end{tabular}

Tabla 2.1 - Composición de la solución (sensing solution type) al 1\% para la ozonosonda SPC-6A 
para el cátodo y el ánodo respectivamente, viene dada por la expresión siguiente:

$$
E \approx-\frac{0,0591}{2} \log \left(\frac{a_{I^{-}}^{2} a_{I_{3}^{-}}}{a_{I_{2}} a_{I^{-}}^{3}}\right)
$$

Si conectáramos ambos electrodos externamente y dejáramos evolucionar al sistema el tiempo suficiente, las semirreacciones de oxidación-reducción anteriores darían como resultado un estado de equilibrio en el cual el cociente de actividades tendería a la unidad, y en consecuencia el potencial de celda sería aproximadamente nulo (o sea, las semirreaciones anteriores ocurren espontáneamente para la celda considerada). A partir de aquí, si logramos de alguna manera modificar la concentración de $I_{2}$ en el cátodo, la fuerza electromotriz pasará a ser positiva, forzando nuevamente los procesos de reducción-oxidación en el sensor de la ozonosonda.

Esto es precisamente lo que ocurre cuando inyectamos aire a la solución del cátodo. El ozono presente en la muestra reacciona con el electrólito en el cátodo según la reacción

$$
2 \mathrm{KI}+\mathrm{O}_{3}+\mathrm{H}_{2} \mathrm{O} \rightarrow 2 \mathrm{KOH}+\mathrm{I}_{2}+\mathrm{O}_{2}
$$

incrementándose de esta manera la concentración de $I_{2}$. Puesto que cada molécula $O_{3}$ genera una molécula $I_{2}$, la corriente medida será proporcional a la concentración de ozono presente en la muestra de aire analizada (pues como se ha visto, en la reacción neta $I_{2}+3 I^{-} \rightarrow$ $2 I^{-}+I_{3}^{-}$tiene lugar el flujo de dos electrones a través del circuito externo). Así pues, consideramos al sensor de ozono como un contador de moléculas de ozono por unidad de tiempo. Podemos ahora relacionar la corriente medida en el circuito externo con la concentración de ozono en la muestra de aire combinando la ecuación de los gases ideales, $(P V=n R T)$ y la ley de Faraday, $\left(c=\frac{i t}{n F}\right)$ de la electrólisis. La presión parcial de ozono se podrá escribir como

$$
p_{O_{3}}=\frac{n}{V} R T
$$

o utilizando la ley de Faraday,

$$
\begin{aligned}
p_{O_{3}} & =\left(\frac{R}{2 F}\right) T \frac{i t}{V} \\
& =4,307 \times 10^{-5} i T\left(\frac{t}{V}\right)
\end{aligned}
$$

Trabajando con unidades de $\mathrm{mPa}, \mathrm{cm}^{3}$ y $\mu A$, resulta ${ }^{2}$

$$
p_{O_{3}}(m P a)=4,31 \times 10^{-4} i T\left(t_{100}\right)
$$

donde

$\mathbf{p}_{\mathrm{O}_{3}}$ : presión parcial de ozono $(\mathrm{mPa})$

i: corriente medida debida al ozono $(\mu \mathrm{A})$

\footnotetext{
${ }^{2}$ El cociente $\left(\frac{V}{t}\right)$ es una medida del flujo de aire generado por la bomba, y su cálculo forma parte de los procedimientos previos al lanzamiento de la ozonosonda. En la práctica, dicha magnitud se obtiene calculando el tiempo empleado por una burbuja jabonosa en recorrer $100 \mathrm{ml}$ de aire.
} 
T: temperatura de la muestra de aire $^{3}$ (en K)

$\mathbf{t}_{\mathbf{1 0 0}}$ : tiempo empleado por la bomba en aspirar $100 \mathrm{ml}$ de aire (s)

Esta es la ecuación básica de la ozonosonda tipo ECC. En la práctica se aplican una serie de correciones que dan cuenta de diversos efectos no tenidos en cuenta en la ecuación 2.1, pero que, como mostraré a continuación, resultan fundamentales a la hora de obtener medidas fiables.

\subsubsection{Factores que afectan al rendimiento de la ozonosonda}

\section{Corriente de fondo, o residual $\left(i_{b g}\right)$}

La ozonosonda no sólo es sensible al ozono. También lo es a otras especies químicas oxidantes. Como resultado de esto, aún en ausencia de ozono, es posible detectar una pequeña corriente a la que llamaremos corriente de fondo, $\mathbf{i}_{\mathbf{b g}}$, definida como la corriente medida cuando la muestra de aire analizada tiene una concentración de ozono nula. La magnitud de esta corriente oscila en torno a $0,08 \mu \mathrm{A}$, o equivalentemente, valores de concentración de ozono del orden de $0,5-1 \mathrm{mPa}$. Por lo tanto, se trata de un parámetro crítico en regiones de la atmósfera con bajos niveles de ozono, en particular en la troposfera media y alta. Es aquí donde la corriente residual puede afectar significativamente a las medidas. Para evitarlo en la medida de lo posible (ver siguiente párrafo), en la ecuación 2.1 se sustituye $i \rightarrow i-i_{b g}$.

Dos son las aproximaciones adoptadas mundialmente para la corrección por corriente de fondo (es preciso señalar aquí que aún hoy el origen exacto de la corriente de fondo sigue siendo una cuestión debatida por la comunidad científica):

$\mathbf{i}_{\text {bg }}$ constante. Se aplica a todo el perfil la corriente residual medida antes del lanzamiento (Smith et al., 1994). Este es el método que tiende a imponerse, y es asimismo el método adoptado por el personal del CIAI desde los comienzos del programa de ozonosondeos en Tenerife

$\mathbf{i}_{\text {bg }}$ dependiente de la altura. Esta forma de proceder se basa en la afirmación de que la respuesta del sensor de ozono depende del oxígeno [Komhyr, 1969]. Consecuentemente, cabe esperar que a medida que la sonda asciende encontrará menor concentración de oxígeno, y la corriente de fondo decrecerá proporcionalmente

\section{Eficiencia de la bomba de muestreo}

Para presiones inferiores a $100 \mathrm{hPa}$ la eficiencia de la bomba disminuye debido a la baja densidad del aire. Para corregir este efecto, el método estándar consiste en aplicar una tabla de factores de corrección en función de la presión atmosférica. Estas tablas son específicas para cada tipo de ozonosonda, y han sido obtenidas a partir de medidas realizadas en laboratorio.

\footnotetext{
${ }^{3} \mathrm{La}$ temperatura de la muestra de aire se mide colocando un sensor de temperatura en un orificio localizado en la bomba de muestreo. Sin embargo, esto es así únicamente para la ozonosonda SPC-6A. En el caso de la SPC-5A, operativa en Tenerife hasta el año 1998, no existía tal orificio, de modo que se tomaba la temperatura en el interior de la caja como aproximación a la temperatura de la muestra de aire. En todo caso, el efecto sobre las medidas al cambiar de una a la otra cabe esperar que sea mínimo (WMO-Report No.158: The 2000 WMO internacional intercomparison of operating procedures for ECC ozone sondes at the enviromental simulación facility at Jülich, WMO TD No.1225)
} 
La tabla 2.2 muestra los factores de correción utilizados para las ozonosondas SPC-5A y SPC-6A [Komhyr, 1986]. Para un nivel arbitrario P, el factor de corrección se obtiene mediante interpolación lineal, considerado dicho factor función de la presión.

\begin{tabular}{cl}
\hline $\begin{array}{l}\text { Presión } \\
\text { atmosférica }(\mathbf{h P a})\end{array}$ & $\begin{array}{l}\text { Correción por eficiencia de la bomba } \\
\mathbf{3}^{\mathbf{3}} \text { de solución en cátodo }\end{array}$ \\
\hline 2.0 & 1.171 \\
3.0 & 1.131 \\
5.0 & 1.092 \\
10.0 & 1.055 \\
20.0 & 1.032 \\
30.0 & 1.022 \\
50.0 & 1.015 \\
100.0 & 1.011 \\
200.0 & 1.008 \\
300.0 & 1.006 \\
500.0 & 1.004 \\
1000.0 & 1.000 \\
\hline
\end{tabular}

Tabla 2.2 - Factores de corrección por eficiencia de la bomba para el sensor de ozono tipo ECC

\section{Normalización a ozono total en columna}

La siguiente corrección consiste en aplicar al perfil de ozono la ratio resultante de dividir el ozono total en columna obtenido con otros medios (por ejemplo, el ozono total proporcionado por un espectrofotómetro Brewer), entre la misma magnitud calculada con los datos de la ozonosonda ${ }^{4}$. Sin embargo, esta práctica ha sido cuestionada, argumentando que puesto que el ozono total en columna se halla fuertemente influenciado por el máximo de ozono localizado en la estratosfera (en torno a $25 \mathrm{~km}$ para la latitud de Tenerife), dicha normalización pudiera afectar seriamente a las medidas en regiones como la troposfera, donde se registran concentraciones de ozono muy inferiores. En todo caso, y aunque no se aplique como factor de corrección, la "ratio" definida resulta útil a la hora de decidir si un perfil es válido o no, utilizando como criterio que el factor de normalización no difiera en más de un $10-20 \%$ de la unidad.

\subsection{4. $\quad$ Ecuación básica de la ozonosonda}

Aplicando las correcciones anteriores, la ecuación básica de la ozonosonda ECC quedará

$$
p_{O_{3}}(m P a)=4,31 \times 10^{-4}\left(i-i_{b g}\right) T t_{100} C_{e f}
$$

\footnotetext{
${ }^{4}$ El método estándar para calcular el ozono total en columna a partir de un perfil de ozono consiste en sumar al perfil integrado el ozono residual. Este último se refiere a la columna de ozono por encima del nivel más alto alcanzado por la ozonosonda, suponiendo una razón de mezcla constante de ozono igual a la obtenida en dicho nivel
} 


\section{Capítulo 3}

\section{Metodología}

\subsection{Depuración de los ozonosondeos. Implementación del mé- todo SLOM (Spatial Local Outlier Measurement)}

Una parte fundamental en el desarrollo de cualquier estudio en el ámbito de la investigación científica consiste en la recopilación de datos con calidad suficiente como para poder confiar en los resultados que obtengamos a partir de ellos. En este sentido son dos las aproximaciones llevadas a cabo para el estudio que nos ocupa: en el caso de los parámetros obtenidos de la radiosonda (fundamentalmente presión y temperatura, además de velocidad y dirección del viento) se han inspeccionado los perfiles verticales en busca de datos anómalos debidos a errores instrumentales (fallos en los sensores o bien fallos en la telemetría), y en el caso de la ozonosonda, además de la eliminación de datos erróneos, se ha chequeado la bondad del perfil de ozono obtenido por comparación de los valores de ozono total calculados a partir de dos medios independientes, en nuestro caso la ozonosonda y un espectrofotómetro brewer (ver sección 2.1.3). En el caso de que la ratio entre ambos valores difiera más del $10 \%$ de la unidad, se descarta el ozonosondeo correspondiente. Dedicaremos las páginas siguientes a comentar brevemente el proceso seguido.

\subsubsection{Depuración de los sondeos}

Como se dijo anteriormente, el software utilizado para la adquisición y el archivo de los datos generados durante el ozonosondeo se denomina METGRAPH, de Väisäla siendo la versión más reciente la 5.21, incorporada a la estación de ozonosondeos en Julio del año 2000. Los archivos generados son archivos en formato binario, y proporcionan, entre otros, los parámetros presión, temperatura, humedad relativa y presión parcial de ozono. Mediante un script PERL, sonozo.pl, es posible generar, a partir de los ficheros binarios, un fichero en formato $A S C I I$ el cual contiene, además de los parámetros mencionados anteriormente, otros derivados directamente de éstos: temperatura potencial, coeficiente de Brünt-Vaisala, ozono integrado y razón de mezcla de ozono (en ppbv). Estos son los ficheros en los que se basa el estudio que nos ocupa.

El periodo de tiempo analizado, desde Noviembre de 1992 hasta Agosto de 2008, ha sido lo suficientemente extenso como para que hayan tenido lugar una serie de cambios de procedimiento más o menos importantes (como puede deducirse de la figura 3.1), sobre todo en el caso de la instrumentación y el software de adquisición. Aunque no es el caso que nos ocupa, 
es fundamental caracterizar del modo más exhaustivo posible la metodología empleada durante el periodo de estudio, entendiendo por metodología los procedimientos de operación de la ozonosonda, así como cualquier cambio en la instrumentación. Esto es particularmente importante siempre que se quiera abordar un estudio serio de series temporales, cálculo de tendencias, etc.

El primer paso en la depuración consistió en eliminar de los sondeos todos los registros erróneos, bien debidos a retornos de carro inapropiados, o bien debidos a truncamientos inesperados, posiblemente originados por fallos puntuales en la telemetría.

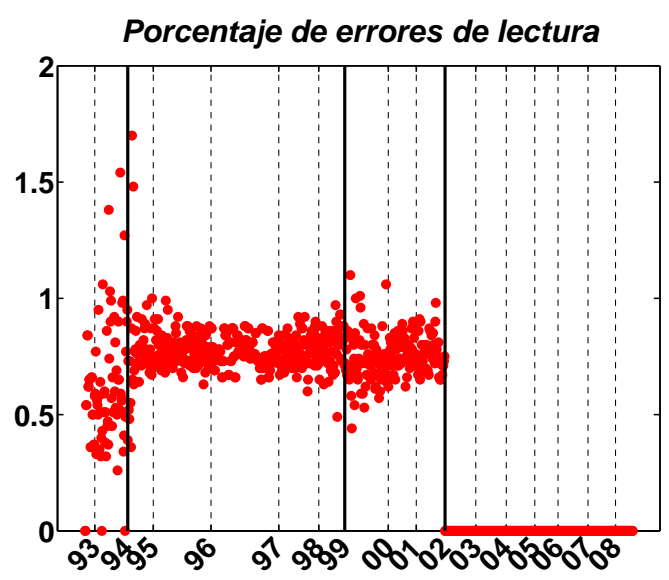

Figura 3.1 - Errores debidos a telemetría defectuosa. Notar que los intervalos entre años consecutivos son proporcionales a los ozonosondeos realizados
La figura 3.1 muestra el porcentaje de tales errores para cada sondeo individual. Se identifica claramente el momento en que se adopta el nuevo software para la adquisición, en el año 2002, lo se traduce en una mejora del $100 \%$ en el nivel de ruido debido a los fallos de software. En todo caso, el numero de líneas eliminadas nunca supera el $1 \%$, salvo en los años 1992 y 1993, si bien es cierto que estos primeros sondeos presentan el menor número de registros (es decir, una menor resolución vertical). Utilizo esta misma figura para hacer notar la frecuencia de lanzamiento de ozonosondeos: salvo en los años 1995, 1996 y 1999, en los que tuvieron lugar en Izaña campañas concretas (por ejemplo TRACAS, Transport of Chemical species Across the Subtropical tropopause, celebrada entre los meses de Febrero,

Marzo y Abril del año 1999), se han llevado a cabo aproximadamente el mismo número de lanzamientos para todos los años.

\subsubsection{Detección de outliers}

Tras la depuración del conjunto de ozonosondeos, aún queda por realizar el filtrado de potenciales outliers, o dicho de otra manera, la detección de elementos del perfil que parecen desviarse de forma anómala respecto del resto de elementos. En absoluto se trata de una tarea trivial, pues a menudo el análisis sistemático de un conjunto de datos en busca de outliers puede llevar a la pérdida de información muy valiosa concerniente a los fenómenos estudiados. Es necesario siempre el conocimiento más o menos detallado por parte del investigador de los procesos básicos involucrados.

En el caso de los perfiles verticales de diferentes parámetros atmosféricos resulta útil tomar como referencia un perfil promedio. Pongamos como ejemplo la concentración de ozono. En el caso de Tenerife ${ }^{1}$ (ver figura 3.2, izquierda), el perfil promedio muestra una concentración aproximadamente constante en la región situada a alturas inferiores al nivel de la tropopausa. En torno a este último nivel se observa un incremento brusco en las

\footnotetext{
${ }^{1}$ En el capítulo 2 de la Nota Técnica no.4, del Observatorio Atmósférico de Izaña: Programa de ozonosondeos del Observatorio Atmósférico de Izaña. El ozono sobre Tenerife y su relación con la procedencia de las masas de aire, se pueden consultar los resultados de la comparación de Izaña con otras estaciones NDSC (actualmente NDACC), así como las características principales de la distribución vertical del ozono en la troposfera y la estratosfera sobre Tenerife.
} 
concentraciones de ozono, alcanzándose un gradiente vertical superior a $500 p_{p b v m^{-1}}$. El máximo de ozono se registra en promedio en torno a los $25 \mathrm{~km}$ de altura, aunque tanto la localización como la magnitud varían en función de la época del año. A partir de este máximo la concentración de ozono disminuye progresivamente a medida que se asciende en la atmósfera.

Sin embargo, en la práctica a menudo se observan desviaciones, bien positivas o bien negativas, respecto de este perfil promedio (ver figura 3.2, derecha). Son frecuentes estructuras laminares de extensión vertical variable, relacionadas con procesos dinámicos o químicos, o bien con una combinación de ambos. Como ejemplo de estos procesos podemos mencionar las intrusiones en la troposfera de aire estratosférico rico en ozono, inducidas por estructuras tales como DANAS (Depresión Aislada en Niveles Altos) [Holton et al., 1995, Cuevas and Rodríguez, 2001] o bien el transporte en la troposfera libre de masas de aire en cuyo seno se ha generado ozono a partir de reacciones fotoquímicas.
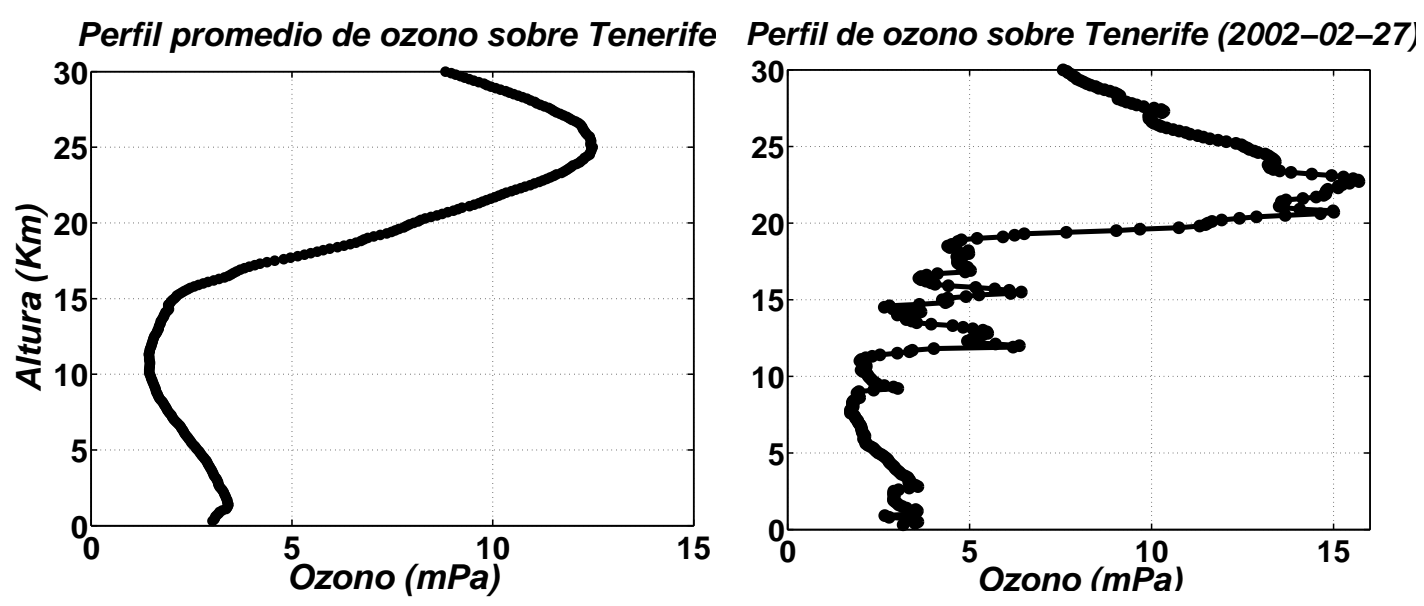

Figura 3.2 - A la izquierda, perfil promedio de ozono sobre la isla de Tenerife (28 $28^{\prime} N$, 16 $16^{\circ} 14^{\prime} W$ ), calculado a partir de un número arbitrario de ozonosondeos. A la derecha, perfil de ozono correspondiente al dia 27 de Febrero de 2002

Conviene por tanto tener esto en cuenta a la hora de evaluar un perfil de ozono atmosférico en busca de outliers. En la práctica estaremos interesados en la detección de datos anómalos debidos a errores instrumentales.

El problema que se plantea ahora es: ¿cómo detectar tales objetos distinguiéndolos de las observaciones debidas a procesos atmosféricos legítimos?. Teniendo en cuenta las consideraciones anteriores, esto es relativamente sencillo de resolver mediante inspección visual directa. Pero en el caso de tener que analizar cientos, quizás miles de perfiles meteorológicos, es preciso implementar alguna técnica capaz de resolver el problema por nosotros.

A priori estoy interesado en el análisis individual de cada ozonosondeo, de modo que estoy tratando con un conjunto de datos de naturaleza intrínsicamente espacial (del orden de 2000 puntos de muestreo por ozonosondeo, suponiendo una altura máxima alcanzada de unos $30 \mathrm{Km}$ ). En este caso es fundamental tener presente que existen mecanismos capaces de conectar unas regiones con otras, o dicho de otra forma, existe correlación espacial entre las diferentes observaciones. Además, dada la enorme variabilidad que muestra la atmósfera en todas las escalas, no hay que perder de vista el hecho de que la varianza no tiene por 
que ser constante a lo largo de todo el perfil.

Es por esto por lo que dejan de ser aplicables los métodos tradicionales de detección de outliers, basados muchos de ellos en la suposición de una determinada función de distribución capaz de modelar más o menos acertadamente la muestra de datos investigada, además de usar las hipótesis de varianza constante y de no autocorrelación. ${ }^{2}$ Este es el caso por ejemplo del conocido umbral \pm 3 desviaciones estándar en el caso de distribuciones normales.

Resulta mucho más acertada la elección de algunas de las técnicas desarrolladas con el fin de aplicarlas al análisis de bases de datos espaciales, entendidas éstas en el sentido de una colección de objetos en las que a cada miembro se le asigna un atributo no-espacial, que caracteriza intrínsicamente al objeto (en nuestro caso el valor que toma cualquiera de los parámetros meteorológicos), y un atributo espacial (el nivel o altura de la masa de aire muestreada).

Después de revisar algunas de estas técnicas de detección de outliers decidí implementar para los sondeos meteorológicos una técnica denominada SLOM (Spatial Local Outlier Measurement). No me extenderé en los detalles de este algoritmo (si se desea puede consultarse el trabajo original "On Local Spatial Outliers" [Sun and Chawla, 2004]). Sólo decir que el parámetro que cuantifica en que grado determinado objeto es candidato o no a outlier viene definido por la relación

$$
\operatorname{SLOM}(j)=d(j) \times \operatorname{beta}(j) \quad \forall j \in \mathcal{N}
$$

donde el factor

$$
d(p)=\frac{\sum_{p \in N(j)}(\operatorname{dist}(j, p)-\operatorname{máx}(d(j))}{|N(j)-1|}
$$

proporciona una medida de la influencia de todos los vecinos sobre el objeto considerado, o sea, da cuenta de la autocorrelación espacial, mientras que el factor

$$
\operatorname{beta}(j)
$$

sería el análogo de la desviación estándar. Puesto que se define para cada punto j, se incluye así el efecto de la varianza no constante.

¿Limitaciones? El método sólo identifica candidatos a outlier. Nos corresponde a nosotros decidir si descartamos o no el objeto detectado. Para resolver esto he reunido por inspección visual un conjunto de sondeos presentando claros outliers en todo los parámetros de interés. He analizado el comportamiento del algoritmo con los diferentes perfiles, tomando por bueno un valor umbral para el parámetro SLOM de 0.015. Quiere esto decir que aquellos puntos del perfil cuyo SLOM supere este límite serán descartados.

Por otro lado, conviene decir que decidimos nosotros qué objetos constituirán la vecindad. Esta arbitrariedad puede resultar útil. Por ejemplo, si lo que queremos es detectar puntos anómalos aislados será conveniente considerar un entorno limitado, digamos de $100 \mathrm{~m}$ en ambas direcciones, mientras que, si por ejemplo buscamos estructuras laminares en la troposfera libre, entonces podríamos considerar un entorno mayor, aproximadamente de 1500 $m$ en ambas direcciones. En todo caso esta posibilidad no la he explorado aún en profundidad. Podría ser útil a la hora de implementar algún método con el objetivo de buscar

\footnotetext{
${ }^{2}$ Estos métodos son conocidos como métodos globales, en el sentido de que la detección del dato anómalo se lleva a cabo en base a una comparación con el total de la muestra. Es obvio que en el caso de los perfiles de parámetros atmosféricos estos no son métodos válidos.
} 
determinadas estructuras atmosféricas, por ejemplo chorros de viento (en bases de datos bidimensionales o tridimensionales), aunque repito que la efectividad del método para esta tarea está aún por estudiar.

Para acabar, mostraré con algunos ejemplos la bondad del método mencionado como herramienta para detectar anomalías que claramente tienen su origen en un error instrumental. A la izquierda de la figura 3.3 se muestra el perfil normalizado correspondiente al ozono (arriba) y a la temperatura (abajo), junto con el parámetro SLOM (círculos rojos) y la línea vertical correspondiente al valor 0.015 (azul), que, como se ha dicho, será utilizado como valor umbral a la hora de detectar candidatos a outlier. A la derecha se muestra el perfil ya depurado, o sea el perfil al cual hemos eliminado los datos detectados como anómalos. Notar la escala en las abcisas de las figuras a la izquierda: normalizando los diferentes perfiles de modo que los valores estén en el intervalo $[0,1]$ podremos trabajar de forma matricial, aplicando el mismo criterio para todos los parámetros.
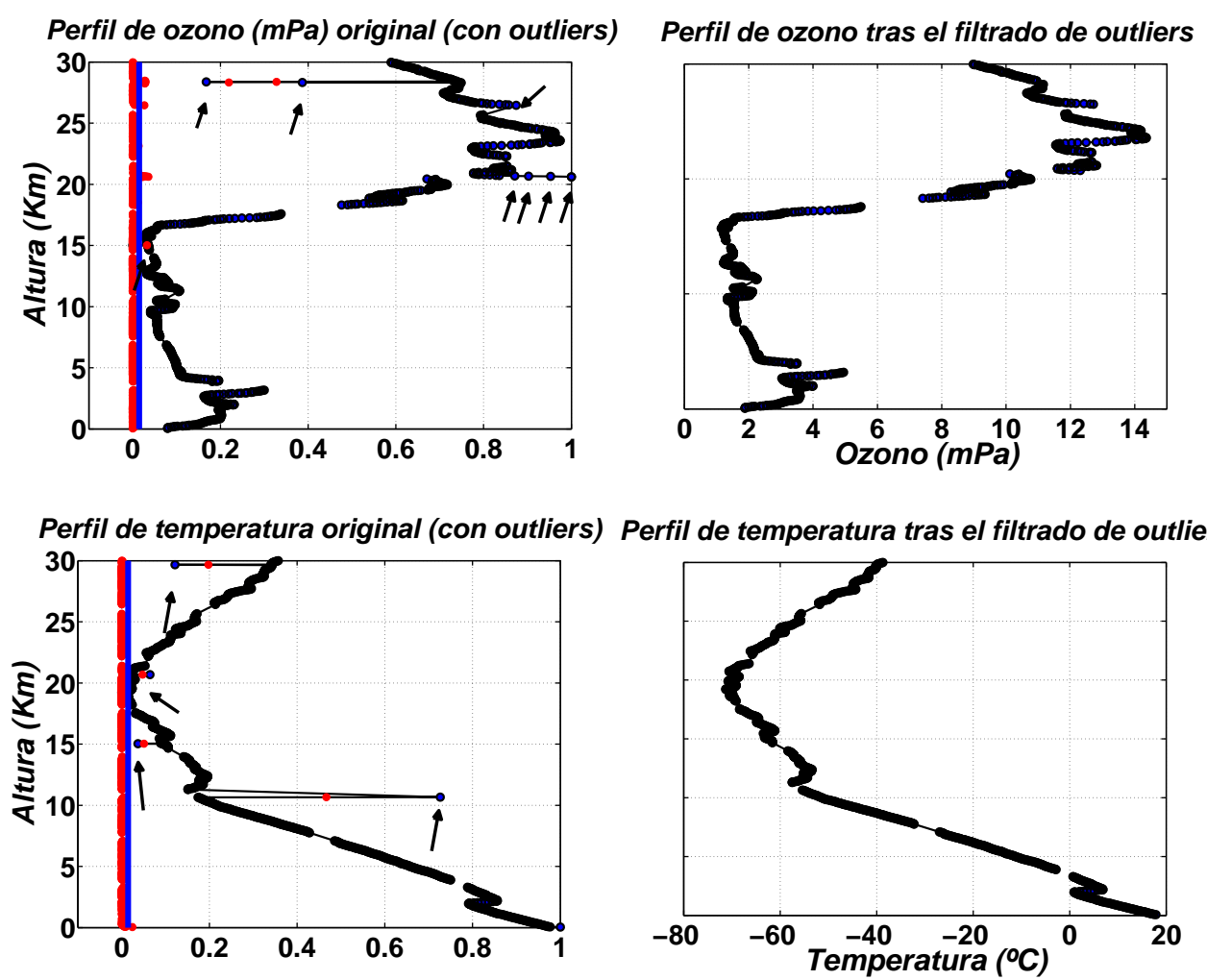

Figura 3.3 - Ejemplos de aplicación del método SLOM para la detección de outliers en los perfiles de dos parámetros: ozono y temperatura. Los valores $\mathbf{S L O M}>0,015$ detectan correctamente outliers en los perfiles (marcados en la figura con flechas). El valor $\mathbf{S L O M}=0$ está representado por la línea azul, y los valores de dicho parámetro por círculos rojos. En las figuras de la izquierda se muestran los mismos perfiles que a la derecha, pero una vez descartados los candidatos a outliers

Como podemos observar, los valores del parámetro SLOM mayores que 0,015 detectan correctamente los posibles candidatos a outliers, identificados en la figura mediante flechas. 


\subsubsection{Homogeneización}

Una vez que han sido eliminados los datos erróneos para todos los parámetros de interés, y como paso previo a la homogeneización espacial, se ha llevado a cabo la interpolación de los perfiles con el objetivo de eliminar los gaps observados (ver figura 3.4). En lugar de interpolar utilizando un spline cúbico ordinario, como es usual en muchos trabajos, he optado por utilizar una interpolación también cúbica, pero definida en tal modo que se trata de mantener en la medida de lo posible la forma original del perfil (definida en el toolbox splines del software MATLAB). De este modo, se evita la posibilidad de obtener oscilaciones irreales en el caso de que los extremos del intervalo de interpolación no estén lo suficientemente próximos.
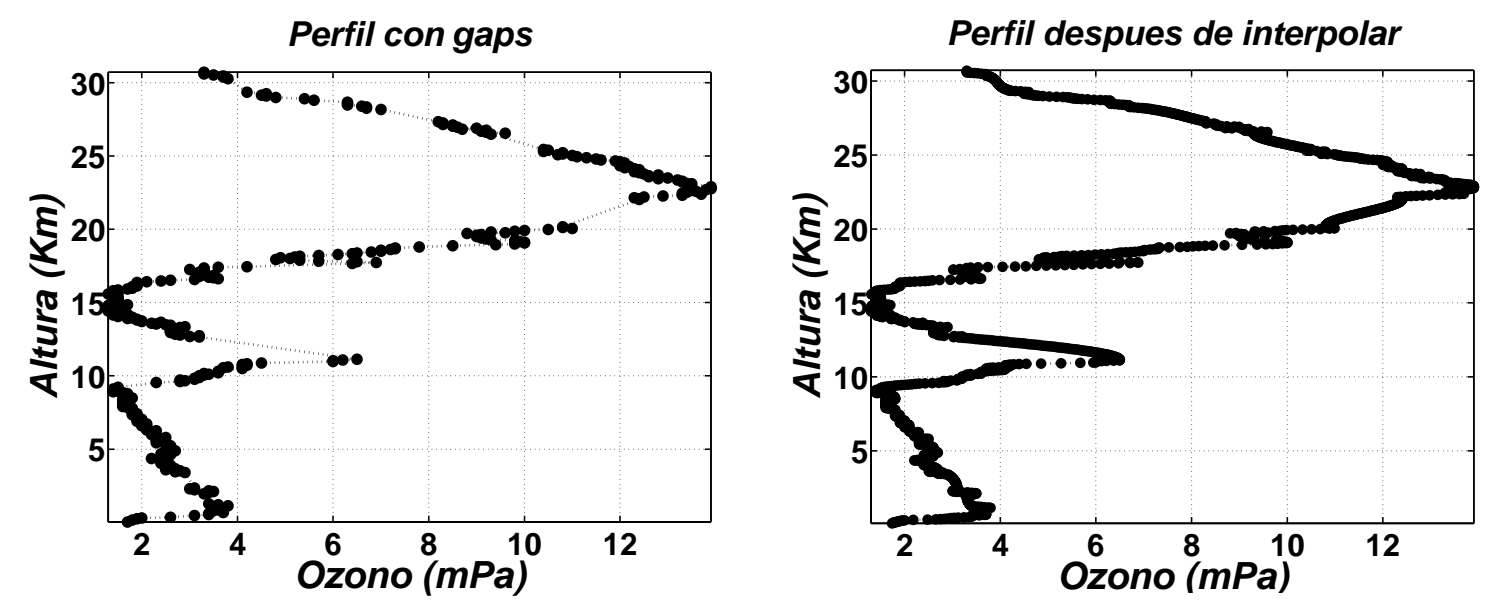

Figura 3.4 - Perfil antes (izquierda) y después (derecha) de interpolar

Para acabar, siempre que el número de gaps en el perfil sea excesivo, se descartará el ozonosondeo considerado.

El último paso en la depuración de los ficheros originales consiste en la homogeneización de la resolución vertical de los perfiles, estableciéndola en $100 \mathrm{~m}$. La razón está en la resolución vertical de los perfiles de ozono, en torno a 100-150 m, constituyendo ésta el límite. Por lo tanto, y aunque la resolución de parámetros como la temperatura es mayor (del orden de $30 \mathrm{~m}$ ), por razones de coherencia se ha optado por establecer para los ozonosondeos una resolución espacial de $100 \mathrm{~m}$, según el siguiente criterio

$$
\begin{array}{ll}
{[0,0,050]} & \equiv 0 \mathrm{~km} \\
{[0,050,0,150]} & \equiv 0,100 \mathrm{~km} \\
{[0,150,0,250]} & \equiv 0,200 \mathrm{~km} \\
{[0,250,0,350]} & \equiv 0,300 \mathrm{~km}
\end{array}
$$




\subsection{Aspectos metodológicos}

Se presenta a continuación la metodología empleada a la hora de abordar el análisis de los ozonosondeos ya depurados. Comenzamos en primer lugar con una breve caracterización de los datos en los que está basado el estudio que nos ocupa, para seguidamente exponer los detalles concernientes a la composición de las climatologías y los diferentes criterios empleados para definir el nivel de la tropopausa.

\subsubsection{Caracterización de la serie de sondeos meteorológicos}

El programa de ozonosondeos del Centro de Investigación Atmosférica de Izaña, CIAI comenzó en Noviembre de 1992, como parte del programa de Vigilancia Atmosférica Global (VAG) de la OMM, http://www.wmo.ch/pages/prog/www/index_en.html, continuando de forma ininterrumpida hasta la actualidad. Los lanzamientos se llevan a cabo desde la estación de Santa Cruz de Tenerife $\left(28^{\circ} 28^{\prime} N, 16^{\circ} 14^{\prime} \mathrm{W}, 36\right.$ m.s.n.m.) cada semana a lo largo de todo el año. En la actualidad este programa forma parte del NDACC, Network for the Detection of Atmospheric Composition Change, http://www.ndsc.ncep.noaa.gov/.

Además de estos ozonosondeos rutinarios, también tienen lugar campañas intensivas en las cuales se realizan ozonosondeos diarios (en ocasiones hasta dos en un mismo día). La hora de lanzamiento siempre está comprendida entre las 10:00 TUC y las 12:00 TUC, independientemente de las condiciones atmosféricas (excepto en los casos en que, por ejemplo, la fuerza de viento impide un lanzamiento con garantías. Si se diera esta circunstancia se aplazará el lanzamiento

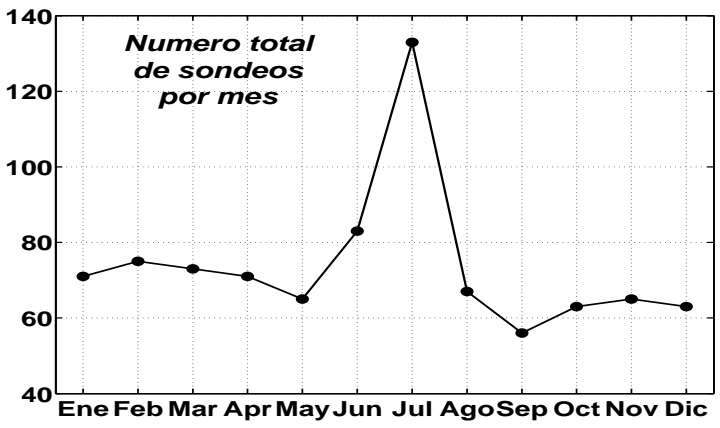

Figura 3.5 - Distribución mensual de ozonosondas lanzadas hasta el día siguiente o cuando las condiciones lo permitan). Podremos afirmar por lo tanto que se han muestreado todos los escenarios meteorológicos posibles, no existiendo preferencia por una situación particular.

Por otro lado, una vez acabado el proceso de depuración expuesto en el capítulo anterior (ver página 24 de la sección 3.1), los sondeos individuales han sido descartados en el caso de que fuera cierta cualquiera de las siguientes condiciones:

- La altura máxima alcanzada por el ozonosondeo es inferior a $20 \mathrm{~km}$.

- No es posible determinar el nivel de la tropopausa.

Con todo, resultan un total de 884 ozonosondeos, cuyas alturas máximas alcanzadas y la distribución estacional están representadas en las figuras 3.6 y 3.5 respectivamente. Notar en la figura 3.5 que Julio es el mes con mayor número de lanzamientos, coincidiendo con la celebración de diferentes campañas intensivas llevadas a cabo (principalmente celebración de campañas en el marco del proyecto TROMPETA, TROpical Monitoring PhasE in The Atmosphere). Además, queda demostrada la validez de los sondeos disponibles para la tarea de investigar la región UTLS subtropical, pues más del $90 \%$ de los sondeos alcanzan altitudes superiores a $30 \mathrm{~km}$, más que suficiente para los objetivos del estudio que nos ocupa (figura $3.6)$. 


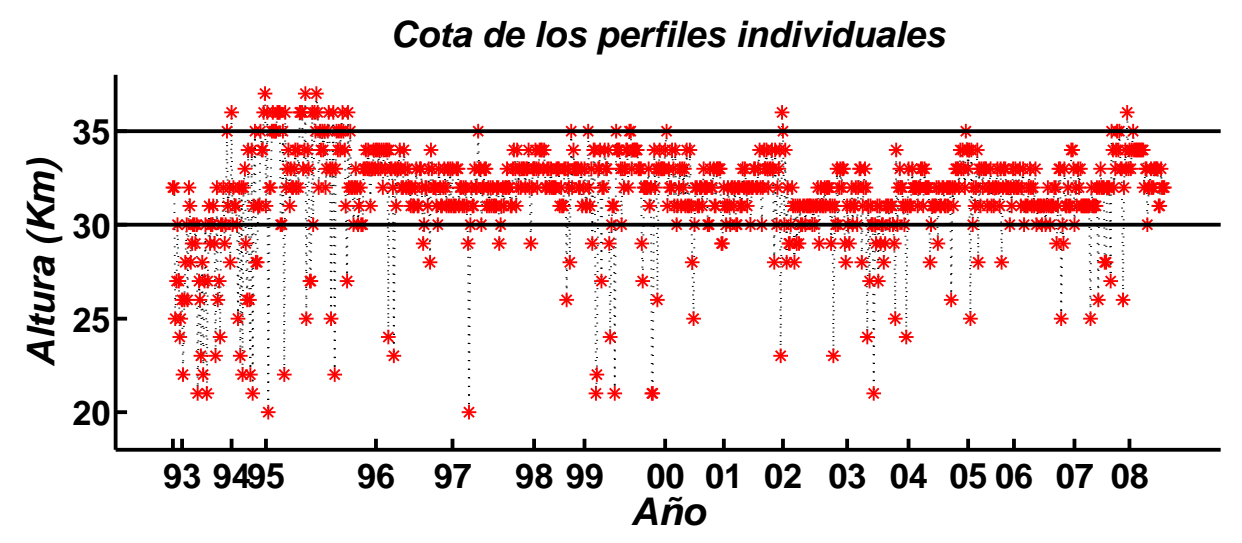

Figura 3.6 - Altura máxima alcanzada por los sondeos individuales para todo el periodo, desde Noviembre de 1992 hasta Agosto de 2008. Notar que los intervalos entre años consecutivos son proporcionales a los ozonosondeos realizados

\subsubsection{Determinación del nivel de la tropopausa. Definiciones}

Tal y como se ha dicho (capítulo 1), aún después de haber transcurrido más de un siglo desde su descubrimiento, el conocimiento de los mecanismos físicos responsables de la formación de la tropopausa es todavía incompleto. En consecuencia, las definiciones existentes son necesariamente empíricas, basada todas ellas en una u otra característica de dicha región atmosférica. En términos generales, la tropopausa a menudo define una región donde tiene lugar una abrupta transición en los valores de propiedades atmosféricas (la temperatura o la vorticidad potencial [WMO, 1986], y en la concentración de especies químicas (ozono, vapor de agua ... [Pan et al., 2004]), siendo esta discontinuidad asociada la que ha servido como base para una serie de definiciones formales. Pasaré a continuación a exponer las definiciones más comúnmente empleadas (que a su vez son las que yo he utilizado), indicando cuando proceda las posibles modificaciones llevadas a cabo con el fin de adaptarlas a nuestra situación geográfica particular.

\section{Tropopausa Térmica}

Esta es una definición muy apropiada a nivel operacional, pues permite la identificación del nivel de la tropopausa únicamente a partir del perfil vertical de temperatura, parámetro medido rutinariamente por todas las estaciones de radiosondeo del mundo. La tropopausa térmica es definida formalmente por primera vez en 1957 del siguiente modo [WMO, 1957]:

"La tropopausa queda definida por el nivel de menor altura en el cual el gradiente vertical de temperatura toma el valor de $2^{\circ} \mathrm{CKm}^{-1}$ o inferior, siempre que el gradiente promedio ${ }^{3}$ entre este nivel y todos los niveles superiores en los siguientes $2 \mathrm{Km}$, al menos, no supere el valor umbral de $2{ }^{\circ} \mathrm{CKm}^{-1}$.

\footnotetext{
${ }^{3}$ Para cada punto $z_{j}$, se ha definido el gradiente del parámetro $\mathcal{X}$ en dicho punto según $\overrightarrow{\operatorname{grad}} \mathcal{X}\left(z_{j}\right)=-\frac{\mathcal{X}\left(z_{j+1}\right)-\mathcal{X}\left(z_{j-1}\right)}{z_{j+1}-z_{j-1}}$. El gradiente promedio para el estrato entre dos niveles arbitrarios $\left(z_{i}, z_{j}\right) i>j$ se ha calculado como $\overline{\operatorname{grad\mathcal {X}}\left(z_{j}\right)}=-\frac{\mathcal{X}\left(z_{j}\right)-\mathcal{X}\left(z_{i}\right)}{z_{j}-z_{i}}$
} 
Si sobre la primera tropopausa el gradiente promedio entre cualquier nivel y todos los niveles superiores es mayor que $3^{\circ} \mathrm{C} \mathrm{Km}{ }^{-1}$, al menos en un estrato de $1 \mathrm{Km}$, entonces quedará definida una segunda (o tercera ...) tropopausa en el primer nivel que cumpla con el requisito dado para la primera"

Modificaciones: En la media y alta troposfera subtropical son frecuentes las inversiones térmicas, asociadas a fenómenos de subsidencia, también originadas por el paso de frentes. Es por esto por lo que se han descartado todas aquellas tropopausas tales que $P_{\text {trop }}>500 h P a$. Asimismo, en el caso de que existiendo un sistema de doble tropopausa el espesor del estrato comprendido entre ellas fuera menor a $1,5 \mathrm{~km}$, he decidido omitir la segunda. Es muy probable que estos fenómenos sean debidos a perturbaciones inducidas por la propagacion de ondas gravitatorias, cuyo análisis no es el objeto de este estudio.

\section{Tropopausa del Punto Frío}

En este caso se asocia el nivel de la tropopausa con el nivel en el cual la temperatura es mínima. Esta definición de tropopausa resulta relevante en latitudes tropicales, en particular asociada al estudio del transporte de vapor de agua hacia la estratosfera [Holton et al., 1995]. No es el caso de las latitudes medias. La he incluido en este estudio considerando que estamos en la región de transición desde latitudes tropicales a latitudes medias.

\section{Tropopausa Dinámica}

Una definición alternativa está basada en la vorticidad potencial de Rossby-Ertel, definida según la ecuación

$$
P V_{\theta}=-g\left(\zeta_{\theta}+f\right) \frac{\partial \theta}{\partial p}
$$

donde $\zeta_{\theta}$ es la vorticidad relativa en una superficie isentrópica y $f$ es el parámetro de coriolis (notar que esta definición sólo será válida en coordenadas isentrópicas). A la unidad de vorticidad potencial, pvu, se le asigna el valor $10^{-6} \mathrm{Kkg}^{-1} \mathrm{~m}^{2} \mathrm{~s}^{-1}$.

La vorticidad potencial se conserva en condiciones adiabáticas y en ausencia de fricción, siendo ampliamente utilizada como un trazador del ozono estratosférico en la troposfera [Beekmann et al., 1994, Folkins and Appenzeller, 1996]. Es por esto por lo que la tropopausa dinámica, definida en términos de una determinada isosuperficie de vorticidad potencial, resulta especialmente útil a la hora de abordar el estudio de fenómenos de intercambio Estratosfera-Troposfera $(S T E)$. Sin embargo, existe un nutrido conjunto de valores umbrales de vorticidad potencial a la hora de definirla, lo que resulta en un gran grado de incertidumbre: por poner algunos ejemplos, en 1986 la Organización Meteorológica Mundial [WMO, 1986] propone el valor $1.6 \mathrm{pvu}$ con el fin de definir la tropopausa dinámica. Otros muchos autores sugieren valores que van desde 1 pvu hasta 4 pvu [Hoinka, 1998, Danielsen, 1968].

Una vez más, aún cuando esta definición es reconocida como más apropiada para latitudes medias, no estando definida en latitudes bajas, se ha decidido incluirla dada la localización geográfica de la isla de Tenerife, en la zona de transición entre ambas.

Modificaciones: Con el fin de determinar el nivel de la tropopausa dinámica no se ha empleado a priori un valor particular de vorticidad potencial. En lugar de eso, y teniendo 
en cuenta el hecho de que la tropopausa está caracterizada por un acusado gradiente en los valores de dicho parámetro, se utiliza como criterio el de máximo en el perfil vertical del gradiente de la vorticidad potencial. Esta es una aproximación diferente a la de estudios previos, en los que se identifica el nivel de la tropopausa dinámica con un valor predeterminado de vorticidad potencial.

\section{Tropopausa Química}

Otra definición empírica de la tropopausa, referida como tropopausa química, está basada en la distribución vertical de ozono [Bethan et al., 1996]. En dicho estudio el autor, a través del análisis de 628 ozonosondeos realizados en cuatro estaciones con latitudes superiores a $60^{\circ} \mathrm{N}$, propone la siguiente definición para la tropopausa química:

"La tropopausa química queda definida en el nivel más bajo verificando las siguientes condiciones:

a) El gradiente vertical de ozono en un estrato de $200 \mathrm{~m}$ de espesor es superior a 60 ppbvKm $\mathrm{Km}^{-1}$ (en la región próxima a la tropopausa dicho gradiente adopta tipicamente valores en el rango [50 - 70] ppbv $\left.\mathrm{Km}^{-1}\right)$.

b) La razón de mezcla de ozono es mayor que 80 ppbv.

c) La razón de mezcla inmediatamente por encima de la tropopausa es mayor que 110 ppbv. Se evita de esta forma la asociación de la tropopausa química con posibles estructuras laminares de aire rico en ozono en la troposfera, donde la razón de mezcla de ozono es inferior a 110 ppbv".

Estudios recientes apuntan hacia una redefinición de la tropopausa química basada en la relación entre marcadores típicamente estratosférico y troposférico en la región de la tropopausa [Zahn et al., 2004, Pan et al., 2004]. En cualquier caso los resultados hallados son coherentes con los expuestos previamente por Bethan, como se verá en la seción 4.4 .

Modificaciones: Se ha sustituido la condición c) por la siguiente:

c) la razón de mezcla promedio en un estrato de $1,5 \mathrm{Km}$ inmediatamente por encima de la tropopausa es superior a $110 \mathrm{ppbv}$.

comprobándose por inspección visual de los perfiles de ozono que aplicando este criterio en lugar del sugerido en el trabajo original de Bethan, el algoritmo de cómputo resulta más eficiente a la hora de descartar las estructuras laminares de aire rico en ozono en la troposfera libre (un valor promedio del espesor de las estructuras laminares en la tropoposfera es de aproximadamente 1,5 Km [Kahya et al., 2005]).

\subsubsection{Climatologías. Cómputo y significancia}

Uno de los objetivos principales del presente estudio es el de obtener una descripción climatológica de la región UTLS subtropical sobre Tenerife.

Con este fin, se han calculado los valores mensuales de diferentes parámetros (concentración de ozono, temperatura, índice de flotabilidad, viento ...), promediando los perfiles disponibles para cada mes durante todo el periodo. Además, se ha comprobado que ningún mes ha tenido mayor peso en la evaluación de lo valores climatológicos, para lo cual se han calculado las medias mensuales de todo el periodo a partir de las medias mensuales de cada año, no existiendo diferencias apreciables entre los dos métodos. 
Los datos han sido analizados tomando como nivel de referencia el nivel de la tropopausa térmica, en vez de hacerlo referenciados al nivel del suelo. Expongo a continuación la motivación de este procedimiento:

\section{Climatología referenciada al nivel de la tropopausa}

Usualmente el cómputo de las variaciones estacionales de parámetros tales como el ozono en diferentes niveles de la atmósfera se lleva a cabo tomando como referencia el nivel del suelo, o dicho de otra manera, el sistema de referencia espacial es fijo en el tiempo y en el espacio para cada estación individual. Sin embargo, este procedimiento debe ser objeto de crítica en el caso que nos ocupa, esto es, el estudio de la región atmosférica conocida como UTLS. La razón fundamental de ésto es que la evolución espacio-temporal de dicha región se halla íntimamente ligada a la tropopausa.

Como se ha dicho, una de las propiedades características de la tropopausa es la de ser una región donde se experimentan acusados gradientes de parámetros tales como la concentración de diversos gases traza así como de la temperatura o la vorticidad potencial. Ahora bien, la tropopausa presenta una gran variabilidad tanto espacial como temporal, de modo que los fenómenos propios de dicha región pueden pasar desapercibidos como resultado de promediar durante periodos de tiempo extensos si tomamos como referencia el nivel del suelo.
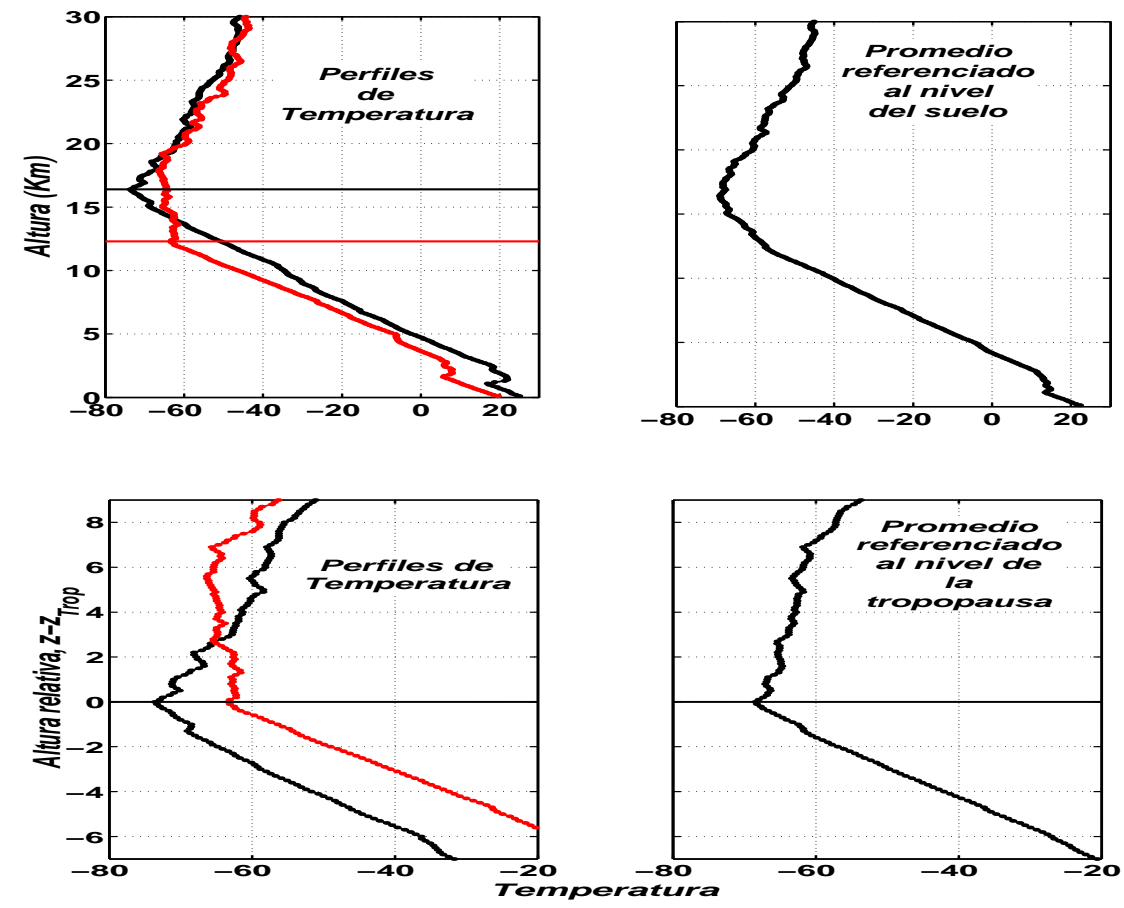

Figura 3.7 - Se compara el resultado de promediar dos perfiles de temperatura arbitrarios (curvas negra y roja, izquierda) utilizando en el cálculo dos aproximaciones diferentes: en la figura superior derecha se muestra el resultado del promedio relativo al nivel del suelo (método SLB), y abajo se ha tomado como referencia el nivel de la tropopausa, equivalente al nivel 0 (método TLB). Notar como en el segundo caso se conserva la discontinuidad asociada a la tropopausa en el parámetro considerado, en este caso la temperatura, mientras que con el método convencional se obtiene un perfil suavizado 
En la figura 3.7 se ilustra el efecto que sobre los valores climatológicos tienen los dos métodos mencionados. En ambos casos se han tomado arbitrariamente dos perfiles de temperatura (izquierda, curvas roja y negra), calculando el perfil resultante de promediar ambos, primero tomando como referencia el nivel del suelo (derecha, arriba) y a continuación tomando como referencia el nivel de la tropopausa (derecha, abajo). En este último caso se ha definido una nueva coordenada vertical como $\tilde{z} \equiv z-z_{\text {trop }}$, siendo $z_{\text {trop }}$ el nivel de la tropopausa. Una vez hecho esto, dado un parámetro cualquiera $\mathcal{X}$, calcularemos su promedio en la forma habitual, $\overline{\mathcal{X}}=\overline{\mathcal{X}\left(t, z-z_{\text {trop }}\right)}$. Finalmente, y una vez obtenida la climatología, deshacemos la transformación anterior según $z=\tilde{z}+\overline{z_{\text {trop }}}$, donde ahora $\overline{z_{\text {trop }}}$ será el valor promedio de la altura de la tropopausa en el periodo considerado (este último cambio no se muestra en la figura anterior, manteniendo el nivel de la tropopausa como nivel 0). La figura 3.7 demuestra la ventaja de trabajar con la tropopausa como nivel de referencia, pues de otra manera, y como consecuencia de promediar en periodos extensos, por un lado, y de la variabilidad espacial de la tropopausa, por otro, se perdería la estructura característica de la región atmosférica asociada a la tropopausa [Logan, 1999, Birner et al., 2002]. En el capítulo siguiente se demostrará con nuevos ejemplos la bondad del método comentado (al que nos referiremos por sus siglas en inglés $\boldsymbol{T L} \boldsymbol{B}$, Tropopause Level Based)

\section{Significancia de los valores climatológicos}

A continuación trataré de responder cuantitativamente a la siguiente pregunta: ¿en que grado son representativos los valores climatológicos obtenidos a partir de la muestra disponible de perfiles verticales atmosféricos?

Desde el punto de vista estadístico el problema queda resuelto usando el error estándar de la media, $S E M$, parámetro que proporciona una medida del error cometido al asignar a determinada población el valor promedio calculado a partir de una determinada muestra de dicha población, independientemente de la distribución que represente al conjunto de datos.

Una estimación del error estándar de la media se obtiene a partir de la expresión

$$
S E M \approx \frac{\sigma}{\sqrt{N}}
$$

siendo $\sigma$ y $N$ el tamaño y la desviación estándar de la muestra respectivamente.

Por otro lado, se puede demostrar que aproximadamente $\pm 2 S E M$ definen un intervalo de confianza del $95 \%$ para los valores climatológicos calculados.

Para ilustar el uso de este parámetro he llevado a cabo el siguiente experimento: en primer lugar se han calculado los perfiles promedio mensuales de ozono para cada mes, junto con la desviación estándar correspondiente para cada nivel. La ecuación 3.1 muestra cómo el error estándar es función de la variabilidad del parámetro considerado así como del número de medidas. En este caso estoy interesado en investigar la dependencia con el tamaño de la muestra, para lo cual se ha calculado el error estándar relativo, definido según $\mathbf{S} E M /$ promedio mensual, para cuatro grupos centrados en $N=20,40,75$ y 150, y considerando tres regiones de la atmósfera: troposfera libre, $[3-7] \mathrm{km}$, UTLS, $[12-18] \mathrm{km}$ y baja estratosfera, $[21-25] \mathrm{km}$. En la figura 3.8 se muestra el resultado para el mes de Marzo, destacando dos aspectos relevantes:

- El error estándar disminuye exponencialmente a medida que aumenta el tamaño de la muestra 
- Para un tamaño de muestra fijo, digamos $\mathrm{N}=75$ (ver figura 3.5), la variabilidad del ozono es mucho mayor en la región UTLS, disminuyendo drásticamente en las otras dos regiones consideradas

Puesto que se ha simulado el valor de $S E M$ a partir de un único valor de la desviación estándar en cada nivel, variando el número de elementos, $\mathrm{N}$, los resultados anteriores son sólo orientativos. En todo caso, para $\mathrm{N}$ pequeño estaremos subestimando el valor real de $S E M$, suponiendo que $\sigma_{N<75} \geq \sigma_{N=75}$, mientras que para valores de $\mathrm{N}$ grandes lo estamos sobrestimando, siempre que $\sigma_{N>75} \leq \sigma_{N=75}$. La figura 3.5 muestra un valor $\mathrm{N} \approx 70$ para todos los meses salvo para el periodo estival, cuando se llevaron a cabo un mayor número de lanzamientos. De este modo se ve, por ejemplo, que $1 S E M$ es $<10 \%$ del valor promedio en la región UTLS, y $<3 \%$ en la troposfera libre y la baja estratosfera (incluso inferior en este último caso). En el capítulo 4 sección 4.4 se analizará con mayor detalle este resultado en relación con el ozono.

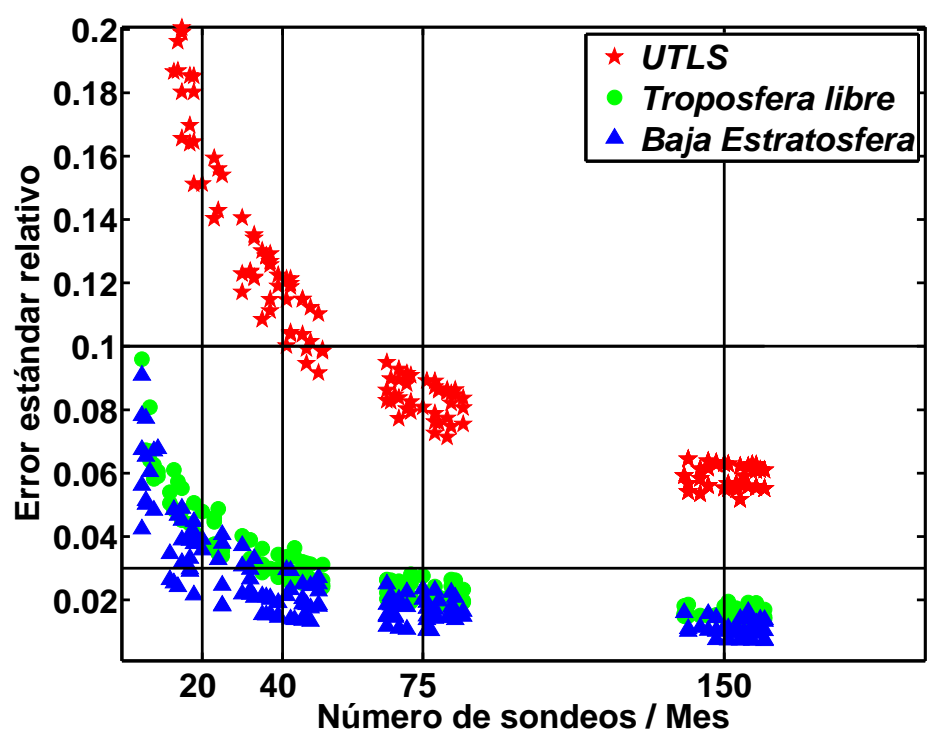

Figura 3.8 - Dependencia con el tamaño de la muestra del error estándar relativo. A partir de la desviación estándar correspondiente al perfil de ozono en el mes de Marzo se genera un conjunto sinténtico de valores de SEM, variando arbitrariamente el parámetro N. Para cada conjunto asi obtenido se promedian los resultados en diferentes estratos de la atmósfera: UTLS, estrato comprendido entre los 12 y los $18 \mathrm{~km}$, Troposfera media, desde los 3 a los $7 \mathrm{~km}$ y Baja estratosfera, desde los 21 a los $25 \mathrm{~km}$. Las lineas horizontales corresponden a los valores $S E M=0,1$ y 0,03. Notar que para $N \not \approx 75$ los resultados son sólo orientativos (ver texto) 


\section{Capítulo 4}

\section{Climatología de la región UTLS subtropical}

Se ofrece a continuación una descripción cualitativa de la región UTLS sobre Tenerife (sección 4.1), destacando los aspectos relevantes referidos a la distribución temporal así como a la relación existente entre las diferentes definiciones de tropopausa (sección 4.2). Se hace patente de esta manera el carácter complejo de dicha región atmosférica para latitudes subtropicales. Hemos considerado conveniente realizar el análisis basándonos en dos aproximaciones complementarias: en primer lugar se lleva a cabo un estudio descriptivo, presentando resultados relativos a distribuciones de altura del nivel de la tropopausa, frecuencias de ocurrencia de dobles tropopausas, variabilidad de los perfiles térmicos ... En una segunda parte se describen los resultados concernientes a los valores climatológicos de diferentes parámetros asociados a la región de la tropopausa (altura y temperatura potencial), analizando la variabilidad mensual de los mismos y tratando de relacionar los resultados hallados con estudios previos realizados por diferentes autores. Se demuestra asimismo la existencia de una región con máximos valores de viento en torno a 35, $40 \mathrm{~ms}^{-1}$ (Chorro Subtropical), analizando su relación con los sistemas de múltiple tropopausa.

Una vez descrita la situación característica de la alta troposfera - baja estratosfera sobre Canarias, en particular los detalles referidos al nivel de la tropopausa y la existencia en la región del Chorro Subtropical, se estudia la estructura térmica de la tropopausa (sección 4.3), evidenciando la existencia de una inversión térmica asociada a la misma. Se analiza la magnitud de esta inversión, así como la variación estacional.

Como último punto del análisis de la región UTLS subtropical, se discute en la sección 4.4 la distribución vertical del ozono, basándonos en los resultados hallados en secciones anteriores. Se ilustra la gran variabilidad que el ozono exhibe aproximadamente entre los $10 \mathrm{y}$ los $18 \mathrm{~km}$, distinguiéndose dos regiones claramente diferenciadas. Se retoma la discusión de los resultados hallados para las tropopausas química y dinámica, interpretando por un lado las discrepancias halladas entre ellas, y por otro haciendo explícito el carácter extraordinario mostrado por la tropopausa química. Una vez establecida la singularidad de la región UTLS en lo que a la distribución del ozono se refiere, discutimos las secciones mensuales de ozono, comparándolas con las encontradas en la sección 4.3 relativas a las propiedades termodinámicas de la misma región. Se hace evidente el papel decisivo desempeñado por el Chorro Subtropical, proponiendo para acabar un modelo conceptual que dé cuenta de los fenómenos observados. 


\subsection{Caracterización de la Tropopausa sobre Tenerife}

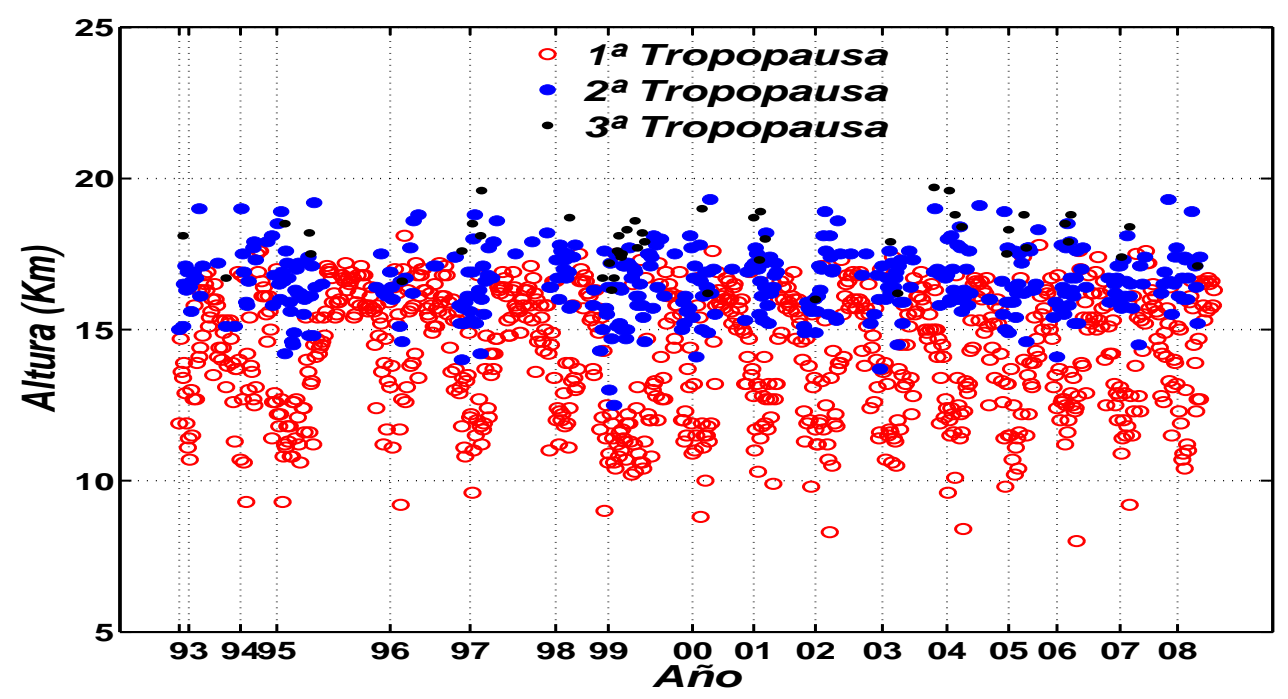

Figura 4.1 - Altura observada de la tropopausa térmica para todo el periodo de estudio y para cada una de las tres situaciones analizadas: tropopausa simple y tropopausa múltiple. Notar que el intervalo entre años consecutivos es proporcional al número de ozonosondeos realizados

En la figura 4.1 se han representado el conjunto de alturas observadas para la tropopausa térmica y para todas las situaciones posibles, esto es, perfiles de temperatura mostrando tropopausa simple (círculos rojos), doble (puntos azules) y triple (puntos negros). A la derecha, figura 4.2, se muestra un ejemplo ilustrativo de perfil térmico para cada uno de los tres casos, señalando con líneas horizontales de diferentes colores el nivel de la tropopausa (en color rojo la primera tropopausa térmica observada en sistemas de tropopausa múltiple, o bien la única hallada, en azul la segunda para sistemas de múltiple tropopausa y en verde se representa una tercera tropopausa, en los casos en los que es detectada).

Se puede ver como el rango de alturas correspondiente a la tropopausa es muy amplio, abarcando aproximadamente toda la región comprendida entre los 10 hasta aproximadamente los $18 \mathrm{~km}$ de altura. Otro aspecto interesante es el marcado ciclo anual que presenta la primera tropopausa: en los meses estivales se trata de la única

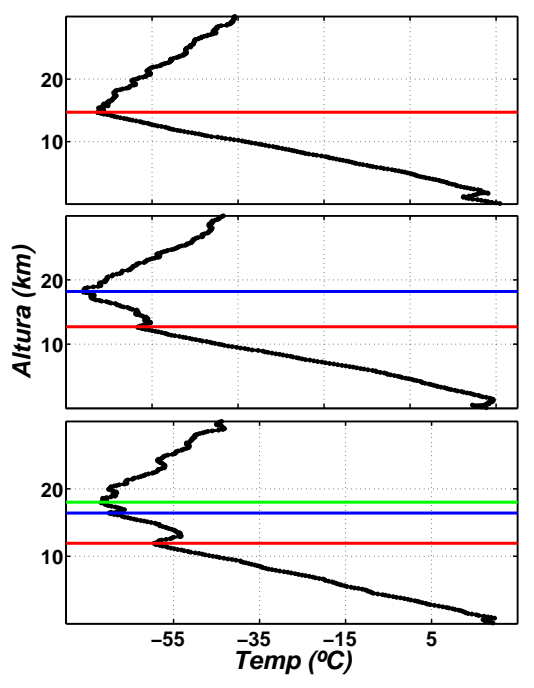

Figura 4.2 - Tres perfiles verticales de temperatura mostrando tropopausa única (arriba) y sistemas de tropopausa múltiple (doble, centro, y triple, abajo) observada, en niveles altos, mientras que en los meses de Invierno y sobre todo durante los primeros cuatro meses del año se localiza a alturas muy inferiores. Además, es en estos meses cuando se observan los sistemas de múltiple tropopausa, ya sea doble o triple. Notar también los pocos casos en los que la tropopausa se observa en niveles anormalmente bajos, por debajo de los $10 \mathrm{~km}$ Estos casos son atribuibles a la 
influencia de perturbaciones baroclinas en la región UTLS, cuyo efecto neto se traduce en un aumento de los valores de presión en el nivel de la tropopausa, fenómeno este conocido y estudiado por diferentes autores (ver por ejemplo [Wirth, 2001]).

La situación anterior es la que se espera para una región situada en la zona de transición entre latitudes tropicales y medias. En el primer caso domina una tropopausa alta, en torno a los 16-17 km. de altura y con muy poca variabilidad estacional [Seidel et al., 2001, Gettelman and de Forster, 2002], mientras que en latitudes medias la tropopausa, en promedio, se localiza en torno a los $12 \mathrm{~km}$. de altura, aunque presentando una mayor variabilidad tanto espacial como temporal [Hoerling et al., 1991, Hoinka, 1998].

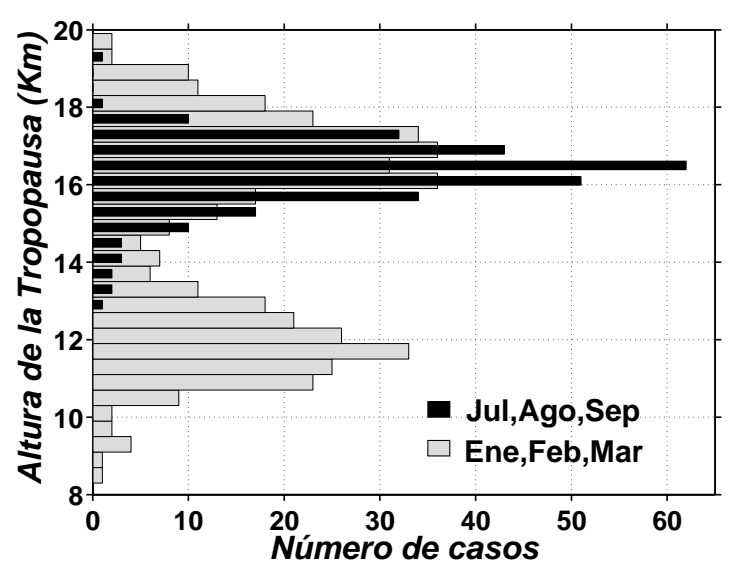

(a)

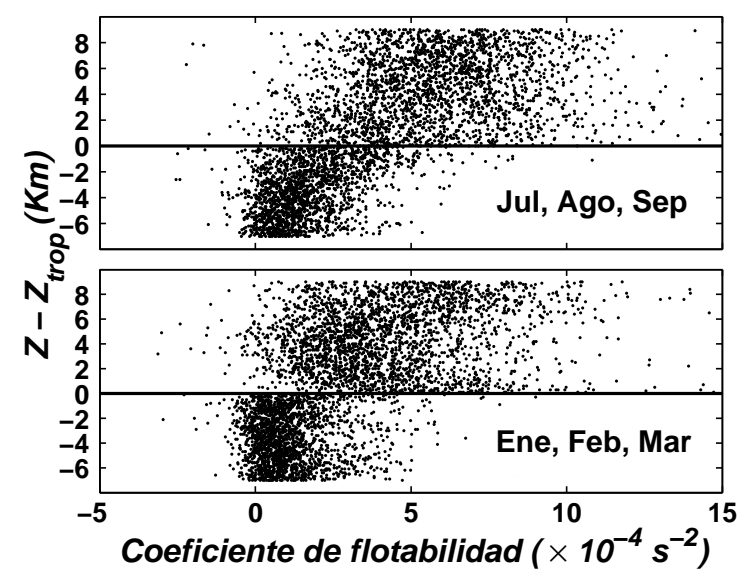

(b)

Figura 4.3 - (a) Distribución de alturas de la tropopausa para los meses de Enero a Marzo y de Julio a Septiembre. (b) Frecuencia de Brunt-Väisälä para los mismos periodos que en (a). Notar la escala de alturas relativa al nivel de la tropopausa, correspondiente al nivel 0

Teniendo en cuenta que las propiedades de estabilidad en la atmósfera varían en función del gradiente térmico vertical, según la diferencia $\Gamma_{d}-\Gamma$, donde $\Gamma_{d}=9,8^{\circ} \mathrm{Ckm}^{-1}$ es el gradiente adiabático del aire seco, y $\Gamma$ el gradiente térmico observado, la definición de tropopausa térmica implica que ésta separa dos regiones diferenciadas en lo que a propiedades de estabilidad se refiere: la troposfera, turbulenta, y la estratosfera, mucho más estable. A su vez se define la frecuencia de Brunt-Väisälä (también llamado índice de flotabilidad) como

$$
N^{2}=\frac{g}{\theta} \frac{d \theta}{d z}=\frac{g}{T}\left(\Gamma_{d}-\Gamma\right)
$$

Físicamente, este parámetro se halla relacionado con la frecuencia de oscilación de una onda gravitatoria en el seno de una atmósfera en reposo (o con movimiento uniforme) y con estratificación estable.

Con el fin de comprobar la exactitud de los niveles de tropopausa hallados, hemos representado perfiles de $N^{2}$ en función de la altura relativa al nivel de la tropopausa, según se ha definido en la sección 3.2.3, para dos periodos diferentes: en la figura 4.3(b), arriba, se muestran los meses [Junio, Julio y Agosto], mientras que abajo aparecen los meses [Enero, Febrero y Marzo]. Para ambos grupos de datos se observa una acusada discontinuidad en la estructura térmica de la atmósfera justo en el nivel de la tropopausa (correspondiente al 
nivel 0 en la figura), pasando de valores típicamente troposféricos, $\approx 1 \times 10^{-4}$, a valores propios de la estratosfera, $\approx 4-5 \times 10^{-4}$. Notar además que la transición ocurre mucho más bruscamente para los meses Enero, Febrero y Marzo, en comparación con el comportamiento mostrado por la frecuencia de Brunt-Väisälä durante los meses centrales del año (sobre esto volveremos en la sección 4.3). Se prueba así que el nivel de la tropopausa térmica ha sido calculado correctamente.

La figura 4.3(a) corresponde a la distribución de alturas de la tropopausa térmica para todos los sondeos llevados a cabo en cualquiera de los dos periodos mencionados anteriormente. Podemos comprobar durante los meses invernales la existencia de una estructura bimodal, con máximos en la frecuencia de ocurrencia para ambas componentes en torno $\sim 12 \mathrm{~km}$ y $\sim 17 \mathrm{~km}$ respectivamente, y un mínimo entre ellos en torno al nivel $\sim 14.5 \mathrm{~km}$. A la vista de la figura 4.1 es evidente que la distribución bimodal se corresponde con los episodios de múltiple tropopausa frecuentes en esta época del año. En cuanto a los meses de Julio a Septiembre, es característica una distribución de alturas presentando un único máximo, centrado en torno a $\sim 17 \mathrm{~km}$.

En cuanto a la forma de las distribuciones anteriores, es notable la asimetría mostrada por la distribución correspondiente a los meses estivales, con un número significativo de casos en los que se detecta la tropopausa en niveles anormalmente bajos. En cuanto a la distribución correspondiente a los meses de Enero a Marzo, ésta presenta una mayor simetría. Aún así, también es cierta en este caso idéntica desviación hacia los niveles bajos, observable sobre todo para la componente inferior. Anteriormente se propuso como explicación a este fenómeno el efecto que sobre el nivel de la tropopausa tiene la presencia de una pertubarción ciclónica, a saber, un "hundimiento", o aumen-

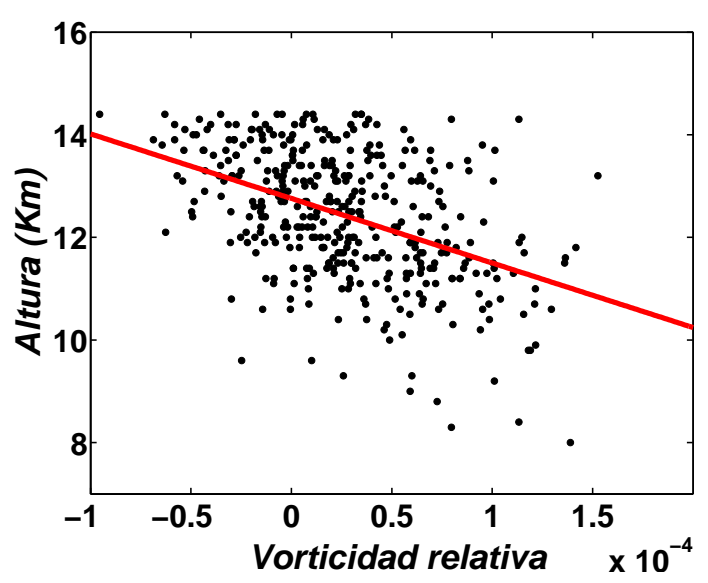

Figura 4.4 - Relación entre la altura de la primera tropopausa térmica observada y la vorticidad relativa en el nivel de $250 \mathrm{hPa}$ to de la presión. Como prueba de la validez de dicha hipótesis he representado valores de vorticidad relativa en el nivel de $250 \mathrm{hPa}$ frente a la altura observada de tropopausa para un número arbitrario de perfiles cumpliendo con la condición $Z_{\text {trop }}<14,5 \mathrm{~km}$ (ver figura 4.4). Se ha realizado un ajuste lineal, aunque únicamente con la intención de resaltar la correlación negativa entre ambos parámetros. Notar como a mayor valor positivo de vorticidad (circulación ciclónica), menor es la altura de la tropopausa.

Para acabar, la figura 4.5 muestra el porcentaje relativo al total de sondeos disponibles para cada mes de perfiles de temperatura para los que se detectaron una única tropopausa (línea roja continua), tropopausa doble (línea punteada) y tropopausa triple (línea discontinua). También se muestra en color azul el resultado de sumar los casos con tropopausa doble y triple. En adelante me referiré a este último caso como sistema de tropopausa múltiple. Tres son los aspectos a destacar:

- elevado porcentaje de perfiles mostrando tropopausa múltiple (en torno al 80\%) para los meses comprendidos entre Diciembre y Abril, ambos incluídos. Correspondientemente un mínimo de casos (inferior al $20 \%$ ) durante el periodo de Junio a Agosto 
- cambio del grupo predominante (frecuencias de ocurrencia de sistemas de tropopausa múltiple o simple mayor o menor al $50 \%$ ) en los meses de Mayo y Noviembre. Se trata de un resultado interesante, puesto que podemos asociar con estos meses los periodos de transición entre dos estados diferentes de la atmósfera en Canarias

- máximo de ocurrencia de tropopausa triple en el mes de Marzo, alrededor de un $20 \%$ de todos los ozonosondeos realizados. No se observa en los meses de verano

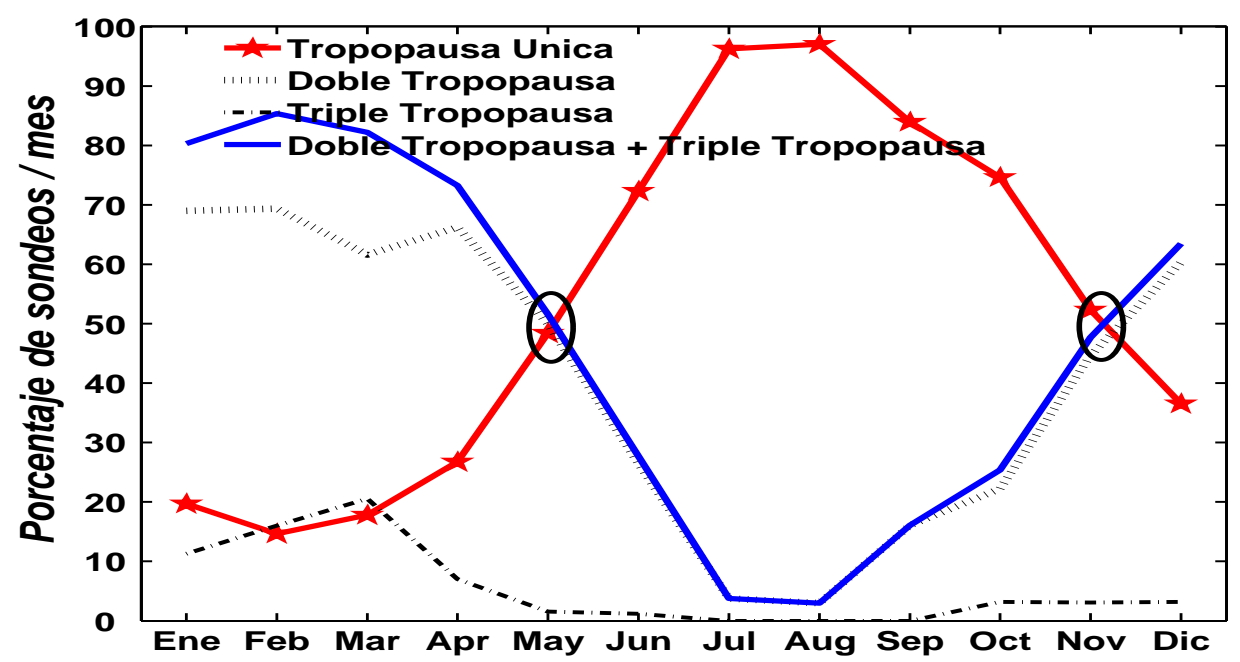

Figura 4.5 - Porcentaje de sondeos mostrando tropopausa térmica simple, doble y triple. Se representa también el resultado de sumar los casos con doble y triple tropopausa

\subsection{Climatología de parámetros relativos al nivel de la tro- popausa}

Se analiza la variación anual de dos parámetros asociados al nivel de la tropopausa: la altura y la temperatura potencial. Se ha escogido este último parámetro dada su importancia en lo que a procesos de transporte se refiere. En particular, los procesos adiabáticos en la atmósfera se caracterizan por ocurrir paralelamente a las superficies isentrópicas (superficies con temperatura potencial constante). Además, el análisis se lleva a cabo para la tropopausa definida según los criterios expuestos en la sección 3.2.2, proporcionando de esta manera una imagen lo más completa posible de dicha región. En todos los casos, y en base a lo expuesto en la sección anterior, se ha realizado el estudio considerando dos grupos, esto es, separando las situaciones que presentan un sistema de tropopausa múltiple de las que presentan una sola tropopausa, aún cuando el porcentaje de sondeos pertenecientes a este último grupo es muy inferior, principalmente en la primera mitad del año. Sin embargo, como se verá durante el desarrollo de este trabajo, su inclusión en el análisis facilitará la interpretación de los resultados obtenidos. Como referencia, se muestra abajo (tabla 4.1) la información contenida en la figura 4.5, pero esta vez tomando en consideración unidades absolutas, y sumando los episodios de tropopausa doble y múltiple bajo la etiqueta Múltiple Trop. 
En la página 38 se muestra la variación estacional de ambos parámetros para la tropopausa perteneciente a situaciones de tropopausa térmica múltiple, mientras que los resultados relativos a sistemas de tropopausa térmica simple se muestran en la página 41. Se ofrece también con cada gráfico una medida de la variabilidad mensual, representando con este fin la desviación estándar para cada valor climatológico.

\subsubsection{Sistemas de tropopausa múltiple}

Unicamente se ha calculado la climatología a partir de aquellos meses para los que el porcentaje mensual de ozonosondeos presentando sistemas de tropopausa múltiple es $\geq$ $20 \%$, con el fin de poder contrastar los resultados con trabajos previos concernientes a estos sistemas [Randel et al., 2007, Bischoff et al., 2007]. De esta forma han quedado excluídos del análisis los meses de Julio a Septiembre. La mayor complejidad se observa durante el primer semestre del año, coincidiendo con la migración del Chorro Subtropical hacia el Norte y su paso sobre Canarias, mientras que desde Octubre a Diciembre se observa un comportamiento muy regular para la tropopausa.

Desde un punto de vista general, dos son las características a destacar: en primer lugar, el espesor de la región situada entre la primera y la segunda tropopausa térmica no muestra una variación anual importante, manteniéndose dicho valor en torno a $4-5 \mathrm{~km}$. Otra peculiaridad exhibida es el comportamiento de la tropopausa química en relación a TT1. Notar como entre los meses de Abril y Mayo pasa de estar en niveles superiores, posición que ocupa desde el Otoño hasta principios de primavera, a situarse por debajo de $\mathbf{T T 1}$ a partir de Mayo.

\section{Altura de la tropopausa}

La figura 4.6 se refiere a la variación estacional de la altura para todas las definiciones de tropopausa consideradas, es decir, tropopausa térmica (TT1, TT2, TT3), tropopausa del punto frío $(\boldsymbol{C P T})$, tropopausa química $(\boldsymbol{O} 3 \boldsymbol{T})$ y tropopausa dinámica $(\boldsymbol{D T})$.

TT1 exhibe el ciclo anual de mayor amplitud, variando en el rango comprendido entre $\sim 12 \mathrm{~km}$ en los meses de Diciembre a Marzo, hasta $\sim 14 \mathrm{~km}$ a finales de Primavera y principio de Otoño, mientras que TT2 muestra una menor variación a lo largo del año, con una altura alrededor de $\sim 16,5 \mathrm{~km}$. TT3 se encuentra en torno a $\sim 18 \mathrm{~km}$ durante todos los meses en los que el número de casos detectados es significativo (en la práctica, no se han tomado en consideración a la hora de realizar los promedios los meses para los que el porcentaje de sondeos con triple tropopausa térmica fuera inferior a 10\%). En cuanto a la tropopausa del punto frío, $\boldsymbol{C P T}$, se podría hablar de una altura aproximadamente constante durante los meses analizados, con un valor en torno a $17 \mathrm{~km}$., si bien habría que matizar la existencia de valores anómalos, principalmente durante el primer trimestre del año, con una altura $\sim 18 \mathrm{~km}$. En promedio, siempre se encuentra alrededor de $\sim 1-1,5 \mathrm{~km}$ por encima de la segunda tropopausa térmica, salvo en los meses de Enero a Marzo, cuando ésta diferencia es máxima, en torno a $\sim 2 \mathrm{~km}$, así como durante el mes de Mayo, cuando prácticamente coincide con $\boldsymbol{T}$ T2. Llegados a este punto de la discusión, podemos identificar la segunda tropopausa térmica observada con la tropical. En efecto, los resultados encontrados para $\boldsymbol{T} \boldsymbol{T} 2$ coinciden con los hallados en estudios previos referidos a la tropopausa tropical [Seidel et al., 2001, Gettelman and de Forster, 2002]. En las siguientes secciones se proporcionan evidencias adicionales que permiten justificar esta asociación. 


\begin{tabular}{l|c|c|c|c|c|c|c|c|c|c|c|c} 
& Ene & Feb & Mar & Abr & May & Jun & Jul & Ago & Sep & Oct & Nov & Dic \\
\hline Total & 71 & 75 & 73 & 71 & 64 & 83 & 133 & 67 & 56 & 63 & 65 & 63 \\
\hline Unica Trop. & 14 & 11 & 13 & 19 & 31 & 60 & 128 & 65 & 47 & 47 & 34 & 23 \\
\hline Multiple Trop. & 57 & 64 & 60 & 52 & 33 & 23 & 5 & 2 & 9 & 16 & 31 & 40
\end{tabular}

Tabla 4.1 - Número de ozonosondeos para los que se detecta una única o múltiple tropopausa. La fila etiquetada como Total se refiere a la suma de sondeos realizados para cada mes durante el periodo de 1992 a 2008

Tropopausa Múltiple. Altura

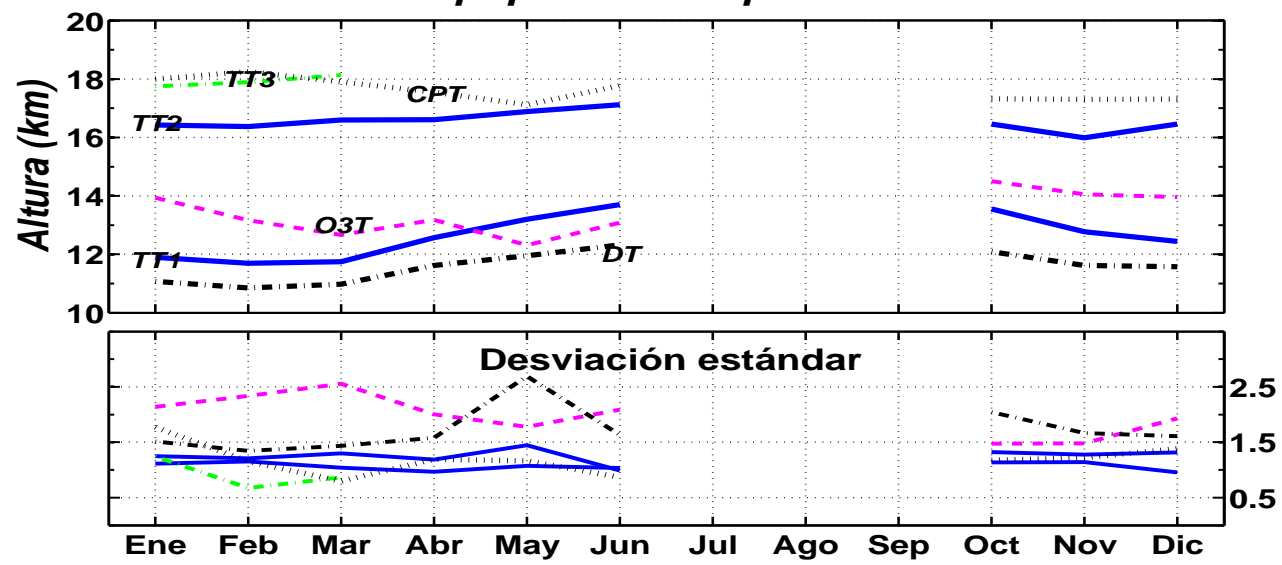

Figura 4.6 - Variación estacional de la altura de la tropopausa definida según los criterios dados en la sección 3.2.2. Valores climatológicos calculados a partir de todos los sondeos que presentan múltiple tropopausa. Se representa además la desviación estándar para cada valor mensual (abajo)

Tropopausa Múltiple. Temperatura Potencial

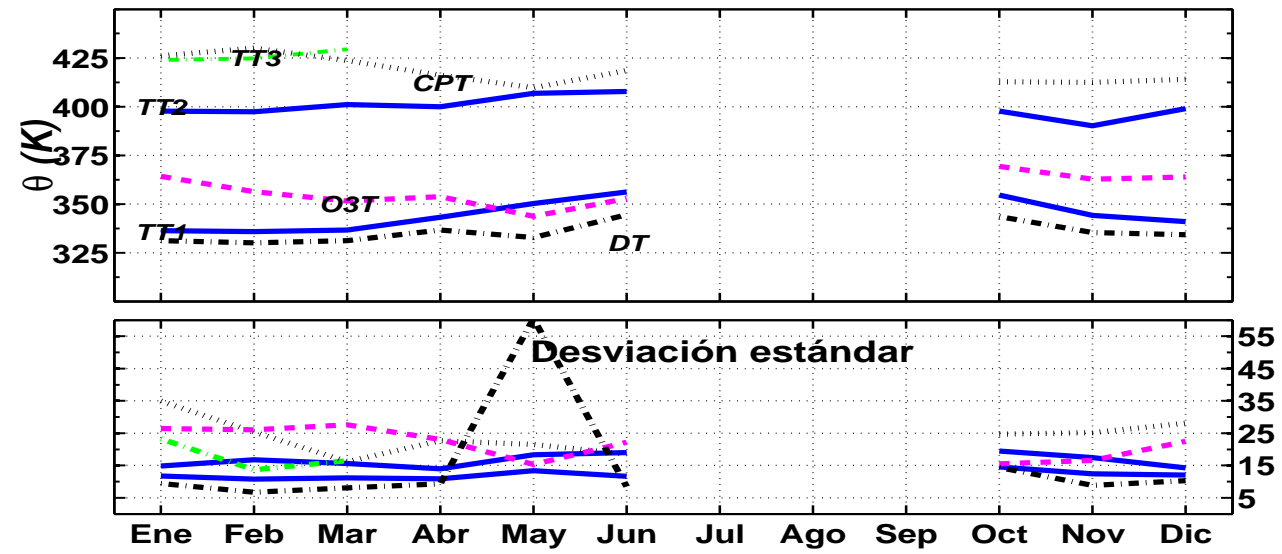

Figura 4.7 - Idem a figura 4.6, pero en este caso considerando la temperatura potencial 
En referencia a la tropopausa dinámica, $\boldsymbol{D} \boldsymbol{T}$, el comportamiento observado es cuando menos sorprendente. En efecto, tradicionalmente se ha considerado al ozono como buen trazador para masas de aire de origen estratosférico, en particular cuando se trata de fenómenos de transporte asociados a procesos adiabáticos [Danielsen, 1968, Beekmann et al., 1994]. Puesto que grandes valores de vorticidad potencial son generados en la estratosfera, y dado que esta es una magnitud conservada bajo condiciones adiabáticas, cabe pensar que ambas magnitudes, vorticidad potencial y ozono se comporten de modo similar al considerarlas como trazadores estratosféricos. Sin embargo, no es esto lo que se observa. A diferencia de $\boldsymbol{O} 3 \boldsymbol{T}$, la tropopausa dinámica, $\boldsymbol{D T}$, siempre se localiza $\sim 1 \mathrm{~km}$ por debajo de $\boldsymbol{T T} \mathbf{1}$, exceptuando el periodo comprendido entre los meses de Abril a Junio, cuando dicha diferencia aumenta ligeramente. Es precisamente aquí cuando el comportamiento entre $\boldsymbol{O} 3 \boldsymbol{T}$ y $\boldsymbol{D T}$ se aproxima más a lo esperado.

Como se explicó en la sección 3.2.2, para el cálculo de $\boldsymbol{D} \boldsymbol{T}$ no se aplica a priori un valor umbral de vorticidad potencial. En lugar de eso, se asignará ésta al primer nivel que verifique la condición de máximo en el gradiente vertical de PV, resultando de esta manera unos valores mensuales en el rango $[2,53,5]$ pvu. Son estos los valores para los cuales diferentes autores han encontrado el mejor acuerdo entre la tropopausa dinámica y la térmica [Hoerling et al., 1991]. En la sección 4.4 se discutirán las consecuencias de este resultado.

Como indicativo de la variabilidad estacional de la altura de los niveles de tropopausa observados, se representa en la misma figura, abajo, la desviación estándar, $\sigma$, para cada valor calculado. Sin embargo, dado el amplio espectro de alturas a comparar, se analiza la variabilidad para cada valor mensual a partir del coeficiente de variación, definido según

$$
c_{v}=\frac{\sigma^{\mathcal{X}}}{\overline{\mathcal{X}}}
$$

Tanto $\sigma^{\boldsymbol{T T} 1}$ como $\sigma^{\boldsymbol{T T} 2}$ y $\sigma^{\boldsymbol{C P T}}$ muestran un valor similar, $\sim 1 \mathrm{~km}$, con muy poca variación estacional durante los meses considerados. Dicho valor supone un coeficiente de variación aproximado del $6 \%$ y $7 \%$ respectivamente, excepto para $\mathbf{T T} 1$ en Marzo, con un valor mínimo $c_{v} \approx 2 \%$. La menor variabilidad se observa para TT3, $c_{v} \approx 2,5 \%$. Notar la variación sinusoidal de $\sigma{ }^{\boldsymbol{C P T}}$ durante el primer semestre. Los valores máximos de desviación estándar son mostrados por $\boldsymbol{O} 3 \boldsymbol{T}$ durante el primer semestre del año, con un coeficiente de variación en el rango comprendido entre el valor máximo $c_{v} \approx 19 \%$ de Marzo hasta un mínimo $c_{v} \approx 13 \%$ en Mayo. El modo de variación es similar al exhibido por $\boldsymbol{C P} \boldsymbol{T}$ durante el mismo periodo, aunque con un desfase de $180^{\circ}$. La tropopausa dinámica, por otra parte, muestra muy poca variabilidad para todos los meses considerados, en torno a $\sim 1,5 \mathrm{~km}$. La excepción la constituye el mes de Mayo, con $\sigma^{\boldsymbol{D}} \sim 2,5 \mathrm{~km}$. Una vez descartada la posibilidad de outliers que pudieran producir este valor anómalo de $\sigma$, la existencia de procesos dinámicos intensos podrían justificar el comportamiento hallado. En este sentido no se han obtenido resultados concluyentes. Para los meses de Octubre a Diciembre la variabilidad mensual para todas las tropopausas definidas es muy similar, en torno a $\sim 1,5 \mathrm{~km}$.

\section{Temperatura Potencial de la tropopausa}

La variación anual de la temperatura potencial, definida como $\theta=T(1000 / p)^{R_{d} / c_{p}}$, se muestra en la figura 4.7, siendo ésta muy similar a la variación de la altura para cada tipo de tropopausa estudiada. El aspecto más interesante a destacar es el valor que toma 
$\theta$ en el nivel asignado a $\boldsymbol{T T} \mathcal{L}, \theta \approx 400 \mathrm{~K}$. Notar que este es un valor superior al sugerido como relevante para los procesos de intercambio estratosfera-troposfera, $\theta \approx 380 \mathrm{~K}$ [Holton et al., 1995]. En dicho trabajo se lleva a cabo una división de la atmósfera a escala global en base al comportamiento mostrado por las superficies de temperatura potencial constante (iséntropas). Así, a la región verificando que las iséntropas se hallan enteramente en la troposfera se la denomina "underworld", mientras que cuando las iséntropas se hallan en la estratosfera, la región atmosférica correspondiente recibe el nombre de "overworld". Entre ambas estaría lo que el autor llama "lowermost stratosphere" o sea, aquella región tal que las superficies isentrópicas se hallan en parte en la troposfera (para latitudes bajas) y en parte en la estratosfera (para latitudes altas). Es precisamente aquí donde podrían tener lugar fenómenos de transporte adiabáticos entre la estratosfera y la troposfera, y viceversa. El límite superior de la región "lowermost stratosphere" viene dado por la iséntropa de $380 \mathrm{~K}$, algo inferior al hallado por nosotros en relación con la segunda tropopausa en sistemas de múltiple tropopausa.

En cuanto a la variabilidad anual, $\boldsymbol{T T} \mathbf{T}, \boldsymbol{T} \boldsymbol{T} 2, \boldsymbol{T} \boldsymbol{T} 3$ y $\boldsymbol{D T}$ muestran un coeficiente de variación $c_{v} \approx 3 \%$, salvo por el valor excepcional $c_{v} \approx 17 \%$ para $\boldsymbol{D T}$ en Mayo. A diferencia de lo que ocurre con la altura, la variabilidad en el caso de $\boldsymbol{C P T}$ es ligeramente superior a la correspondiente a la tropopausa térmica, $\left(c_{v} \approx 5 \%\right)$. O3T muestra un $c_{v} \approx 7 \%$ durante todos los meses en los que se observan sistemas de tropopausa múltiple.

\subsubsection{Sistemas de tropopausa simple}

De forma análoga que en el caso de tropopausa múltiple, para los ozonosondeos presentando una tropopausa térmica simple se observa un comportamiento más complejo durante el primer semestre del año. Entre los meses de Enero a Junio se observa un patrón sinusoidal en la variación de ambos parámetros, con un mínimo local en el periodo de Abril a Mayo. Es notable la evolución paralela para todos los tipos de tropopausa, a diferencia de lo que se observa en la situación estudiada con anterioridad. El comportamiento de todas las tropopausas aparece más regular durante el segundo semestre.

\section{Altura de la tropopausa}

En la figura 4.8 se muestra la variación anual de la altura asignada a cada uno de los tipos de tropopausa consideradas. Dicho gráfico revela un comportamiento más ordenado, a diferencia de lo observado para múltiple tropopausa térmica. En efecto, la situación es la que se esperaba, con $\boldsymbol{O} 3 \boldsymbol{T}$ y $\boldsymbol{D T}$ en consonancia y localizadas ambas aproximadamente $1 \mathrm{~km}$ por debajo de $\boldsymbol{S i n g} \boldsymbol{T}$, y $\boldsymbol{C P} \boldsymbol{T}$ en torno a $1,5-2 \mathrm{~km}$ por encima de ésta. Sin embargo, existen ciertas características notables, la primera siendo una evolución sinusoidal durante el primer semestre, con valores máximo y mínimo en los meses Febrero-Marzo y Abril-Mayo respectivamente. Los valores máximos corresponden a $\sim 18 \mathrm{~km}(\boldsymbol{C P T}), \sim 16 \mathrm{~km}(\boldsymbol{S i n g} \boldsymbol{T})$ y $\sim 15 \mathrm{~km}(\boldsymbol{O} 3 \boldsymbol{T}$ y $\boldsymbol{D T})$, mientras que los valores mínimos varían desde $\sim 18 \mathrm{~km}$ para $\boldsymbol{C P T}$, hasta $\sim 12 \mathrm{~km}$ para el caso de $\boldsymbol{D} \boldsymbol{T}$. Notar como el mínimo valor en altura para $\boldsymbol{D} \boldsymbol{T}$ se halla desplazado en un mes, ocurriendo en Abril, mientras que para todos los demás tipos tiene lugar en Mayo. En cuanto al segundo semestre del año, todos los tipos de tropopausa muestran una variación monótona de la altura, desde $\sim 16,5-15,5 \mathrm{~km}$ en el periodo estival, hasta $\sim 15 \mathrm{~km}$ a final de año. Cabe destacar para este periodo la transición experimentada por $\boldsymbol{O} 3 \boldsymbol{T}$, pasando a estar por encima de Sing $\boldsymbol{T}$ a partir de Noviembre. 


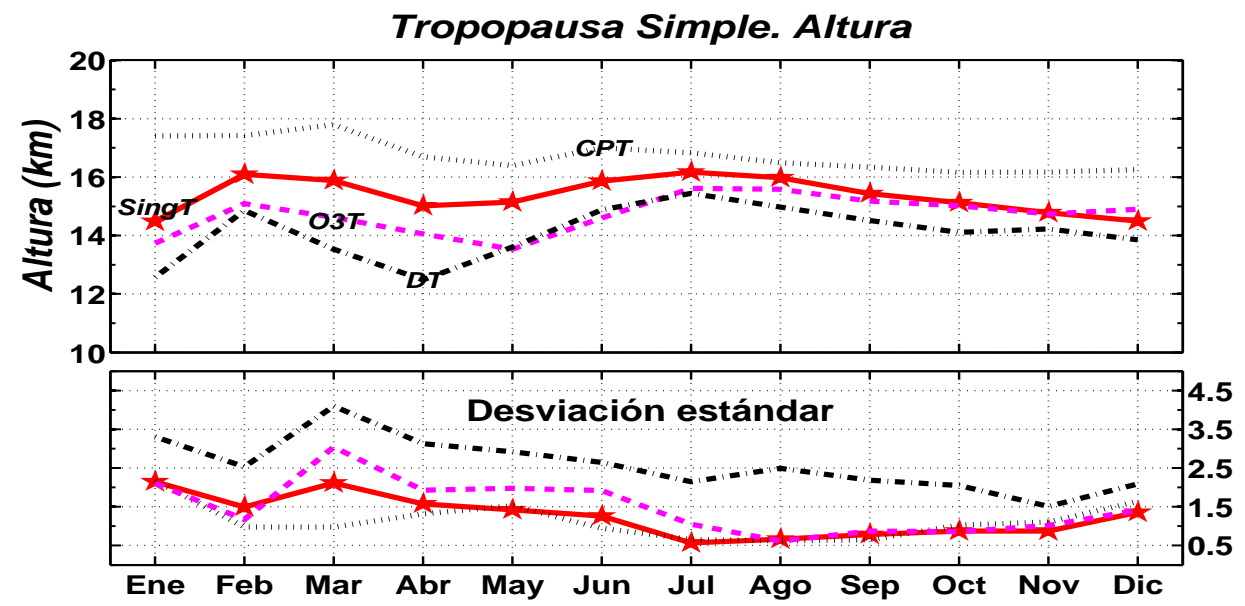

Figura 4.8 - Variación estacional de la altura de la tropopausa definida según los criterios dados en la sección 3.2.2. Valores climatológicos calculados sólo con los sondeos que presentan tropopausa térmica simple. Se representa además la desviación estándar para cada valor mensual (abajo)

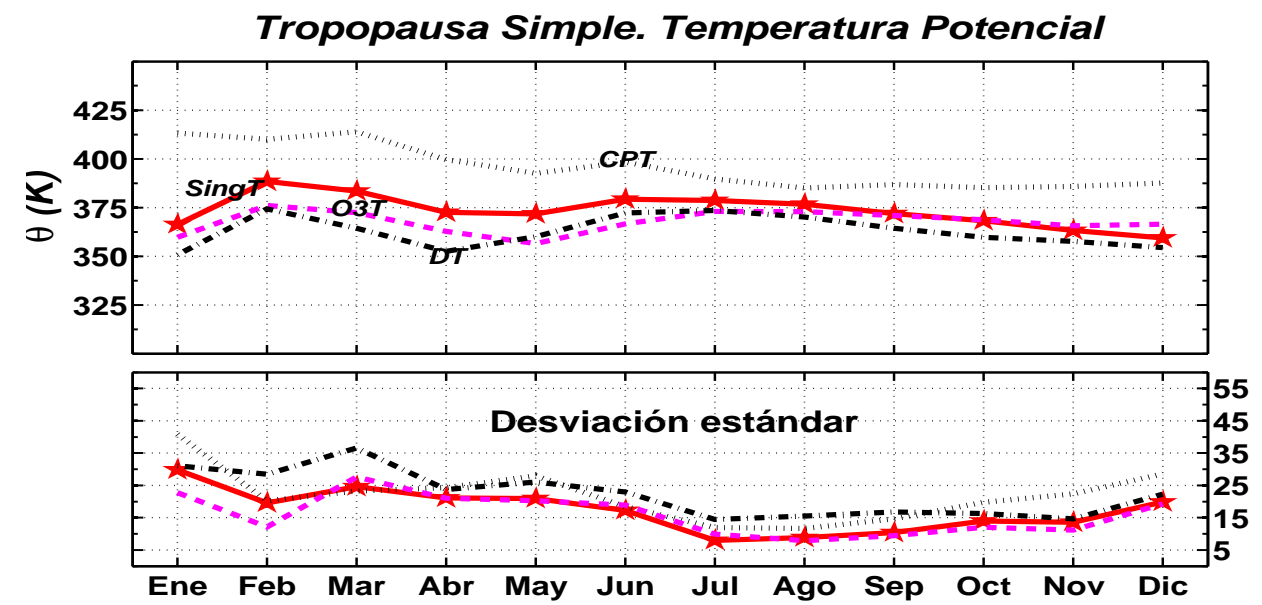

Figura 4.9 - Idem a figura 4.8, pero en este caso considerando la temperatura potencial

A diferencia de las demás, la altura de $\boldsymbol{C P} \boldsymbol{T}$ permanece aproximadamente constante, $\sim 16 \mathrm{~km}$ durante el mismo periodo, manteniendo de esta forma la diferencia en altura referida anteriormente con respecto a la tropopausa térmica.

En relación a la variabilidad, cuantificada a partir del coeficiente de variación, se observa diferente comportamiento al considerar los dos semestre del año. De Enero a Junio tanto $\boldsymbol{D T}$ como $\boldsymbol{O} \mathbf{3} \boldsymbol{T}$ y $\boldsymbol{S i n g} \boldsymbol{T}$ muestran la misma variación mensual en la desviación estándar, con un valor máximo en el mes de Marzo, aunque la variabilidad resulta ser mayor para la primera y menor para SingT. En el orden dado, el coeficiente de variación promedio para los meses de Enero a Junio resulta $\sim 23 \%, \sim 14 \%$ y $\sim 7 \%$, mientras que para el máximo registrado en Marzo se encuentra $\sim 30 \%, \sim 20 \%$ y $\sim 12 \%$ respectivamente. Notar como la tropopausa del punto frío no experimenta este valor máximo, siendo $c_{v} \approx 6 \%$ para todo el primer semestre. 
Durante el segundo semestre, y a excepción de $\boldsymbol{D T}, c_{v} \approx 6 \%$ para todos los tipos de tropopausa definidos. En el caso de la tropopausa dinámica se observa la mayor variabilidad, siendo $c_{v} \approx 14 \%$.

\section{Temperatura Potencial de la tropopausa}

En la figura 4.9 se muestra la variación anual de la temperatura potencial. La evolución anual es semejante a la analizada en el caso de la altura, encontrándose incluso una menor dispersión entre los diferentes tipos de tropopausa para el primer semestre. Esto sugiere la existencia de procesos cuyo efecto neto resulta en un apilamiento de las líneas isentrópicas. La excepción la encontramos en $\boldsymbol{C P T}$, la cual exhibe los máximo valores, $\theta \approx 410 \mathrm{~K}$ de Enero a Marzo y $\theta \approx 400 K$ entre Abril y Junio. Para la tropopausa térmica se halla en promedio $\theta \approx 380 K$ todo el año, aunque con valores ligeramente superiores $(\theta \approx 387 K)$ y algo inferiores $(\theta \approx 360 K)$ en los meses de Febrero a Marzo y Octubre a Diciembre respectivamente. Notar como estos resultados coinciden aproximadamente con el esquema global propuesto por Holton [Holton et al., 1995], y que discutimos en su momento brevemente. Aquí lo importante es la discrepancia hallada entre las climatologías obtenidas a partir de los ozonosondeos mostrando múltiple tropopausa, por un lado, y una única tropopausa, por el otro.

La variabilidad mensual muestra de igual forma una menor dispersión durante el primer semestre, sin diferencia apreciable entre los diferentes tipos de tropopausa. En promedio se encuentra un coeficiente de variación $c_{v} \approx 6 \%$, con un máximo para $\boldsymbol{D T}$ durante Marzo de magnitud $c_{v} \approx 9 \%$. En cuanto al segundo semestre del año, se observa un coeficiente de variación $c_{v} \approx 2,5 \%$, con tendencia creciente hacia final de año.

\subsubsection{Perfiles de viento}

Es sabido que la tropopausa no se halla a la misma altura para todas las latitudes, variando desde $\sim 16-17 \mathrm{~km}$ en los trópicos hasta $\sim 8-9 \mathrm{~km}$ en latitudes altas. Sin embargo, la transición entre ambos extremos no ocurre de modo continuo, sino que tiene lugar a partir de zonas de discontinuidad, o "tropopause breaks" [Kochanski, 1955, Pan et al., 2004]. Se han observado tales regiones en latitudes subtropicales y subpolares, separando la baja estratosfera hacia el Norte de la alta troposfera hacia el Sur. Como consecuencia de acusados gradientes horizontales de temperatura, es de esperar que a su vez existan en estas discontinuidades de la tropopausa global vientos especialmente intensos, tal y como se deduce de la ecuación de viento térmico

$$
\frac{\partial \overrightarrow{V_{g}}}{\partial \ln p}=-\frac{R_{d}}{f} \vec{k} \times \overrightarrow{\nabla_{p}} T
$$

donde $\overrightarrow{V_{g}}$ es el viento geostrófico y $\overrightarrow{\nabla_{p}}$ se refiere al operador $\vec{\nabla}$ actuando sobre superficies isobáricas. Se deduce de aquí que a mayor gradiente térmico horizontal mayor será la variación vertical (cizalladura) de las compontes zonal y meridional del viento. Dada la latitud de la isla de Tenerife, es de esperar la presencia del chorro subtropical en la región UTLS. Existen varios criterios para discernir la existencia de chorros en altura. Uno de ellos asigna el valor umbral $v=50 \operatorname{nudos}(K T) \approx 26 \mathrm{~ms}^{-1}$ para la determinación de tales corrientes [Glickman, 2000]). 
En la figura 4.10 se muestra la variación estacional del módulo del vector viento sobre Tenerife $\left(28^{\circ} \mathrm{N}, 16^{\circ} \mathrm{W}\right)$

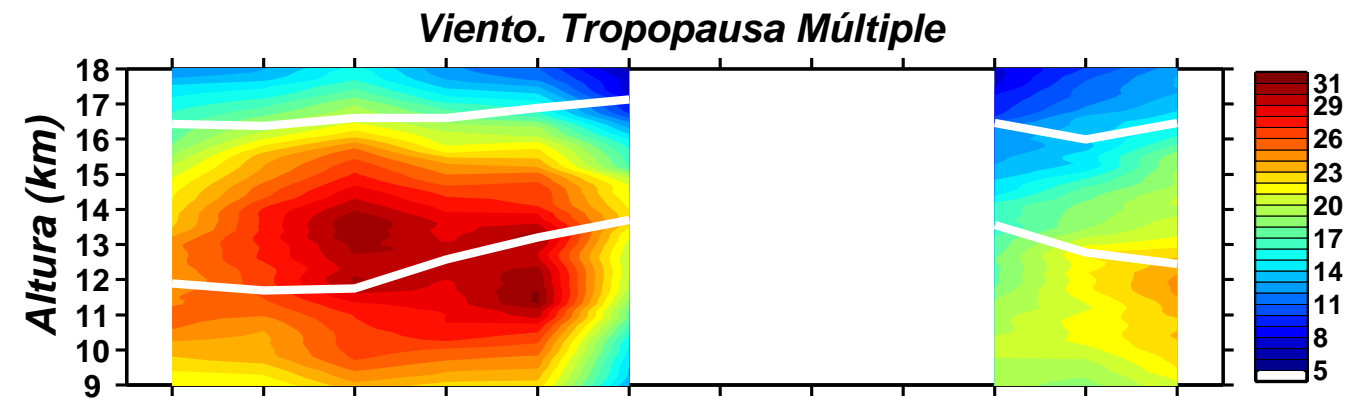

(a)

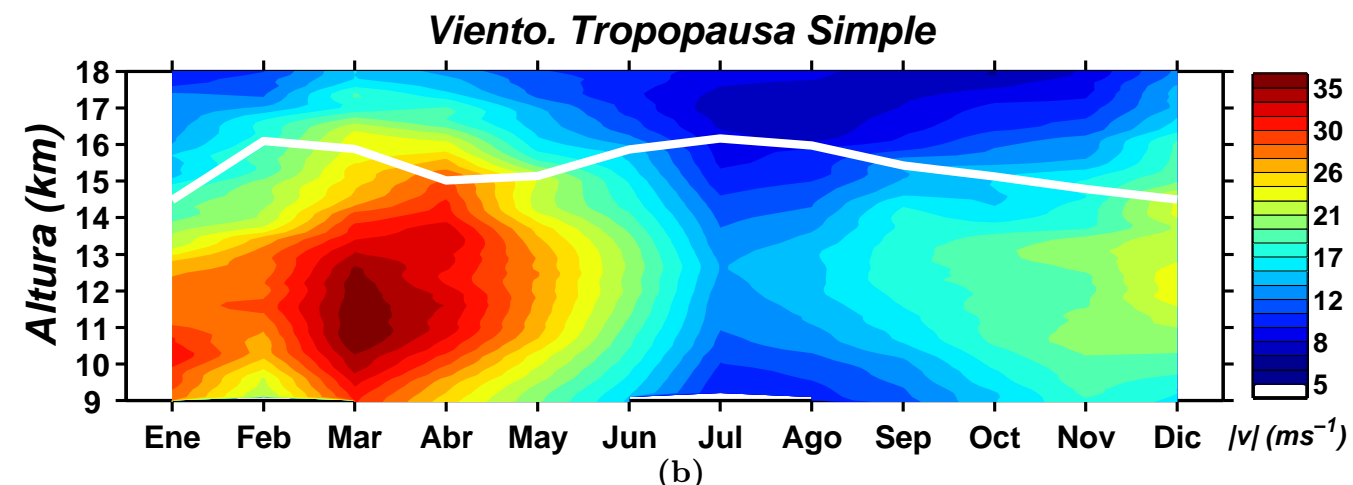

Figura 4.10 - Climatología del viento para situaciones de tropopausa múltiple (a) y de tropopausa simple (b), en ambos casos indicando el nivel de la tropopausa térmica

Se observa claramente un ciclo anual, con máximo valor entre los meses de Marzo a Mayo, así como la ausencia de vientos fuertes en niveles altos durante el periodo estival. Esta es la evolución estacional conocida para el chorro subtropical en la posición de Tenerife [Cuevas and Rodríguez, 2002]. En dicho estudio los autores implementan un algoritmo que, tras un proceso de suavizado de los datos, es utilizado para la detección de puntos donde el viento es máximo. Para el estudio se usan los años 1998 y 1999, concluyendo lo siguiente:

- migración del chorro subtropical hacia el Norte desde su posición más meridional, aproximadamente en Enero, situándose en la vertical del archipiélago canario en los meses de Marzo a Mayo. En todos los casos se observa el máximo de viento en los niveles isentrópicos $\sim 340-350 \mathrm{~K}$

- máxima intensidad en torno al mes de Marzo

- en los meses de Junio, Julio, Agosto y Septiembre no se identifica un Jet próximo a Canarias, confundiéndose con el chorro polar muy al Norte de Canarias al final del verano

Los resultados mostrados en la figura 4.10 confirman los hallados en el estudio anterior, si bien en situaciones de tropopausa múltiple (a) se exhiben dos máximos de magnitud 
semejante en los meses de Marzo y Mayo, este último localizado en niveles ligeramente inferiores. Una posible explicación a este máximo de vientos en Mayo podría estar relacionada con la interacción del chorro con perturbaciones en altura, teniendo en cuenta que la máxima frecuencia de ocurrencias de tales pertubaciones en el entorno de las canarias tiene lugar durante los meses de Abril a Mayo [Cuevas and Rodríguez, 2001]. Esta hipótesis está respaldada por los resultados de la figura 4.6, en particular con el cambio en la posición de la tropopausa química respecto de la tropopausa térmica durante el mismo periodo, lo cual sugiere procesos de transporte hacia la troposfera (notar además en la misma figura el máximo valor de la desviación estándar para la tropopausa dinámica en Mayo). En la sección 4.4 se analizarán aspectos relacionados con el transporte en la región UTLS subtropical.

Sorprendentemente, se observa como para el caso de una única tropopausa persiste la presencia de un chorro en niveles altos, además con valores climatológicos de máximo de viento superiores a los hallados para tropopausa múltiple. Si tenemos en cuenta el esquema sugerido hasta ahora serán posibles dos situaciones en relación a la posición del sistema de tropopausa múltiple: en el caso de que esté desplazado al Norte de Canarias estaremos viendo la tropopausa tropical, en torno a $16 \mathrm{~km}$, mientras que si está desplazado al Sur observaremos una única tropopausa, por debajo de $\sim 14,5 \mathrm{~km}$, con características propias de latitudes medias (observar en la figura 4.3(a) de la sección 4.1 que para la distribución bimodal hallada para los meses de Enero a Marzo existe un mínimo de casos para alturas de la tropopausa del orden de $\sim 14,5 \mathrm{~km})$. Con el fin de ilustrar ambas, he examinado el viento en $200 \mathrm{hPa}$, además de la presión en el nivel de la tropopausa (datos proporcionados por Juan Bustos) para los casos de Enero a Mayo con una única tropopausa. En la figura 4.11, se muestran los perfiles de viento y temperatura resultantes del ozonosondeo llevado a cabo el día 25 de Marzo de 1999 (b), y el viento en 200 hPa con la presión de tropopausa (a). Se aprecia un intenso chorro cuya entrada se localiza aproximadamente sobre la vertical de Tenerife. Sin embargo, la discontinuidad en la tropopausa (región con fuerte gradiente en la presión de la misma), se halla desplazada hacia el Norte, observando sobre Canarias una única tropopausa localizada en torno a $16 \mathrm{~km}$, tropical (línea roja horizontal en (b)). En la tabla 4.2 se indican el número de ozonosondeos presentando una única tropopausa en niveles bajos, $\mathbf{z}_{\mathbf{S i n g T}}<\mathbf{1 4 , 5} \mathbf{k m}$, así como con una única tropopausa alta, $\mathbf{Z}_{\mathbf{S i n g T}} \geq \mathbf{1 4 , 5} \mathbf{k m}$ . Como referencia se indican también el número total de ozonosondeos para cada mes, así como el total de ozonosondeos con una única tropopausa detectada. Se comprueba que los casos correspondientes al esquema $\mathbf{Z}_{\mathbf{S i n g T}}<\mathbf{1 4 , 5} \mathbf{k m}$, son los menos a lo largo del año. Al inspeccionarlos visualmente, se observó que en gran parte de ellos el nivel de la tropopausa había sido asignado arbitrariamente, decidiendo por ello no tenerlos en cuenta en lo que sigue, por coherencia con la estrategia escogida en este trabajo, o sea, la elección de la tropopausa como referencia en todos los cálculos. A pesar de todo, se observa un comportamiento destacable: notar que a partir de Febrero el número de tropopausas sin precisar aumenta monótonamente hasta un valor máximo en Mayo, coincidiendo con el periodo de mayor actividad baroclina en la alta troposfera [Cuevas and Rodríguez, 2001]. En el futuro se acometerá un análisis más detallado de estos ozonosondeos.

Si se tiene en cuenta el porcentaje de sondeos presentando tropopausa múltiple (exceptuando el periodo estival), figura 4.5, y la situación descrita para los pocos casos en que nos encontramos con una sola tropopausa, podremos afirmar que la discontinuidad en la tropopausa global en latitudes subtropicales es una característica persistente, y no un fenómeno aislado. Muy probablemente dicho salto en la tropopausa global (y el chorro asociado), reflejen la diferente naturaleza de este nivel en diferentes latitudes: una tropopausa 


\begin{tabular}{l|c|c|c|c|c|c|c|c|c|c|c|c} 
& Ene & Feb & Mar & Abr & May & Jun & Jul & Ago & Sep & Oct & Nov & Dic \\
\hline Ozonosondeos & 71 & 75 & 73 & 71 & 64 & 83 & 133 & 67 & 56 & 63 & 65 & 63 \\
\hline Simple total & 14 & 11 & 13 & 19 & 31 & 60 & 128 & 65 & 47 & 47 & 34 & 23 \\
\hline $\mathbf{Z}_{\text {SingT }} \geq \mathbf{1 4 , 5} \mathbf{~ k m}$ & 7 & 10 & 11 & 13 & 19 & 51 & 128 & 64 & 40 & 35 & 23 & 10 \\
\hline $\mathbf{Z}_{\text {SingT }}<\mathbf{1 4 , 5} \mathbf{~ k m}$ & 7 & 1 & 2 & 6 & 13 & 10 & 0 & 1 & 7 & 13 & 11 & 14
\end{tabular}

Tabla 4.2 - Número de ozonosondeos mostrando una única tropopausa térmica tal que $\mathbf{Z}_{\mathbf{S i n g T}} \geq \mathbf{1 4 , 5}$ ó bien $\mathbf{Z}_{\mathbf{S i n g} \mathbf{T}}<\mathbf{1 4 , 5}$, para todos los meses. Se añaden además el número total de ozonosondeos por mes y el número total de ozosondeos con una única tropopausa térmica detectada
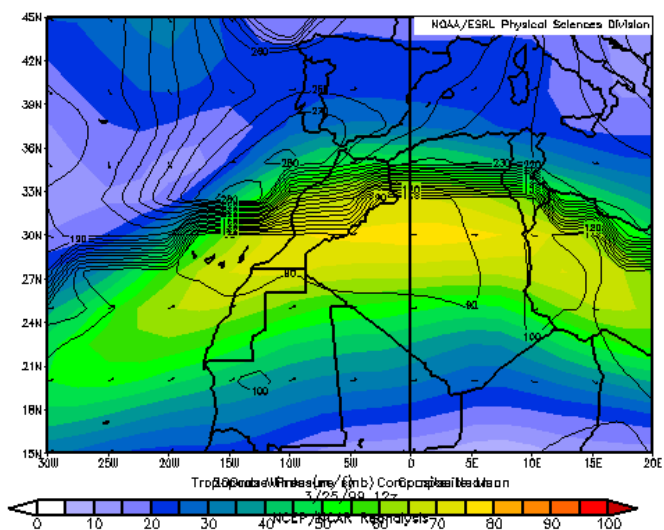

(a)

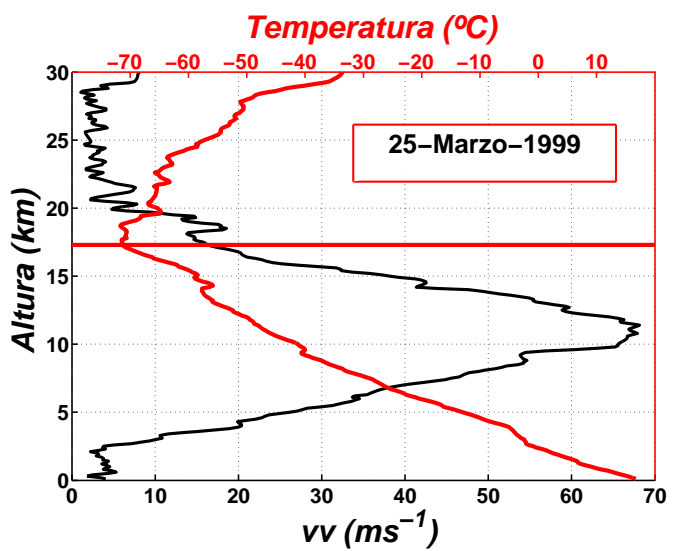

(b)

Figura 4.11 - Situación correspondiente a una única tropopausa térmica detectada con chorro intenso. En (b) se muestra el sondeo correspondiente con la tropopausa detectada (linea horizontal roja). En (a) se muestra el viento en $200 \mathrm{hPa}$, más la presión en el nivel de tropopausa, para el mismo día 
marcada por el equilibrio convectivo-radiativo en la atmósfera tropical y una tropopausa condicionada por procesos baroclinos en el caso de latitudes medias.

\subsection{Estructura térmica en la región de la tropopausa}

En los últimos años se ha retomado el interés por la región de la tropopausa a escala global, también en relación con la problemática del cambio climático global. Uno de los estudios en torno a dicha región que más interés ha suscitado se refiere a la inversión térmica hallada inmediatamente por encima de la tropopausa [Birner et al., 2002, Birner, 2006]. Dicha característica había sido pasada por alto en las anteriores caracterizaciones climatológicas de la tropopausa a escala global principalmente debido a dos motivos:

- resolución vertical insuficiente

- cálculo de promedios referidos al nivel de la superficie, en lugar de referidos al nivel de la tropopausa

Posteriormente a la publicación de este resultado, varios autores llevaron a cabo una serie de estudios encaminados a proporcionar una justificación física de dicha región, así como una caracterización estacional y global [Wirth, 2004, Randel et al., 2007, Bell and Geller, 2008]. En este sentido resulta muy interesante la serie de perfiles disponibles desde el CIAI, pues además de estar localizada dicha estación en una situación clave, desde la que resulta factible estudiar características de ambas tropopausas, tropical y de latitudes medias, se cuenta con una serie larga de perfiles atmosféricos de alta resolución espacial.

En la figura 4.12 se compara un perfil promedio $N^{2}$, obtenido a partir de dos métodos difentes: evaluación del promedio tomando como referencia el nivel de la tropopausa ( $\boldsymbol{T} \boldsymbol{L} \boldsymbol{B}$, Tropopause Level Based), línea roja, y el nivel del suelo (SLB, Sea Level Based), línea negra. En este ejemplo se han tomado 19 perfiles arbitrarios correspondientes al mes de Marzo, resultando la diferencia entre ambos métodos mayor a medida que aumentan el número de perfiles a promediar. Resulta clara la ventaja de tomar como referencia para el cálculo de la climatología el nivel de la tropopausa, ya que en caso contrario y debido a la variabilidad espacial de la tropopausa, como se ha dicho anteriormente, al promediar sobre un número suficientemente grande de elementos se obtiene una imagen difusa de lo que realmente ocurre en el entorno de dicho nivel. En lo que sigue siempre me referiré a valores climatológicos hallados a partir del método $\boldsymbol{T} \boldsymbol{L} \boldsymbol{B}$.

El ejemplo de la figura anterior ilustra perfectamente la inversión asociada a la tropopausa de la que he habla-

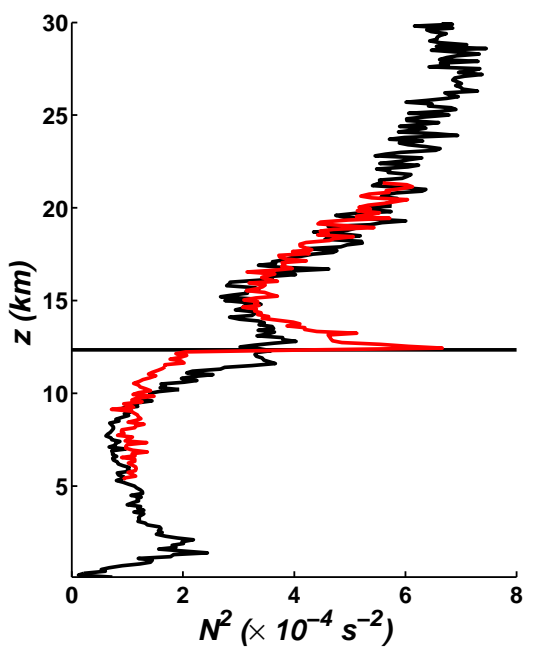

Figura 4.12 - Comparación de perfil promedio $S L B$ vs TLB para la frecuencia de Brunt-Väisälä. Se muestra también el nivel promedio de la tropopausa do, en particular en los valores de $N^{2}$ (recordar que $N^{2}$ y el gradiente térmico se hallan relacionados entre si según $N^{2}=\frac{g}{T}\left(\Gamma_{d}-\Gamma\right)$ ). En este caso se trata de un estrato con espesor $\sim 3 \mathrm{~km}$ y estabilidad muy acusada, con valores máximos en $N^{2}$. Notar el fuerte gradiente en dicho parámetro asociado al nivel de la tropopausa, pasando de valores típicamente troposféricos $\left(\sim 1 \times 10^{-4} s^{2}\right)$ a un valor máximo en torno a $6 \times 10^{-4} s^{2}$. Resulta también interesante 
la transición entre ambos rangos de valores que tiene lugar 2-3 km por debajo del nivel de la tropopausa.

En primer lugar se analizará la frecuencia Brunt-Väisälä $\left(N^{2}\right)$ en la región UTLS sobre Tenerife, para a continuación investigar la variación estacional de la capa de inversión térmica asociada a la tropopausa en las dos situaciones posibles, esto es, tropopausa simple y múltiple.

En la figura 4.13 se muestra la sección climatológica para $N^{2}$ representativa de la situación encontrada sobre las Islas Canarias

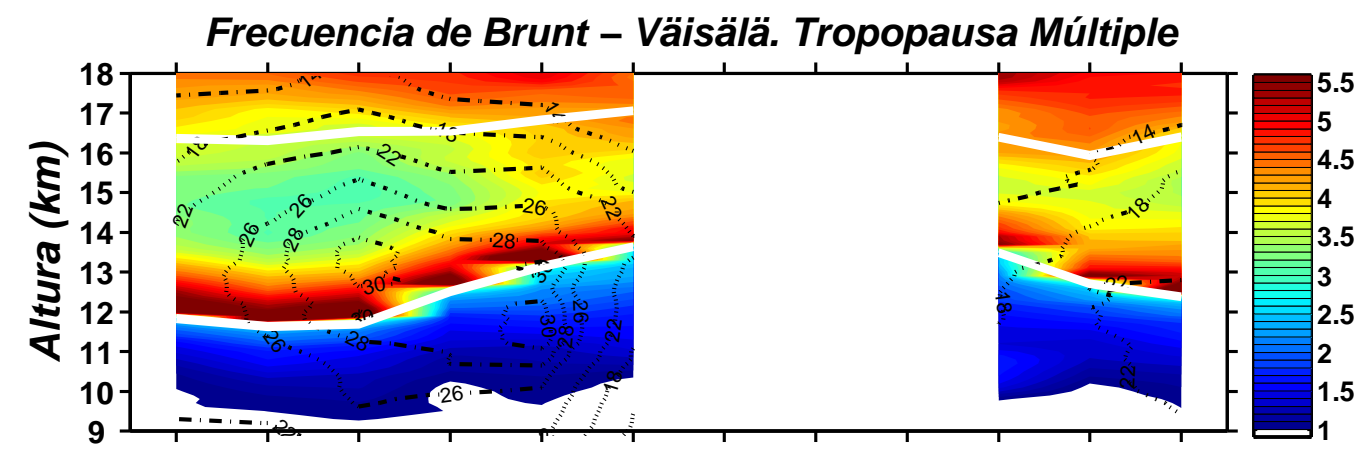

(a)

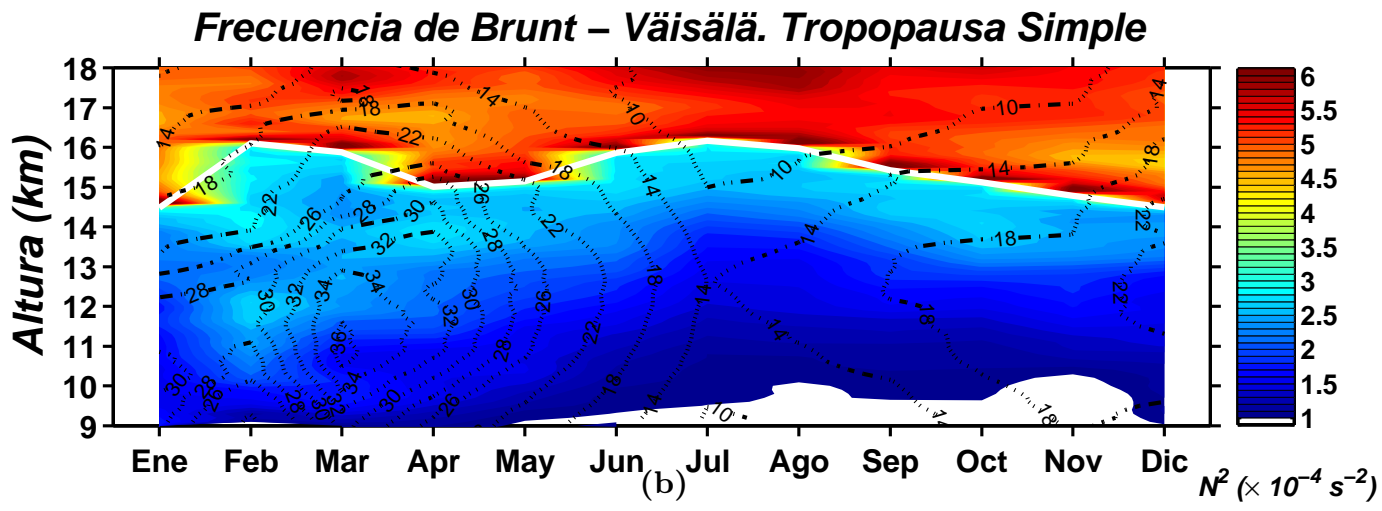

Figura 4.13 - Climatología de la frecuencia de Brunt-Väisälä para situaciones de tropopausa múltiple (a) y de tropopausa simple (b), en ambos casos indicando el nivel de la tropopausa. Se representan también las lineas de contorno (isotacas) correspondientes al viento

Uno de los aspectos que más llaman la atención de la figura anterior es la región situada entre las dos tropopausas (figura 4.13(a)), con unos valores de $N^{2}$ algo inferiores a lo esperado. Se observa tal estructura principalmente durante los meses de Noviembre a Abril, independientemente del máximo de viento en los meses de Marzo y Abril. Es muy probable que esta región con mínimo local en las propiedades de estabilidad se deba a la mezcla de dos masas de aire con diferentes propiedades: una tropical, con bajos valores de $N^{2}$, al sur, y otra de latitudes medias, de carácter estratosférico, al norte. En todo caso, el chorro actuará favoreciendo la mezcla de ambas. La figura 4.13(b), mostrando el ciclo anual de $N^{2}$ para los casos en los que es detectada una única tropopausa, refuerza esta última hipótesis. Dicha sección exhibe una región con valores perturbados de $N^{2}$ por debajo de 
la única tropopausa detectada, análogamente al caso anterior. Notar la región con valores anormalmente superiores en torno a $13 \mathrm{~km}$ en Primavera y en niveles inferiores, alrededor de $11 \mathrm{~km}$, en Invierno. En cualquier caso se encuentran tales regiones por encima del chorro, sugiriendo la entrada de aire desde la alta tropoposfera tropical hacia latitudes superiores (asumiendo que el chorro en Invierno se encuentra en niveles inferiores y al Sur de Canarias, según sugieren las figuras $4.10(\mathrm{a})$ y (b)). Se deduce también de aquí que el eje del chorro representa una barrera frente a la mezcla isentrópica, es decir, a movimientos de aire paralelos a las líneas de temperatura potencial constante.

Una diferencia importante entre las figuras 4.13(a) y 4.13(b) reside en la extensión vertical de la región analizada. Notar que en (b) existe una cierta dispersión en los valores de $N^{2}$ hacia niveles inferiores, mientras que en (a) la tropopausa impide el movimiento de las masas de aire en la misma dirección. En esta misma figura, por el contrario, se observa análoga dispersión en el sentido opuesto, sugiriendo transporte hacia la estratosfera. Sin embargo, es preciso interpretar este último resultado con cautela. El motivo es el modo en que se han calculado los valores promedios representados, esto es, utilizando el nivel de la primera tropopausa observada como referencia. Para garantizar que el resultado era correcto, se calculó idéntica sección, pero esta vez utilizando $Z_{T T 2}$ como referencia. El resultado es el mostrado en la figura siguiente (figura 4.14), mostrando una vez más la diferencia entre los resultados obtenidos a partir de los procedimientos $\boldsymbol{T} \boldsymbol{L} \boldsymbol{B}$ y $\boldsymbol{S} \boldsymbol{L} \boldsymbol{B}$. Es de suponer que en el caso de que TT1 y TT2 estuvieran fuertemente acopladas, experimentando idéntico signo en su movimiento y en el mismo momento, bastaría con considerar TT1 a la hora de obtener valores climatológicos. Vemos que no ocurre así. A grosso modo, la estructura en la región entre las dos tropopausas es similar a la exhibida en la figura 4.13(a), aunque para lograr una imagen de lo que realmente ocurre será necesario considerar ambas secciones.

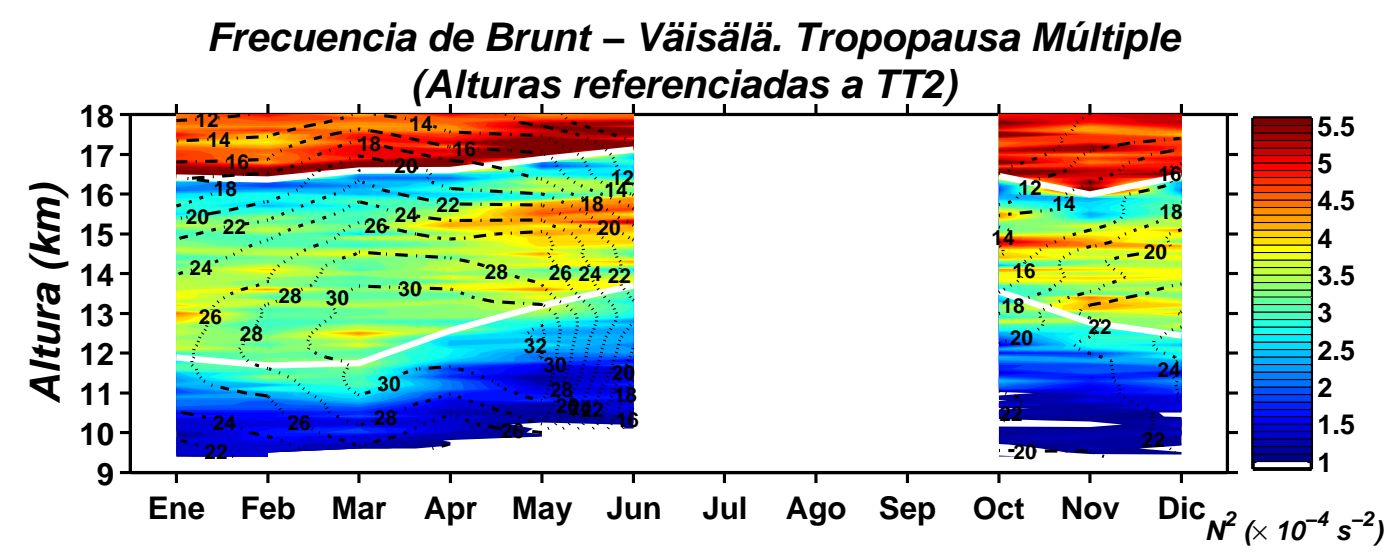

Figura 4.14 - Climatología de la frecuencia de Brunt-Väisälä referida al nivel de la segunda tropopausa (primera y segunda tropopausas mostradas con líneas blancas)

De todos los resultados mostrados hasta ahora se concluye que desde un punto de vista climatológico los procesos de transporte entre la troposfera y la estratosfera, en cualquiera de los dos sentidos, no son significativos, entendiendo que son más bien la excepción al escenario dominante.

En este sentido observamos como desempeña un papel fundamental otra característica excepcional de las figuras anteriores. Se trata de la región inmediatamente por encima del 
nivel de la tropopausa con una intensificación local de la estabilidad (me referiré en lo que sigue a esta región por las siglas $\boldsymbol{T I L}$, Tropopause Inversion Layer). Con el fin de evitar la influencia de los métodos de interpolación usados en las figuras anteriores, he tratado de caracterizar el ciclo anual de dicha región definiendo perfiles promedios para cada una de las estaciones. Dada la similitud observada entre TT2 y SingT, se ha calculado la estadística considerando ambas conjuntamente. El resultado se muestra en la siguiente figura

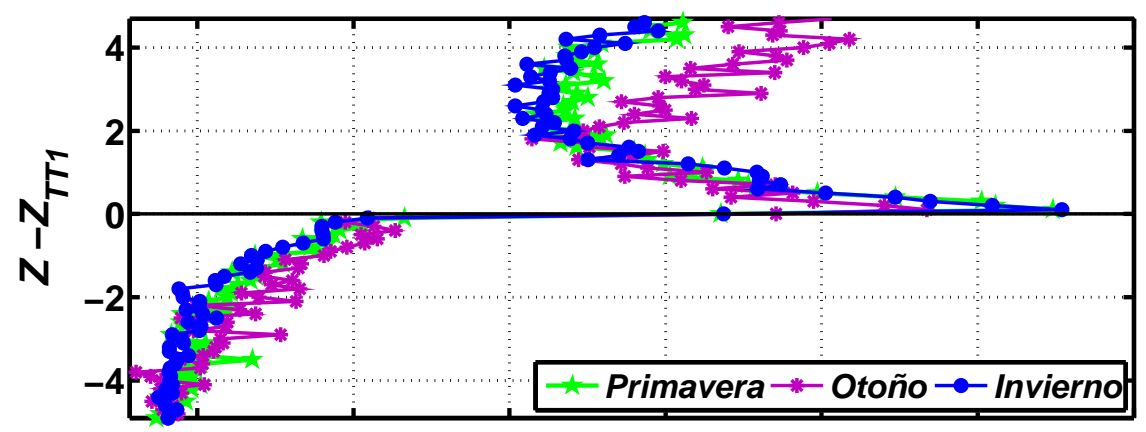

(a) Primera tropopausa observada en sistemas de tropopausa múltiple, TT1

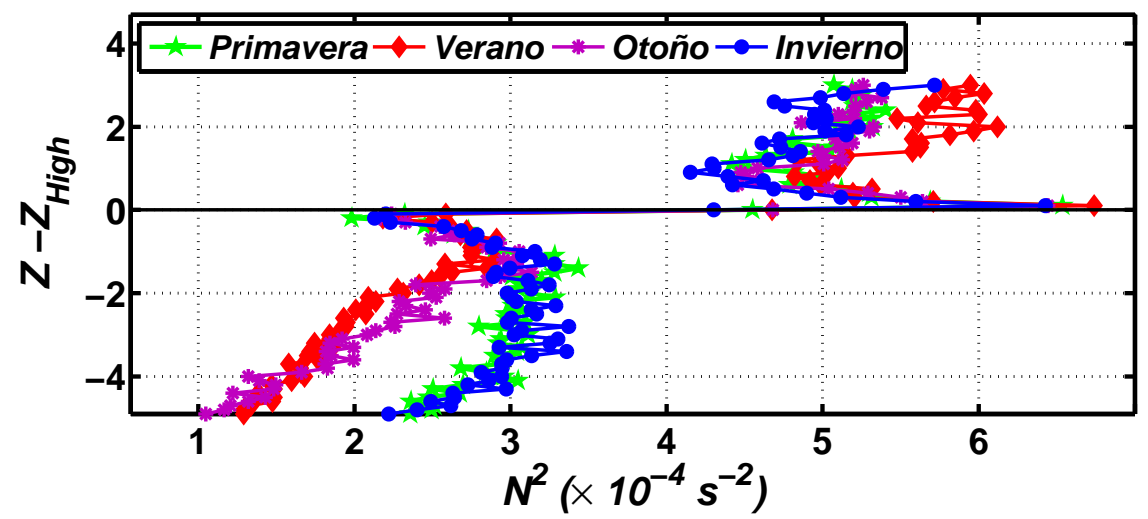

(b) Segunda tropopausa observada en sistemas de tropopausa múltiple (TT2) + única tropopausa (SingT)

Figura 4.15 - Variación estacional de la capa de inversión asociada al nivel de la primera tropopausa observada en sistemas múltiples (a) y a la tropopausa localizada en niveles altos, (b). En ambos casos se consideran alturas relativas al nivel correspondiente

La figura 4.15(a) corresponde a los sondeos mostrando múltiple tropopausa, alturas relativas a TT1, mientras que para 4.15 (b) se han considerado TT2 y SingT indistintamente, refiriéndome a la atura de cualquiera de ellas como $Z_{H i g h}$. En los dos casos se han calculado los perfiles estacionales en base al siguiente agrupamiento: Primavera (Marzo, Abril, Mayo), Verano (Junio, Julio, Agosto), Otoño (Septiembre, Octubre, Noviembre), Invierno (Diciembre, Enero, Febrero).

Existen notables diferencias entre ambos grupos. Considerando como medida del espesor de la TIL (Tropopause Inversion Layer) la distancia vertical comprendida entre el nivel de la tropopausa y el nivel aproximado donde se halla un punto de inflexión en el perfil de $N^{2}$, observamos los mayores espesores para TT1, figura 4.15 (a), del orden de $\sim 3 \mathrm{~km}$, mientras que para la tropopausa detectada en niveles altos el volumen de la $\boldsymbol{T I} \boldsymbol{L}$ se reduce drásticamente, 
siendo éste $<1 \mathrm{~km}$. En los dos casos la magnitud del máximo es similar, $\sim 6 \times 10^{-4} \mathrm{~s}^{-2}$. No se aprecia un ciclo anual significativo en ninguno de los dos grupos.

Estos resultados coinciden por los hallados en estudios previos relativos a la $\boldsymbol{T I L}$. En particular, Shaun W. Bell en el estudio "Tropopause inversion layer: Seasonal and latitudinal variations and representation in standard radiosonde data and global models" [Bell and Geller, 2008] encuentra para los meses de Otoño y para nuestra latitud un espesor muy inferior, del orden de $1 \mathrm{~km}$. Esto es debido a que en los cálculos no hace distinción entre tropopausa múltiple ó simple, de modo que cabe pensar que promedia considerando TT1 y SingT conjuntamente. Si además se tiene en cuenta el porcentaje de ocurrencia de múltiple tropopausa para dicho periodo, figura 4.5, estará introduciendo un bias hacia espesores propios de la tropopausa de niveles altos en los valores climatológicos.

Otra diferencia importante entre 4.15(a) y 4.15(b) la encontramos inmediatamente por debajo de la tropopausa. En el caso de TT1 se observa una región de transición con un espesor $\sim 2 \mathrm{~km}$ en la que se pasa de valores de $N^{2} \sim 1 \times 10^{-4}$ a $N^{2} \sim 2 \times 10^{-4}$ en el nivel de la tropopausa, mientras que para la tropopausa hallada en niveles altos se aprecia también una región de transición de espesor inferior, $\sim 1 \mathrm{~km}$, pero donde ocurre justo lo contrario, es decir $N^{2}$ disminuye desde $N^{2} \sim 3 \times 10^{-4}$ hasta $N^{2} \sim 2 \times 10^{-4}$. Se trata de un comportamiento extraordinario, suponiendo una característica propia de la tropopausa tropical. Notar que de esta manera se conserva la discontinuidad de $\sim 4$ unidades en los valores de $N^{2}$ en el nivel de la tropopausa tanto para $\boldsymbol{T T} 1$ como para la tropopausa de niveles altos. Puesto que los resultados anteriores apuntan hacia un transporte neto de aire desde la alta troposfera tropical hasta la región inter-tropopausa subtropical, por encima del eje de máximo viento del Chorro Subtropical, cabe pensar que el comportamiento descrito sea en parte debido a la advección cuasi- horizontal de aire en la alta troposfera. En cuanto a la diferencia entre las estaciones Invierno-Primavera y Verano-Otoño en la alta troposfera en 4.15(b), observamos el fenómeno ya comentado anteriormente en alusión a la figura 4.13(b).

Se ha demostrado por tanto la existencia de una región muy estratificada inmediatamente por encima del nivel de la tropopausa (tanto de $\boldsymbol{T T 1}$ como de $\boldsymbol{T T 2}$ ), comprobándose que desde un punto de vista estadístico esta región de inversión asociada a la tropopausa impedirá los procesos verticales de transporte entre la estratosfera y la troposfera. Sin embargo, teniendo en cuenta que el transporte horizontal en el seno de la TIL ocurrirá adiabáticamente, podemos afirmar que éste sí será favorecido. Se aventura aquí la hipótesis de que durante los episodios de tropopausa simple (también para tropopausa múltiple) en el primer semestre del año, que como se ha visto corresponden a un salto de la tropopausa desplazado hacia el Norte de las Canarias, aún en presencia de un Jet intenso, existe un transporte neto de aire de carácter estratosférico desde la baja estratosfera de latitudes medias hacia la alta troposfera tropical, siendo el chorro subtropical reinante el responsable de modular dichos procesos. En el capítulo siguiente se explorará en mayor profundidad esta posibilidad. 


\subsection{Distribución de Ozono en la región UTLS subtropical}

Una vez descrita la tropopausa subtropical (secciones 4.1 y 4.2), así como las propiedades termodinámicas de la región adyacente (sección 4.3), se dispone ya del marco apropiado para el análisis de la distribución de ozono en la región UTLS subtropical. Dada la complejidad de los fenómenos anteriormente reseñados, es de esperar una situación similar para el caso que nos ocupa ahora.

Como primera aproximación al problema se muestran en la figura 4.16 las anomalías climatológicas mensuales para los perfiles de ozono obtenidos a partir de los ozonosondeos.

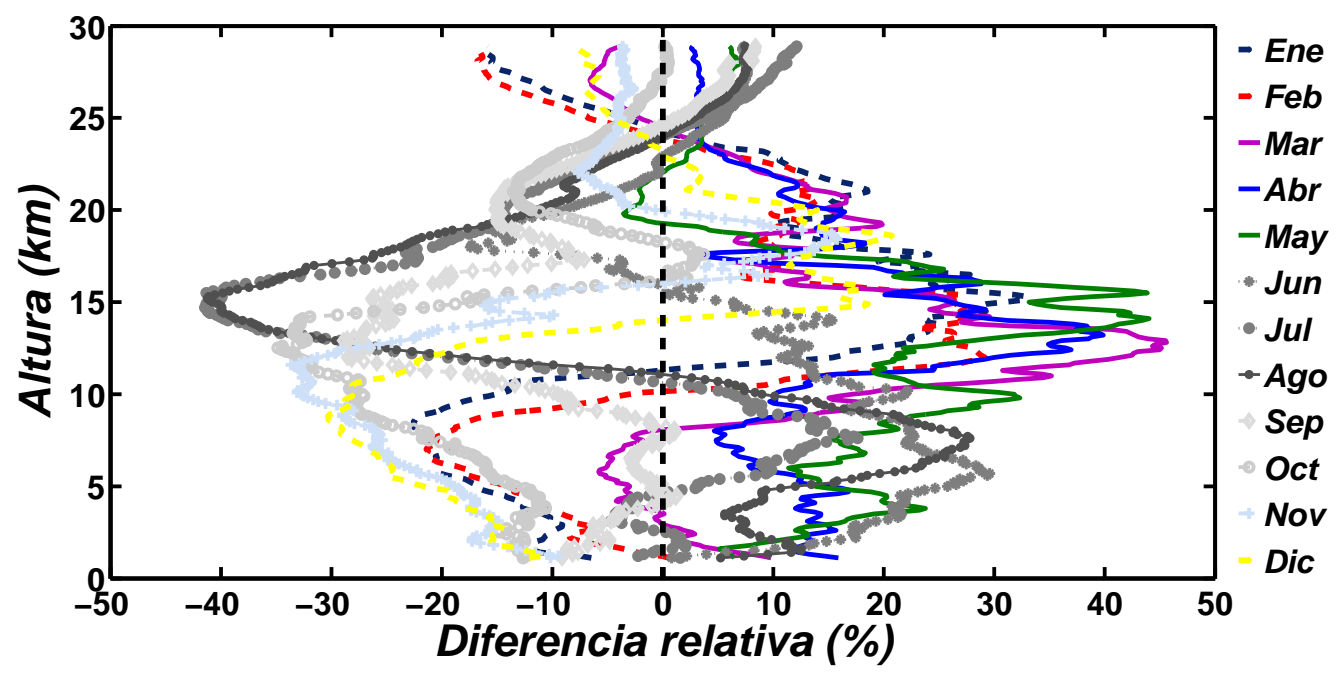

Figura 4.16 - Anomalías climatológicas mensuales para los perfiles de ozono. La escala vertical se refiere a altura referenciada al nivel del suelo. Los diferentes colores usados se corresponden con las estaciones de la siguiente manera: Primavera, lineas discontinuas de color, Verano, escala de grises oscuros, Otoño, escala de grises claros, Invierno, lineas sólidas de color

Los perfiles anteriores se han obtenido de la siguiente manera: se calcula en primer lugar un valor climatológico anual, promediando todos los ozonosondeos disponibles, para a continuación restar este perfil anual a cada uno de los perfiles climatológicos mensuales, computando la diferencia porcentual relativa según

$$
{\overline{O_{3}}}^{\text {anom }}\left(z_{i}\right)=\frac{{\overline{O_{3}}}^{\text {mens }}\left(z_{i}\right)-{\overline{O_{3}}}^{\text {ann }}\left(z_{i}\right)}{{\overline{O_{3}}}^{\text {ann }}\left(z_{i}\right)} \times 100
$$

La inclusión de todos los meses en el gráfico anterior me permite justificar la agrupación por estaciones utilizada en la sección 4.3, figura 4.15. En efecto, podemos observar un comportamiento similar para todos los meses usados al definir cada una de las estaciones, quizás exceptuando el mes de Junio (Verano). Notar que para este mes y en el rango de alturas comprendidas entre $\sim 12 \mathrm{~km}$ y $\sim 16 \mathrm{~km}$ se muestran diferencias porcentuales respecto del promedio anual el rango $[-10 \%,+10 \%]$, muy superiores al valor $\sim-40 \%$ hallado para los meses de Julio y Agosto. Esto es debido a que no se ha hecho distinción entre sistemas de tropopausa múltiple y simple, de modo que aún cuando el número de casos de tropopausa múltiple en Junio es muy inferior al de episodios de tropopausa simple (ver tabla 4.1, sección 4.2 ), son suficientes para alterar notablemente el perfil climatológico. 


\begin{tabular}{l|c|c|c|c|c|c|c|c|c|c|c|c} 
& Ene & Feb & Mar & Abr & May & Jun & Jul & Ago & Sep & Oct & Nov & Dic \\
\hline Ztrop-2 km & 17 & 15 & 14 & 15 & 11 & 12 & 5 & 6 & 13 & 13 & 15 & 12 \\
\hline Ztrop+2 km & 16 & 17 & 14 & 14 & 12 & 10 & 6 & 8 & 11 & 14 & 17 & 17 \\
\hline alta UTLS & 24 & 28 & 27 & 21 & 17 & 12 & 4 & 7 & 10 & 12 & 16 & 19
\end{tabular}

Tabla 4.3 - Error estándar relativo $(\times 2)$ mensual para perfiles de ozono y para diferentes regiones de la atmósfera. Se ha tomado el nivel de la primera tropopausa observada como nivel de referencia, mostrándose el valor promedio en diferentes estratos

A grandes rasgos se pueden apreciar tres zonas claramente diferenciadas, centrándonos en lo que sigue en el análisis de la segunda región de las abajo enumeradas, correspondiente a la UTLS.

- $[0-10] \mathrm{km}$, máxima diferencia relativa absoluta en torno al $20 \%$

- $[11-17] \mathrm{km}$, aquí se encuentra la mayor variabilidad estacional, con valores máximos absolutos en torno al $40 \%$. Notar en esta región la similitud de comportamiento mostrada por el Invierno y la Primavera, con diferencias respecto del promedio anual del orden de $+30 \%$, y el Verano y el Otoño, con anomalías del orden de $-30 \%$

- $[18-30] \mathrm{km}$, región con los mínimos valores de diferencia relativa. Este es un dato interesante, en el sentido de que nos muestra la poca variabilidad anual del máximo de ozono estratosférico para latitudes subtropicales [Sancho and Romero, 2002]

Se comprueba a partir de estos resultados que en latitudes subtropicales no es conveniente utilizar un perfil climatológico como representativo de la atmósfera, ya que, como se ha visto, existen máximos valores de variabilidad estacional de hasta el $40 \%$.

Por otra parte, en la tabla 4.3 mostramos valores mensuales de dos veces el error estándar relativo $(2 \times S E M)$ calculado para los perfiles de ozono en diferentes estratos de la atmósfera, etiquetados como sigue: Ztrop-2 $\mathbf{~ k m}$, estrato limitado entre el nivel de la tropopausa y $2 \mathrm{~km}$ por debajo de la misma, Ztrop $+\mathbf{2} \mathbf{~} \mathbf{~ m}$, primeros $2 \mathrm{~km}$ por encima de la tropopausa, y alta UTLS, estrato limitado entre los niveles situados a 2 y $5 \mathrm{~km}$ por encima de la tropopausa. Estos valores equivalen, como se ha descrito en la sección 3.2.3 del capítulo anterior, al rango de certidumbre del $95 \%$ relativo a los valores promedios. Es decir, si $\bar{O}_{3}\left(z_{i}\right)$ es el valor promedio calculado, el valor climatológico real estará incluido con un $95 \%$ de confidencia en el rango $\bar{O}_{3}\left(z_{i}\right) \pm 2 \times S E M$.

Dado que, salvo en Julio, el número de sondeos disponibles para cada mes es similar, $\sim 70$, el error estándar proporciona un idea de la variabilidad mensual (o sea, de la desviación estándar). Durante los meses de Diciembre a Mayo resulta notable la existencia de un estrato de espesor en torno a $4 \mathrm{~km}$ y centrado en el nivel de la tropopausa mostrando parecida variabilidad. Se trata de una observación muy interesante, puesto que en la sección 4.3, donde se analizaron las características termodinámicas en la región UTLS, encontramos la misma región con valores anómalos en la frecuencia de Brunt-Väisälä (ver figura 4.15). Ambos resultados parecen reforzar la interpretación de la tropopausa como un estrato a través del cual ocurre la transición entre la estratosfera y la troposfera, en lugar de considerar esta como una superficie más o menos definida. En la región etiquetada como alta uTLS la variabilidad aumenta casi el doble de la observada en la región inmediatamente inferior, con máximos valores en los meses de Enero a Abril. Notar que, asumiendo que el nivel de máximo viento sobre Tenerife se sitúa en torno a $12-13 \mathrm{~km}$, estaríamos hablando de un 
estrato localizado justo por encima del chorro subtropical, donde, según se ha comentado, tienen lugar procesos de mezcla intensos. En el periodo de Junio a Noviembre no se aprecian diferencias significativas entre las tres regiones analizadas, correspondiendo la menor variabilidad a los meses de Julio y Agosto.

Anteriormente (sección 4.2) se subrayaron dos peculiaridades notables mostradas por las tropopausas química $(\boldsymbol{O} 3 \boldsymbol{T})$ y dinámica $(\boldsymbol{D} \boldsymbol{T})$, respecto de su posición relativa a la tropopausa térmica (TT1) a lo largo del año. Se trata, en primer lugar, de la $\boldsymbol{O} 3 \boldsymbol{T}$ localizada por encima de $\boldsymbol{T T} \mathbf{1}$ durante los meses de Octubre a Abril, para los sistemas de múltiple tropopausa (ver figura 4.6), y en segundo lugar, una tropopausa dinámica hallada siempre bajo $\boldsymbol{T T} \mathbf{T}$. Además resulta interesante el cambio observado entre los meses de Abril a Mayo en la posición de $\boldsymbol{O} 3 \boldsymbol{T}$ respecto del nivel de $\boldsymbol{T T} \mathbf{1}$ : durante los primeros meses se encuentra por encima de la tropopausa térmica, y en Marzo comienza a

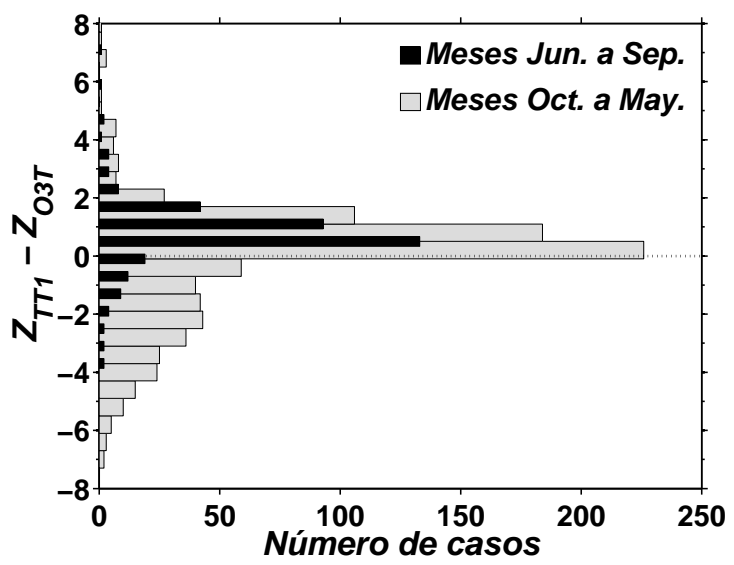

Figura 4.17 - Histograma mostrando la distribución de diferencias $\mathbf{T T 1}$ - O3T para los periodos de Junio a Septiembre (negro) y de Octubre a Noviembre (gris)

modificar su posición para acabar en niveles inferiores. En la figura 4.17 se muestra el histograma de frecuencias de la diferencia de alturas $\boldsymbol{T T 1}-\boldsymbol{O} 3 \boldsymbol{T}$ considerando todos los ozonosondeos realizados en los meses de Junio a Septiembre (en negro) y de Octubre a Mayo (en gris). Observamos que en Invierno y Primavera la distribución es bimodal, con máximos localizados en torno a $\sim-2 \mathrm{~km}$ (es decir, tropopausa química $\sim 2 \mathrm{~km}$ por encima de la tropopausa térmica) y $\sim 0,5 \mathrm{~km}$ (tropopausa química $\sim 0,5 \mathrm{~km}$ por debajo de la tropopausa térmica). De Junio a Septiembre la distribución aparece muy asimétrica, con muy pocos casos en los que $\mathbf{Z}_{\mathbf{T T 1}}<\mathbf{Z}_{\mathbf{O 3 T}}$, y con un máximo para $\mathbf{Z}_{\mathbf{T T 1}}-\mathbf{Z}_{\mathbf{O 3 T}} \approx 0,8 \mathrm{~km}$. Estos resultados coinciden con los obtenidos en estudios previos [Bethan et al., 1996, Pan et al., 2004], donde se halló una tropopausa química en promedio localizada en torno a $[0,81] \mathrm{km}$ por debajo de la tropopausa térmica. Sin embargo, y a diferencia de los trabajos mencionados, observamos en la figura 4.17 un número significativo de casos para los que la tropopausa química se halla por encima de la térmica. En la tabla 4.4 se exponen para cada mes el porcentaje de ozonosondeos para los que se halló $\mathbf{Z}_{\mathbf{T T 1}}>\mathbf{Z}_{\mathbf{O 3 T}}$ y $\mathbf{Z}_{\mathbf{T T 1}}<\mathbf{Z}_{\mathbf{O 3 T}}$, así como los valores mensuales promedios de la diferencia en cada caso.

Así pues, estamos ante un resultado novedoso. Una inspección más detallada de la figura 4.17 sugiere para el periodo de Octubre a Mayo una distribución resultante de la superposición de dos distribuciones independientes, com máximos de frecuencia en torno a $-2 \mathrm{~km}$ y $0,8 \mathrm{~km}$ respectivamente. Notar la similitud entre la distribución para el periodo de Junio a Septiembre y la "componente positiva" del otro grupo considerado.

Si bien en los trabajos referenciados previamente se atribuyen los pocos casos con $\mathbf{Z}_{\mathbf{T T 1}}<\mathbf{Z}_{\mathbf{O} \text { 3T }}$ a sistemas de circulación anticiclónica, en el caso de la región UTLS subtropical parece un fenómeno relacionado con la tropopausa múltiple, tal y como queda demostrado en la figura siguiente (figura 4.18), mostrando la diferencia $\mathbf{Z}_{\mathbf{O 3 T}}-\mathbf{Z}_{\mathbf{T T 1}}$, junto con las alturas halladas para los niveles de $\boldsymbol{T}$ T1, TT2 y TT3. Con el fin de poder 


\begin{tabular}{l|c|c|c|c|c|c|c|c|c|c|c|c} 
& Ene & Feb & Mar & Abr & May & Jun & Jul & Ago & Sep & Oct & Nov & Dic \\
\hline $\mathbf{Z}_{\text {TT }}>\mathbf{Z}_{\text {O3T }}(\%)$ & 28 & 36 & 38 & 44 & 77 & 66 & 52 & 49 & 43 & 35 & 18 & 13 \\
\hline Diff. media (km) & 1.0 & 1.4 & 1.3 & 1.1 & 1.4 & 1.5 & 0.8 & 0.8 & 0.9 & 1.1 & 0.8 & 1.2 \\
\hline $\mathbf{Z}_{\mathbf{T T}}<\mathbf{Z}_{\text {O3T }}(\%)$ & 72 & 64 & 62 & 56 & 23 & 34 & 49 & 51 & 57 & 64 & 82 & 87 \\
\hline Diff. media (km) & -2.7 & -3.0 & -2.7 & -1.9 & -0.9 & -0.9 & -0.2 & -0.3 & -0.8 & -0.9 & -1.4 & -1.7
\end{tabular}

Tabla 4.4 - Porcentaje de ozonosondeos con el nivel de la tropopausa térmica hallada por encima de la tropopausa química y viceversa, junto con la diferencia promedio $\mathbf{Z}_{\mathbf{T T 1}}-\mathbf{Z}_{\mathbf{O} \mathbf{3}}$ en cada caso $y$ para todos los meses

comparar gráficamente las diferencias anteriores con los niveles de las tropopausas consideradas se ha representado $\left(\mathbf{Z}_{\mathbf{O} 3 \mathbf{T}}-\mathbf{Z}_{\mathbf{T T 1} \mathbf{1}}\right)+15$, de modo que los puntos en el nivel de $15 \mathrm{~km}$ equivalen a $\mathbf{Z}_{\mathbf{O} \mathbf{T}}-\mathbf{Z}_{\mathbf{T T 1}}=0$. Resulta obvia la relación entre episodios de tropopausa múltiple y $\boldsymbol{O} 3 \boldsymbol{T}$ localizada por encima de $\boldsymbol{T} \boldsymbol{T} \mathbf{1}$.

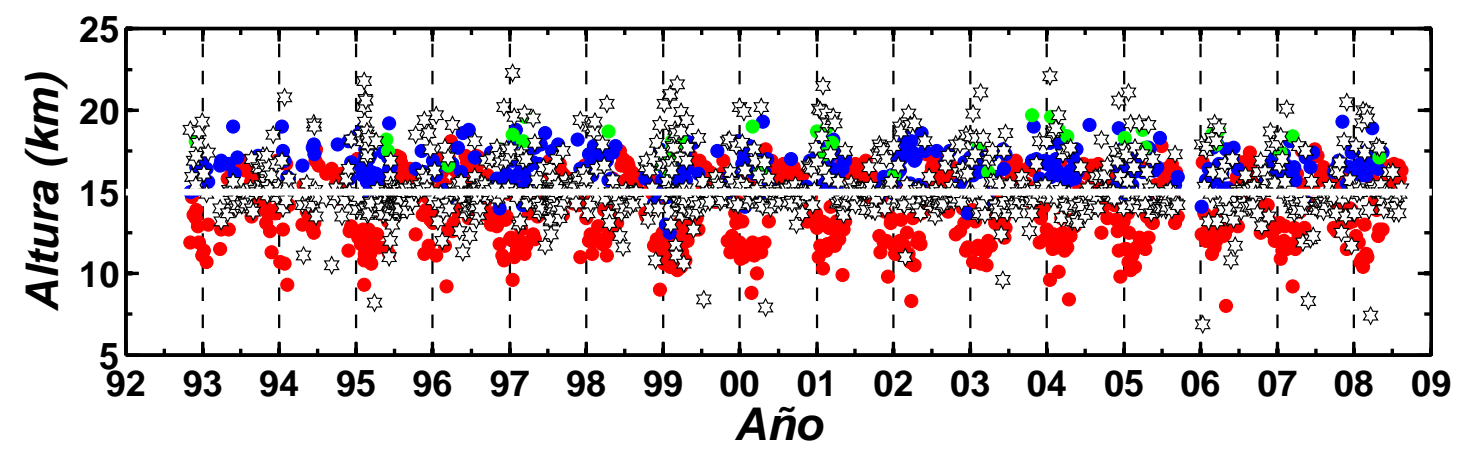

Figura 4.18 - Diferencia $\mathbf{Z}_{\mathbf{O 3 T}}-\mathbf{Z}_{\mathbf{T T 1}}$ (representada por estrellas blancas) junto altura hallada para los niveles de TT1, TT2 y TT3 durante todo el periodo analizado. La línea gruesa blanca corresponde a la situación correspondiente a ambas tropopausas en el mismo nivel, $\mathbf{Z}_{\mathbf{O} \mathbf{3} \mathbf{T}}-\mathbf{Z}_{\mathbf{T T} \mathbf{1}}=0$, situada arbitrariamente en $15 \mathrm{~km}$

En la figura 4.19 se ilustran las situaciones correspondientes a la tropopausa química (línea horizontal azul) por encima de la primera tropopausa térmica (línea horizontal negra), (a), y a la tropopausa química bajo la única tropopausa térmica observada (b). En ambos casos se muestran además los perfiles de Temperatura (negro), Ozono (azul) y Viento (rojo). A partir de estos dos ejemplos se puede comprobar el efecto de la modificación realizada al algoritmo utilizado para detectar la tropopausa química. Recordar (sección 3.2.2) que esta modificación consistió en reemplazar el estrato de $200 \mathrm{~m}$ en el cual el gradiente de ozono debía superar un cierto valor umbral, por un estrato mayor, de $1,5 \mathrm{~km}$. El objetivo era descartar las estructuras laminares en la troposfera con concentraciones elevadas de ozono, puesto que el algoritmo original tiende erróneamente a identificar dichas estructuras con el nivel de $\boldsymbol{O} 3 \boldsymbol{T}$.

En los dos casos, (a) y (b) se identifica correctamente el nivel de la tropopausa química, siempre que a partir de este nivel la concentración de ozono aumenta más o menos monótonamente hasta valores propios de la estratosfera. Notar en (a) el máximo local de ozono en torno a $12 \mathrm{~km}$. En (b) se observa un máximo local similar, aproximadamente en $13 \mathrm{~km}$. La diferencia principal entre ambos reside en el espesor de la estructura asociada y la magnitud del máximo, siendo notablemente mayor para el caso de múltiple tropopausa. Se trata esta 


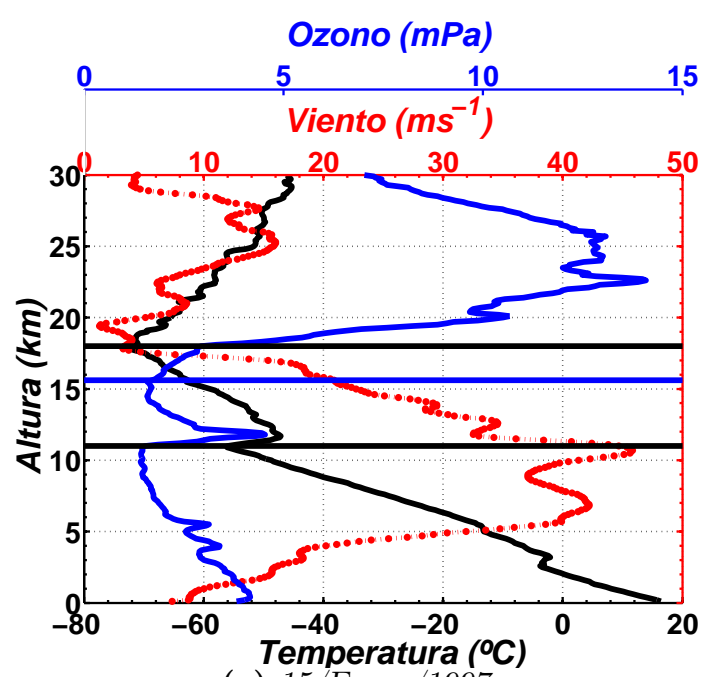

(a) $15 /$ Enero $/ 1997$

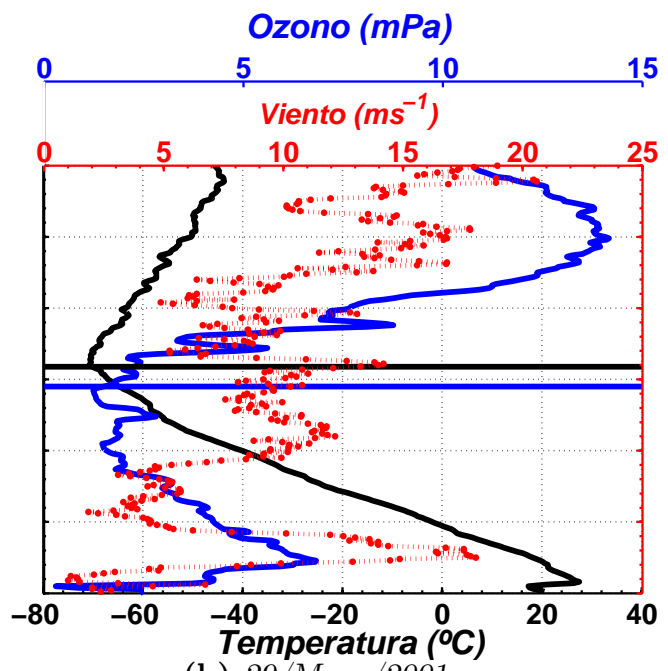

(b) $29 / \mathrm{Mayo} / 2001$

Figura 4.19 - Dos ejemplos mostrando la posición relativa de O3T (línea horizontal azul) respecto de TT1 (línea horizontal negra). En (a) se ilustra el caso $\mathbf{Z}_{\mathbf{O} \mathbf{T}}>\mathbf{Z}_{\mathbf{T T} 1}$ para un perfil de tropopausa

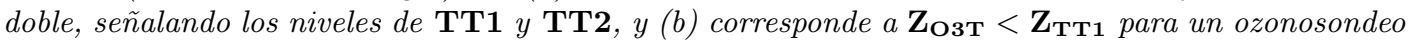
con tropopausa simple. Se representan además los perfiles de temperatura (negro), ozono (azul) y viento (rojo). La escala vertical es la misma en los dos casos

de una característica propia de los sistemas de múltiple tropopausa, que discutiremos más en profundidad en lo que sigue. Notar que la consideración anterior nos permiter justificar los resultados mostrados en la figura 4.6, es decir, el desacuerdo mostrado por $\boldsymbol{D T}$ y $\boldsymbol{O} 3 \boldsymbol{T}$, hallándose la primera siempre por debajo de la segunda, aún cuando ambas deberían presentar un comportamiento similar. La discrepancia entre ambas se debe a la diferente resolución vertical de ambos parámetros. En efecto, los campos de vorticidad potencial extraídos del ECMWF presentan en la región UTLS una resolución vertical aproximada de $\sim 2 \mathrm{~km}$, insuficiente para detectar las estructuras observadas.

Se discute a continuación el ciclo anual del ozono en la región UTLS subtropical. Basaremos el análisis en secciones de contorno, aplicando una escala de colores para los diferentes intervalos de valores. Recientemente se ha llevado a cabo un estudio similar al que nos ocupa, aunque utilizando distribuciones de probabilidad como técnica de análisis [Ray et al., 2004]. En todo caso los resultados obtenidos en dicho trabajo son comparables a los que se presentan a continuación.

La figura 4.20(a) muestra los valores climatológicos de ozono en la región UTLS calculados a partir de los ozonosondeos mostrando un sistema de múltiple tropopausa. Además, y con el fin de facilitar el análisis, se muestra en (b) el ciclo anual de la frecuencia de Brunt-Väisälä. Las figuras 4.21(b) y 4.21(b) representan la misma situación, aunque esta vez el nivel de la segunda tropopausa térmica observada, TT2, ha sido tomado como referencia espacial. Como se ha dicho anteriormente, a partir de ambas se obtendrá una imagen más exacta de la situación real. La figura 4.22 es equivalente a las anteriores, con la diferencia de que sólo se han incluído en los cálculos los ozonosondeos presentando una única tropopausa térmica tal que $\mathbf{Z}_{\text {SingT }} \geq \mathbf{1 4 , 5} \mathrm{km}$. Se muestran en todos los casos las isolíneas de viento así como los niveles de la tropopausa térmica (líneas gruesas de color blanco). Para las secciones correspondientes al ozono se representa además la tropopausa química (línea gruesa de color 
verde).

A primera vista, la característica más notable exhibida en la figura 4.20 es la estructura similar en la región inter-tropopausa para los dos parámetros analizados. Por un lado, observamos durante el primer semestre del año un estrato con máximos valores de ozono aproximadamente en los dos primeros $\mathrm{km}$ por encima del nivel de $\boldsymbol{T T} \boldsymbol{T}$, seguido de una región con mínimos locales en el ozono, extendiéndose desde $\sim 14 \mathrm{~km}$ hasta $\sim 1 \mathrm{~km}$ por debajo de TT2. Ambas regiones muestran una cierta variación mensual, aunque en este sentido es necesario señalar que, puesto que se han promediado un gran número de ozonosondeos, se estarán muestreando un gran número de situaciones sinópticas posibles, entendidas estas en relación a el chorro subtropical. En concreto, esto daría cuenta del máximo relativo de ozono en Marzo entre 14 y $16 \mathrm{~km}$. Es muy probable que para este mes se estén considerando un número significativo de casos en los que el chorro se halla perturbado por la presencia de perturbaciones en altura, alterándose de este modo los perfiles correspondientes. Notar

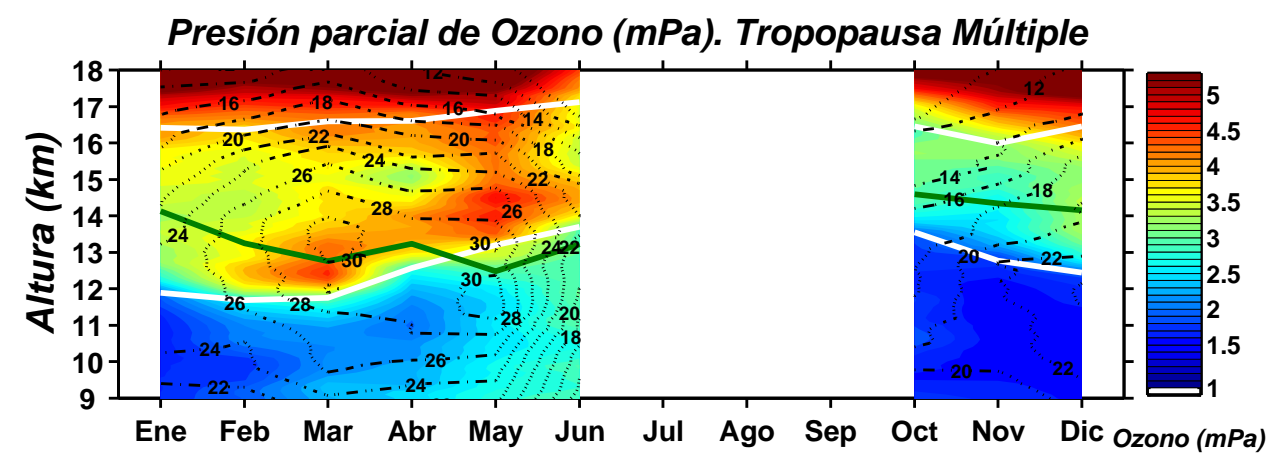

(a)

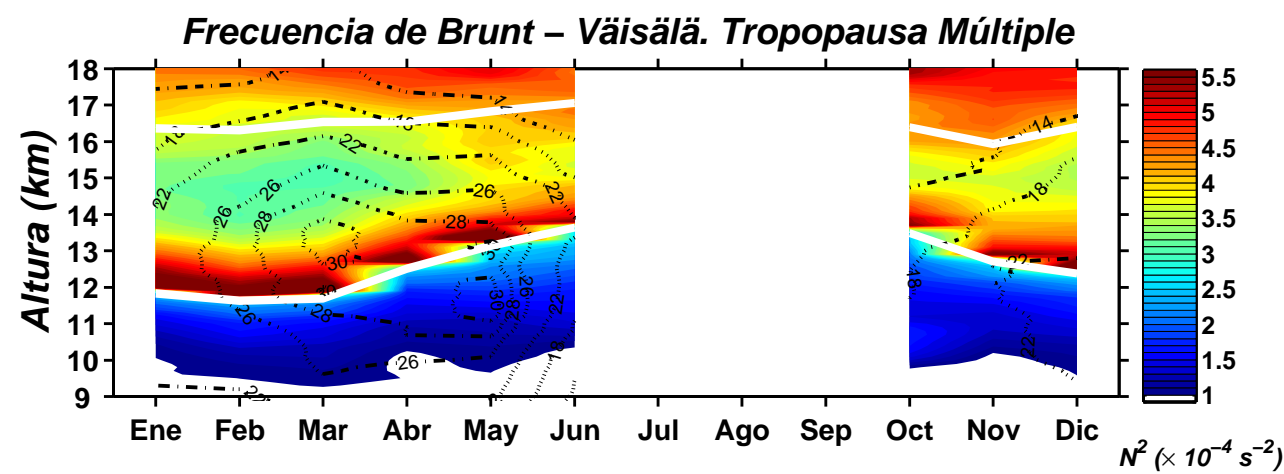

(b)

Figura 4.20 - Ciclo anual observado en el ozono (presión parcial, mPa), (a), y en la frecuencia de Brunt-Väisälä $\left(\times 10^{-4} s^{-2}\right)$, (b), para situaciones de tropopausa múltiple. Se representan los niveles de tropopausa térmica (TT1 Y TT2) como línea gruesa blanca. Para la sección de ozono se muestra también el nivel de la tropopausa química (O3T), línea gruesa verde. Las lineas de contorno en negro representan el viento

que anteriormente habíamos identificado dos zonas en la región UTLS con muy diferente variabilidad estacional (ver tabla 4.3): el estrato que llamamos alta uTLs, localizado entre los niveles $\sim 14 \mathrm{~km}$ y $\sim 16 \mathrm{~km}, \mathrm{y}$ un estrato centrado en el nivel de $\boldsymbol{T T} 1$ con espesor de $\sim 4 \mathrm{~km}$. El primero presentaba máximos valores para el error estándar medio relativo a finales del 
Invierno y principios de Primavera, siempre en torno al doble de los observados para el estrato centrado en $\boldsymbol{T T} \mathbf{T}$.

Así pues, estamos observando en la región inter-tropopausa la mezcla de dos masas de aire: una tropical, de carácter troposférico, y otra de latitudes medias, de carácter estratosférico. Dicha mezcla ocurre más eficientemente en la región localizada por encima de la iséntropa $360 \mathrm{~K}$ (ver figuras 4.20 y 4.21). Por debajo de dicho nivel no parecen existir procesos de mezcla eficientes.

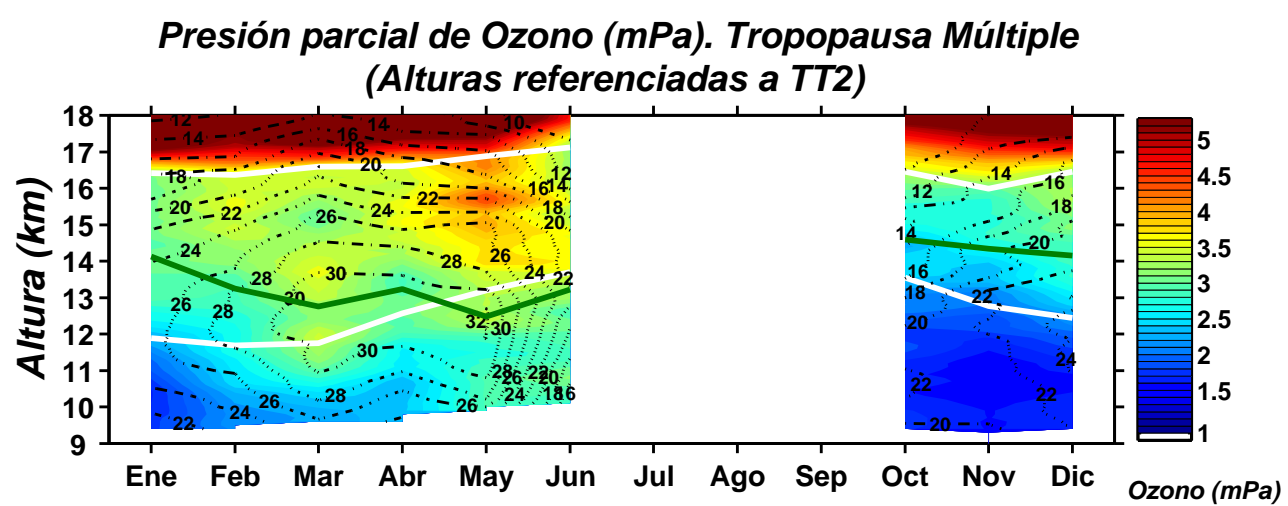

(a)

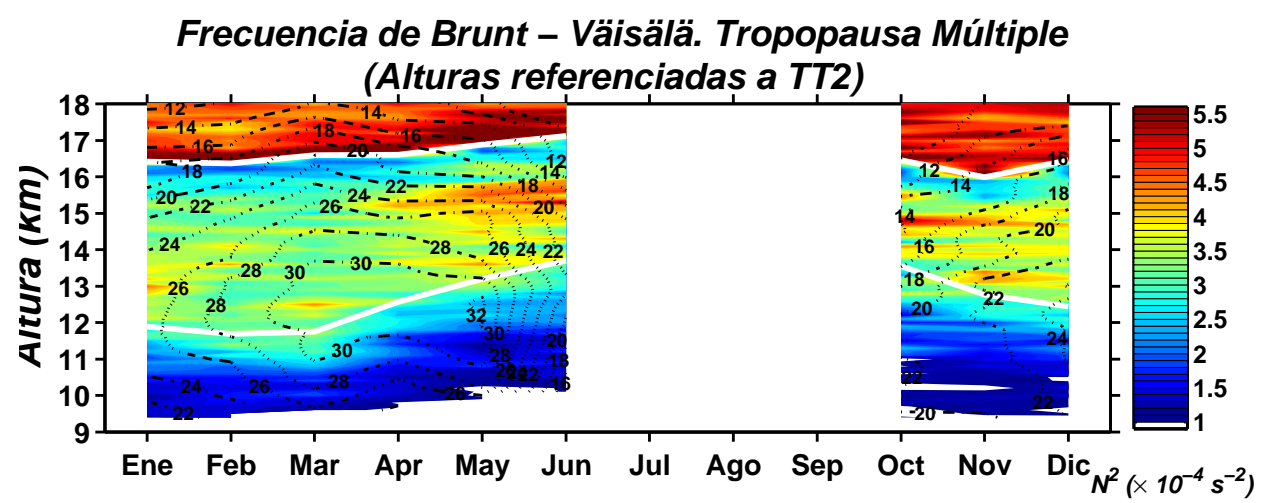

(b)

Figura 4.21 - Idem a figura 4.20, salvo que los valores climatológicos están referenciados al nivel de la segunda tropopausa térmica observada, TT2

Resulta interesante relacionar estos resultados con la inversión térmica asociada a la tropopausa estudiada en la sección anterior. Puesto que se trata de una peculiaridad propia de la tropopausa global (como se deduce de los estudios que sobre ella se han llevado a cabo en los últimos años), es probable que el estrato de máximo ozono asociado no se deba a la acción del chorro. Sería más bien una muestra de aire estratosférico procedente de latitudes medias, confinado en la TIL (Tropopause Inversion Layer) por el efecto de la alta estratificación que la caracteriza. Recíprocamente, las altas concentraciones de ozono halladas en la TIL contribuyen a intensificar la estratificación, puesto que el ozono actuará calentando la región por emisión en onda larga. Así pues, estaríamos hablando de un posible mecanismo en el mantenimiento e intensificación de la TIL, además de las probables contribuciones por parte de procesos dinámicos. En cuanto a los meses de Otoño, las carac- 
terísticas descritas anteriormente se hallan definidas en menor grado, incluso resulta notable la ausencia de máximo de ozono por encima del nivel de $\boldsymbol{T T}$ 1. La región TIL aparece a su vez menos intensa, lo que podría confirmar el papel desempeñado por el ozono, como se ha dicho arriba. En todo caso, estariamos viendo el estado de transición desde la atmosfera en Verano, tropical, hacia la atmosfera en Invierno y Primavera, mucho más compleja desde el punto de vista dinámico (ver también la figura 4.16). En lo que concierne a los procesos de transporte entre la estratosfera y la troposfera, en ambos sentidos, desde un punto de vista climatológico no parece existir una gran actividad, salvo durante la Primavera, cuando es más probable la interacción del chorro con perturbaciones baroclinas en niveles altos [Cuevas and Rodríguez, 2001].

En la sección 4.3 se propuso como posible mecanismo de transferencia de masa asociado a la discontinuidad en la tropopausa subtropical el transporte isentrópico a través de la inversión térmica característica de la tropopausa. Con el fin de explorar esta posibilidad se ha partido de la siguiente consideración: en los casos en los que el sistema de tropopausa múltiple se halla desplazado hacia el Norte de Canarias, observaremos una unica tropopausa en niveles altos, así como una alta troposfera tropical. Sin embargo, si fuera cierto que justo en la discontinuidad de la tropopausa ocurre transporte isentrópico desde la estratosfera hasta la troposfera, a través de la TIL asociada a la tropopausa inferior, tendríamos una perturbación propagándose hacia el Sur. De forma análoga, en los casos en los que el sistema de tropopausa múltiple se halle situado al Sur de Canarias tendríamos sobre nosotros una tropopausa en niveles bajos, propia de latitudes medias. Salvo que ahora la perturbación que veremos será la debida al transporte isentrópico desde la tropopausa tropical, o sea, transporte cuasi-horizontal de aire troposférico hacia la estratosfera de latitudes medias.

Para aislar las dos situaciones anteriores se ha dividido el total de tropopausas simples para cada mes en dos grupos, usando como valor umbral $\mathbf{Z}_{\text {SingT }}=\mathbf{1 4 , 5} \mathrm{km}$ (ver figura 4.3(a) de la sección 4.1). Los pocos ozonosondeos mostrando una única tropopausa tal que $\mathbf{Z}_{\text {SingT }}<\mathbf{1 4 , 5} \mathrm{km}$ no se han tomado en consideración, debido a que muestran en muchos casos una tropopausa incorrectamente asignada, (ver sección 4.1). Así pues, únicamente se analizará la situación correspondiente a $\mathbf{Z}_{\text {SingT }} \geq \mathbf{1 4 , 5} \mathrm{km}$, que llamaremos Tropopausa Simple-Alta. Es de esperar que el grupo así definido sea representativo de la situación equivalente al sistema de múltiple tropopausa desplazado al Norte de Canarias.

El resultado se muestra en la figura 4.22. En (a) se representa el ciclo anual para la presión parcial de ozono (mPa), y en (b) la misma sección para la frecuencia de Brunt-Väisälä, en ambos casos calculadas a partir de los ozonosondeos mostrando una única tropopausa por encima de $14,5 \mathrm{~km}$. La línea gruesa blanca corresponde a la tropopausa térmica. Conviene advertir que, a la vista de la estadística mostrada en la tabla 4.2, los resultados sólo podrán tener validez limitada, dado el escaso número de elementos con los que se han calculado los perfiles promedio. En todo caso, parecen confirmar el modelo conceptual descrito anteriormente. Dos son las características más notables:

- máximo de ozono en los meses de Marzo a Junio, por debajo de los $12 \mathrm{~km}$. En el caso de que realmente estuviera teniendo lugar transporte neto desde la TIL extratropical hacia la alta troposfera sería esto lo que se observaría. Notar que es justamente a partir de Marzo cuando el chorro pasa por encima de nosotros en su migración anual hacia el Norte [Cuevas and Rodríguez, 2002], y es entonces cuando estaremos más expuestos a los efectos del transporte isentrópico desde la TIL de latitudes medias hacia la alta troposfera tropical. 


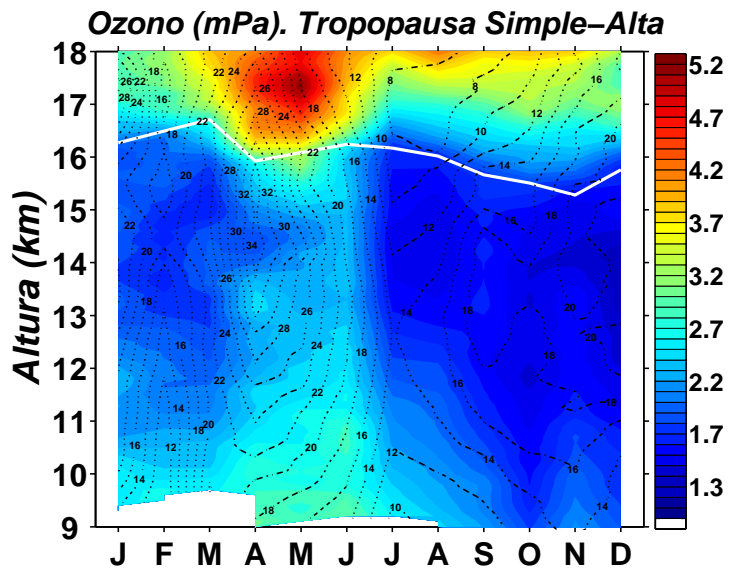

(a)

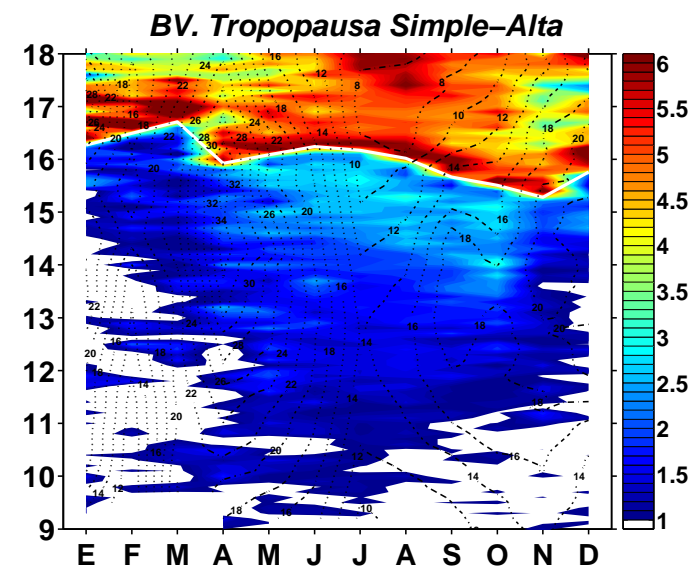

(b)

Figura 4.22 - Sección anual para el ozono, (a) (presión parcial, mPa) y la frecuencia de Brunt-Väisälä (b) $\left(\times 10^{-4} s^{-2}\right)$, hallada a partir de todos los ozonosondeos mostrando una única tropopausa tal que $\mathbf{Z}_{\text {Singt }} \geq \mathbf{1 4 , 5}$. La línea gruesa representa el nivel de la tropopausa térmica, SingT. Las lineas de contorno en negro representan el viento

- En los meses de Enero a Marzo el máximo de viento se localiza en niveles ligeramente inferiores, en torno a $\sim 10 \mathrm{~km}$. Notar en (a) que los máximos locales de ozono se hallan aproximadamente por debajo del máximo de viento, tanto durante el primer trimestre como durante el segundo. Este resultado parece confirmar el papel desempeñado por la región de máximo viento como barrera a la mezcla isentrópica

Un valor añadido de la figura 4.22 es que nos permite analizar el estado de la atmósfera tropical durante el segundo semestre, especialmente entre los meses de Junio a Octubre. Se trata de una información especialmente importante, puesto que la gran mayoría de estudios concernientes a la alta troposfera tropical se refieren a latitudes inferiores a $20^{\circ}$ [Highwood and Hoskins, 1998, Seidel et al., 2001, Gettelman and de Forster, 2002]. En la región subtropical se dispone de pocos datos a nivel global. Aunque no es el objetivo del estudio que nos ocupa, es interesante hacer notar, durante los meses de Verano principalmente, el nivel $\sim 12 \mathrm{~km}$ con un mínimo valor de estabilidad. Este es el límite inferior asignado a la TTL, o Tropical Tropopause Layer [Gettelman and de Forster, 2002]. Notar además la región con valores de ozono por debajo de $1,5 \mathrm{mPa}$ en la alta troposfera durante el Otoño.

Para acabar con la discusión de la UTLS subtropical, se presenta a continuación un modelo conceptual que dé cuenta de los resultados obtenidos. Puesto que, como ha quedado demostrado, el Chorro Subtropical desempeña un importante papel modulando el transporte en la UTLS, será fundamental tenerlo en cuenta a la hora de proponer dicho modelo. En la figura 4.23 se muestran para la latitud de Tenerife los valores promedios del viento en diferentes niveles isentrópicos $(330 \mathrm{~K}, 340 \mathrm{~K}$ y $350 \mathrm{~K})$, en función de la longitud. Los meses escogidos son Diciembre (a), Febrero (b), Abril (c) y Junio (d) (reproducidas aquí con autorización de los autores). Podemos apreciar el ciclo ya descrito, es decir, un incremento en la intensidad de los valores máximos de viento a partir de Diciembre, para llegar a valores mínimos en Junio.

Otra característica importante de la figura anterior consiste en el aumento de la intensidad del chorro a partir de aproximadamente $0^{\circ}$ de longitud para los meses comprendidos 


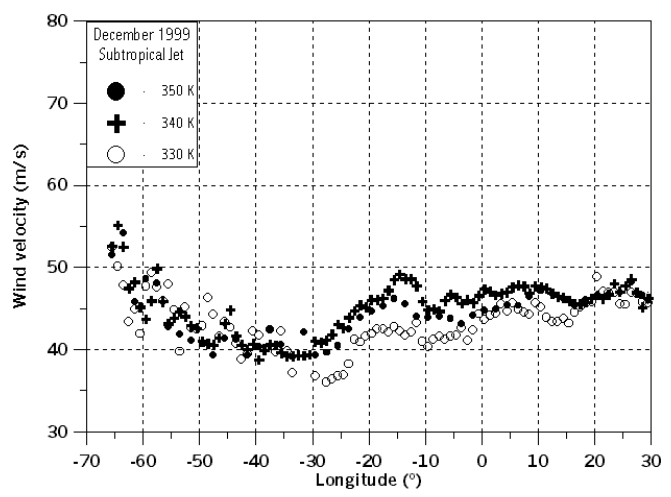

(a) Diciembre

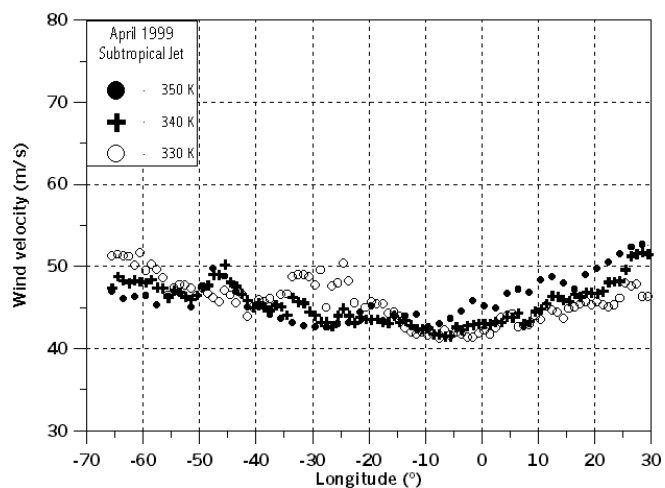

(c) Abril

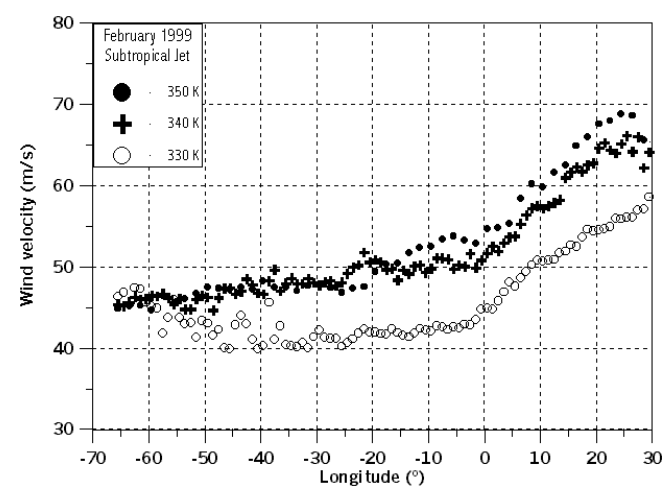

(b) Febrero

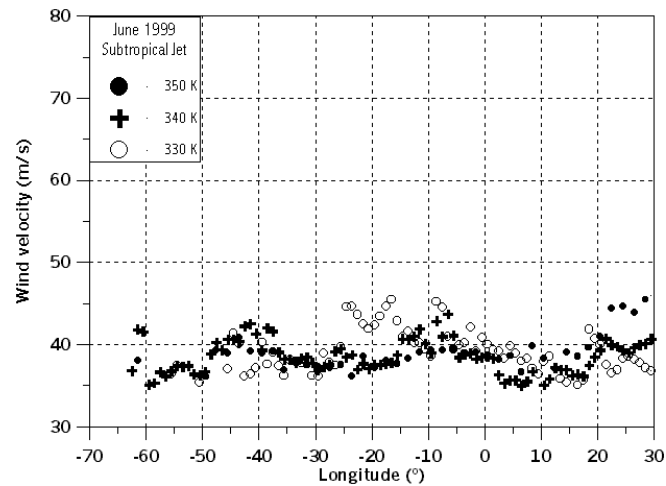

(d) Junio

Figura 4.23 - Se muestran para la latitud de Tenerife los valores promedios del viento hallados durante 1999 en diferentes niveles isentrópicos ( $330 \mathrm{~K}, 340 \mathrm{~K}$ y $350 \mathrm{~K}$ ), en función de la longitud. Los meses representados corresponden a Diciembre (a), Febrero (b), Abril (c) y Junio (d) (reproducidas con autorización de los autores, Emilio Cuevas y José Rodriguez) 
entre Febrero a Mayo, lo cual sugiere una aceleración del Chorro Subtropical a partir de dicha posición. Así pues, se deduce de la figura 4.23 que Canarias se halla en promedio a la entrada del chorro, presentando éste los máximos valores de viento a partir de $0^{\circ}$ de longitud, o sea, sobre el norte del continente africano. Un ejemplo típico de tal situación se mostró en la sección 4.1. Por claridad se incluye a continuación la sección latitud-longitud correspondiente (figura 4.24).

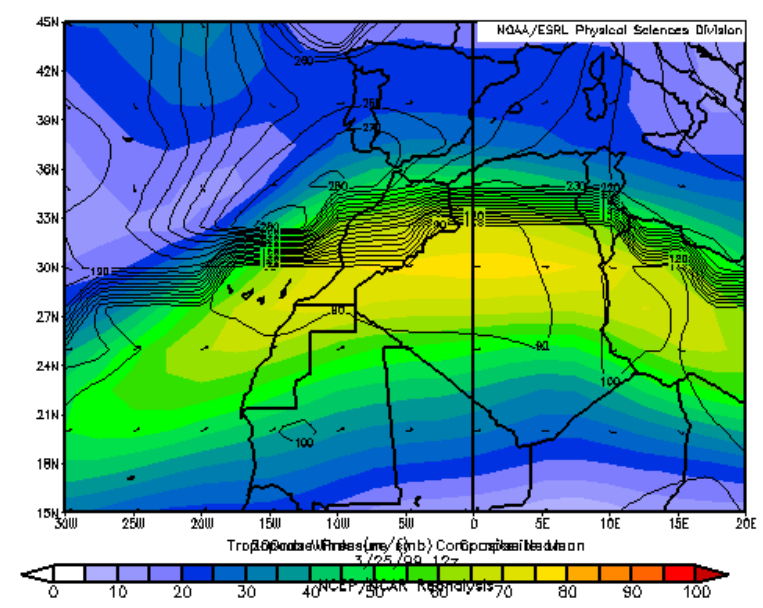

Figura 4.24 - Viento en 200 hPa, más la presión en el nivel de tropopausa, para el día 25 de Marzo de 1999

El siguiente elemento decisivo a la hora de presentar un modelo que justifique los resultados observados lo constituyen los patrones de circulación asociados al Chorro. Como consecuencia de la aceleración experimentada por el vector viento en las proximidades del chorro, y con el objeto de obtener una imagen precisa de la circulación asociada, se hace necesario tomar en consideración la componente ageostrófica del viento. La figura 4.25 muestra el esquema de la situación resultante de resolver las ecuaciones correspondientes [Ziv and Paldor, 1998]. El Norte equivale a la parte superior, y viceversa. La "Circulación Directa", CD, corresponde a la situación encontrada en la zona de entrada del chorro, o región de aceleración, observando como resultado neto un ascenso en la parte ciclónica del chorro, hacia el Sur, y un descenso en el lado opuesto. Observar que esto es precisamente lo que hemos encontrado, a saber, una región con mezcla intensa por encima del chorro, y transporte isentrópico desde la baja estratosfera de latitudes medias hacia la alta troposfera tropical, a través de la zona de inversión térmica asociada a la tropopausa 
térmica TT1. Con todo, en la página siguiente, figura 4.26 se muestra un esquema del modelo sugerido como interpretación de los resultados hallados a lo largo de este estudio.

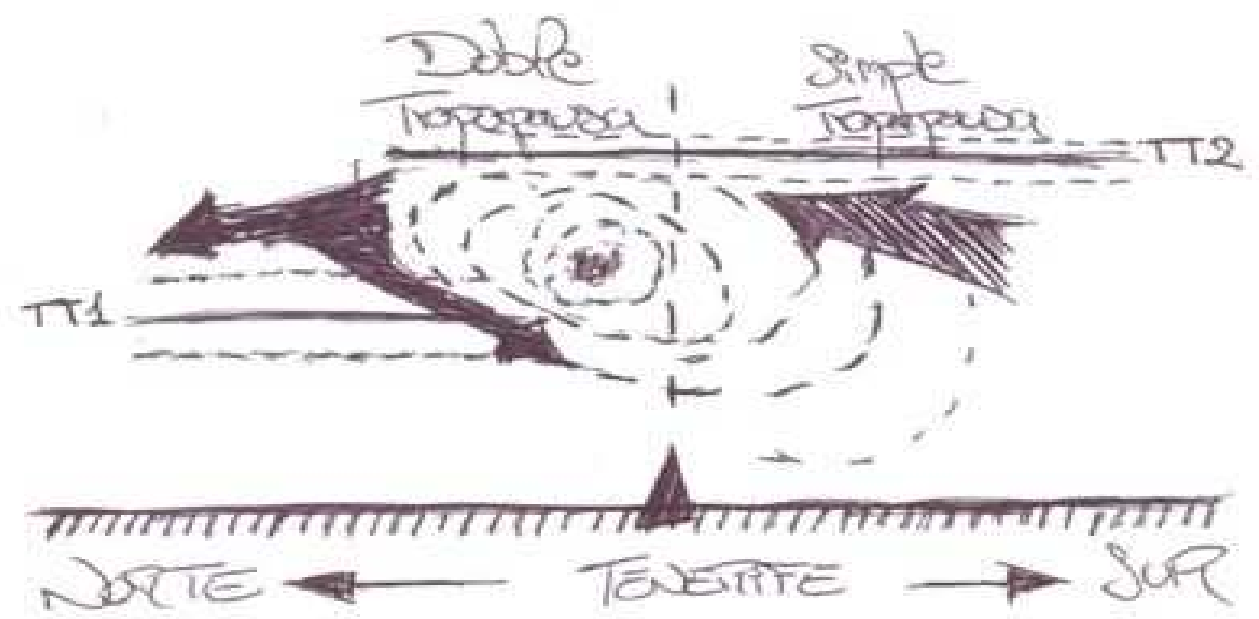

Figura 4.26 - Modelo conceptual propuesto para dar cuenta de los resultados obtenidos. Se muestra el Chorro Subtropical en la región inter-tropopausa (el chorro se mueve hacia el interior del plano del papel), ligeramente desplazado con respecto al extremo Sur de la tropopausa de latitudes medias, TT1, indicando además el nivel de la tropopausa tropical, TT2. Las lineas discontinuas paralelas a las dos tropopausas representan la zona de inversión térmica TIL asociada a la tropopausa. Las flechas sugieren el sentido neto de la circulación transversal asociada al chorro (su tamaño será equivalente a la intensidad de los procesos de transporte a los que representan). La circulación transversal asociada a la región de entrada del Chorro Subtropical provoca la advección cuasi-horizontal de aire desde la alta troposfera tropical hacia la baja estratosfera, forzando el transporte por encima de la región de máximo viento. En el lado septentrional del chorro tiene lugar el transporte de aire desde la baja estratosfera de latitudes medias hacia la tropoposfera tropical, siendo esta rama de la circulación directa menos intensa. Se muestra también el papel desempeñado por la región de máximo viento del chorro como barrera a los procesos de mezcla isentrópica 


\section{Capítulo 5}

\section{Conclusiones}

Desde Noviembre de 1992 hasta la actualidad se han realizado semanalmente ozonosondeos desde la isla de Tenerife $\left(28^{\circ} \mathrm{N}, 16^{\circ} \mathrm{W}, 36\right.$ m.s.n.m. $)$ utilizando para ello ozonosondas ECC, en particular del tipo $\boldsymbol{S P C - 5 A}$ (hasta Agosto de 1998) y $\boldsymbol{S P C} \boldsymbol{- 6 \boldsymbol { A }}$ (desde Agosto de 1998 hasta la actualidad), acopladas a una radiosonda estándar ( $R \boldsymbol{S} 80$ y $\boldsymbol{R} \boldsymbol{S 9 2})$. El resultado es una serie muy consistente de 15 años de ozonosondeos, con una distribución anual uniforme, en torno a 70 sondeos por mes, excepto para el mes de Julio, en el que se han llevado a cabo el mayor número de lanzamientos $(\sim 130)$. La altura máxima alcanzada por las ozonosondas individuales es, en promedio, de $32 \mathrm{~km}$. Teniendo en cuenta además que las ozonosondas constituyen la principal fuente de datos a la hora de obtener series temporales de ozono lo suficientemente extensas y con óptima resolución vertical, especialmente en la región UTLS, podemos afirmar que disponemos de un conjunto de datos de gran calidad para abordar el estudio de dicha región en latitudes subtropicales.

Previo al análisis de los datos se ha llevado a cabo un proceso de depuración de los ficheros originales, que podemos resumir en las siguientes etapas:

- Depuración de registros erróneos.

- Detección de "outliers".

- Homogeneización de la escala vertical.

En lo que respecta a la detección de "outliers" se ha adaptado con éxito al caso de los ozonosondeos una técnica aplicable a bases de datos espaciales, que denominamos SLOM, Spatial Local Outlier Measurement, y que asume en su definición la autocorrelación espacial así como una varianza no constante.

Puesto que cabe esperar para la región UTLS un comportamiento íntimamente ligado al nivel de la tropopausa, se ha utilizado ésta como nivel de referencia a la hora de calcular los valores climatológicos. De este modo ha sido posible el estudio de estructuras que de otro modo (por ejemplo si elegimos el nivel del suelo como referencia) hubieran pasado desapercibidas.

A partir del análisis de una serie de 15 años de ozonosondeos se ha demostrado que la región UTLS sobre Tenerife se halla fuertemente influenciada por el ciclo semianual de la célula de Hadley, distinguiéndose dos periodos claramente diferenciados. De Noviembre a Mayo domina en la UTLS la discontinuidad de la tropopausa global $(\sim 65 \%)$, con un 
espesor medio de $\sim 4 \mathrm{~km}$, encontrándose en el periodo de Junio a Noviembre una única tropopausa $(\sim 85 \%)$ hallada en promedio a $16 \mathrm{~km}$, y con un regimen de viento en altura muy diferente. El "Chorro Subtropical" alcanza su máxima intensidad entre Marzo y Abril. Durante el Otoño se observa un número significativo de perfiles con múltiples tropopausas, aunque no hay asociada una corriente en chorro definida. Este resultado confirma que la discontinuidad subtropical puede observarse sin que necesariamente exista un "Jet" intenso en las proximidades.

Una prueba del dinamismo inducido por el Chorro Subtropical en la región UTLS la encontramos en las características propias que muestran los perfiles de diferentes parámetros durante los meses de Noviembre a Febrero, por una parte, y de Marzo a Junio por otra. En este estudio hemos prestado especial atención a los meses en los que la influencia del chorro es patente. Otra opción sería el análisis de los meses en los que se detectan muy pocos casos de doble tropopausa, incluyendo Octubre y Noviembre. En todo caso se trata de un periodo interesante, permitiendo el estudio de la troposfera tropical en la zona de transición hacia latitudes medias. Una línea a seguir en el futuro sería el análisis de series temporales de ozono en la troposfera libre, caracterizando dicha región lo mejor posible. A partir de aquí sería posible obtener información referente a la posibilidad del desplazamiento hacia el Norte del cinturón subtropical, tal y como sugieren estudios recientes.

La mayoría de los sistemas de tropopausa múltiple detectados muestran doble tropopausa térmica, localizadas en $\sim 12 \mathrm{~km}(\sim 330 \mathrm{~K})$ y $\sim 16 \mathrm{~km}(\sim 400 \mathrm{~K})$ respectivamente. La región inter-tropopausa se extiende $\sim 4 \mathrm{~km}$ en dirección vertical durante el primer trimestre del año, para disminuir ligeramente su extensión a partir de Marzo. Los meses con una frecuencia de ocurrencia de triple tropopausa mayor que el $10 \%$ corresponden a Enero, Febrero y Marzo, coincidiendo aproximadamente con la tropopausa del punto frío, Esta última alcanza la máxima altura a lo largo de estos meses, $\sim 18 \mathrm{~km}(\sim 425 \mathrm{~K})$. La tropopausa química se localiza para todos los meses por encima de la primera tropopausa térmica observada, excepto en los meses de Abril a Junio, en los que se encuentra en niveles inferiores. La tropopausa dinámica no se ha identificado a partir de un valor predeterminado de vorticidad potencial, como es usual. En lugar de eso la hemos identificado con el nivel donde se observa un máximo en el gradiente vertical de vorticidad potencial. Los resultado obtenidos equivalen al rango $[2,53,5]$ pvu (potential vorticity unit) para la tropopausa dinámica, encuentrándose en todo momento por debajo de la primera tropopausa térmica observada, en claro desacuerdo con el comportamiento exhibido por la tropopausa química. Se concluye que la resolución vertical de los campos de reanálisis ECWMF $(\sim 2 \mathrm{~km})$ no es suficiente para detectar las estructuras observadas en la región UTLS subtropical.

La situación aparece menos compleja para los ozonosondeos mostrando una única tropopausa. En todo caso se aprecian diferencias notables entre los meses de Diciembre a Mayo, por un lado, y de Junio a Noviembre por otro, cuando la dispersión entre los niveles asignados a las diferentes definiciones de tropopausa es mínima. Entre todas definen una región de espesor $\sim 2 \mathrm{~km}$. Entre Diciembre y Mayo se observa una mayor dispersión, con una diferencia máxima entre tropopausas de $\sim 5 \mathrm{~km}$.

El análisis de la frecuencia de Brunt-Väisäla revela la existencia de una zona de inversión por encima de la tropopausa, con una intensificación de la estabilidad, TIL, Tropopause Inversion Layer. Análogamente, se observa en estos perfiles una región inmediatamente por debajo del nivel de la tropopausa a partir de la cual comienza la transición hacia valores propios de la estratosfera. Este resultado parece apoyar la idea de la tropopausa como 
un estrato de cierto espesor, más que como algo parecido a una superficie. Se observan diferencias apreciables para las dos tropopausas térmicas en lo que respecta a esta región. La tropopausa en niveles bajos muestra una TIL de espesor $\sim 2,5 \mathrm{~km}$, con muy poca variación mensual, mientras que para la tropopausa en niveles altos se encuentra para la TIL un espesor mucho menor, $\sim 0,8 \mathrm{~km}$ a lo largo del año. El máximo valor de la frecuencia de Brunt-Väisälä es aproximadamente igual en los dos casos, $N^{2} \approx 6 \times 10^{-4} s^{-2}$.

Una diferencia importante se observa inmediatamente bajo el nivel asignado a la tropopausa. En el caso de la tropopausa tropical, $N^{2}$ disminuye desde el valor $\sim 3 \times 10^{-4} \mathrm{~s}^{-2}$ en el nivel $-1,5 \mathrm{~km}$, es decir, $1,5 \mathrm{~km}$ por debajo del nivel de la tropopausa, hasta $\sim 2 \times 10^{-4} \mathrm{~s}^{-2}$ en la tropopausa térmica. En el caso de la tropopausa de latitudes medias $N^{2}$ aumenta desde el valor $\sim 1 \times 10^{-4} s^{-2}$ en el nivel $-2 \mathrm{~km}$ hasta $\sim 2 \times 10^{-4} s^{-2}$ en la tropopausa.

Si se comparan estos resultados con los expuestos en el párrafo anterior se concluye la idoneidad del índice de flotabilidad como "trazador" de la región de la tropopausa, TIL. Una línea de trabajo futura podría ser la investigación de la interacción de ondas gravitatorias con esta región peculiar en torno al nivel de la tropopausa térmica.

Con el objetivo de esclarecer en lo posible la influencia del Chorro Subtropical en la región UTLS se ha analizado la distibución vertical y anual del ozono. Las anomalías mensuales halladas en el rango de alturas comprendido entre los $11 \mathrm{~km}$ y los $18 \mathrm{~km}$ muestran desviaciones de hasta el $40 \%$ con respecto al perfil anual. En la troposfera, en torno a $5 \mathrm{~km}$, y la estratosfera alrededor de $25 \mathrm{~km}$ las diferencias son sensiblemente inferiores, $\sim 20 \% \mathrm{y}$ $\sim 10 \%$ respectivamente. El análisis de la variabilidad mensual revela la existencia en la UTLS de dos niveles con muy diferentes valores en la desviación estándar del ozono: una región centrada en el nivel de la primera tropopausa térmica de espesor $\sim 4 \mathrm{~km}$ y error estándar en torno al $15 \%$ para todos los meses salvo Julio, Agosto y Septiembre, y una segunda región entre $2 \mathrm{~km}$ y $5 \mathrm{~km}$ por encima de la tropopausa con valor máximo del error estándar en el mes de Febrero $(\sim 28 \%)$ y mínimo en Noviembre $(\sim 16 \%)$. Estas consideraciones, junto con las propiedades termodinámicas de la región de la tropopausa, apuntan hacia la existencia de una región donde tienen lugar procesos de mezcla. Para investigar este último punto se calculan las secciones anuales para la presión parcial de ozono, las cuales muestran una región de máximo en el ozono coincidente con la TIL asociada a la tropopausa de latitudes medias. El ozono podría jugar un papel activo en el mantenimiento e intensificación de la TIL, contribuyendo a incrementar la estabilidad de dicha región por calentamiento en longitud de onda larga. Sin embargo, es necesario realizar un mayor análisis con el objetivo de corroborar esta hipótesis.

Se observa claramente en la región inter-tropopausa lo que parece ser mezcla de dos masas de aire a un lado y otro de la discontinuidad en la tropopausa global: hacia el Norte, aire de la baja estratosfera de latitudes medias, y hacia el Sur, aire de la alta troposfera tropical. Basándonos en resultados obtenidos en trabajos previos acerca del comportamiento del Chorro Subtropical en la vecindad de Canarias, confirmados a su vez por los obtenidos en este estudio, se propone un modelo conceptual que daría cuenta de los fenómenos observados. La circulación transversal asociada a la región de entrada del Chorro Subtropical provoca la advección cuasi-horizontal de aire desde la alta troposfera tropical hacia la baja estratosfera de latitudes medias, forzando el transporte por encima de la región de máximo viento. En el lado septentrional del chorro tiene lugar el transporte de aire desde la baja estratosfera de latitudes medias hacia la tropoposfera tropical, siendo esta rama de la circulación directa menos intensa. La zona de inversión sobre la tropopausa de latitudes medias 
actuaría favoreciendo el transporte isentrópico. Se confirma además el papel de la región de máximo viento del chorro como barrera a los procesos de mezcla isentrópica.

En vista del modelo propuesto, la isla de Tenerife resulta ser un enclave de máximo intéres para el estudio de los procesos de transporte asociados al Chorro Subtropical. En efecto, en función de la época del año estaremos observando una u otra rama (ascendente y descendente respectivamente) de la circulación transversal asociada al chorro, permitiendo una caracterización precisa de ambas componentes. Será necesario en el futuro un estudio más profundo con el fin de confirmar los procesos esbozados a lo largo de este trabajo. 


\section{Bibliografía}

[Ambaum, 1997] Ambaum, M. (1997). Isentropic formation of the tropopause. J. Atmos. Sci., 54:555-568.

[Baray et al., 1998] Baray, J., Ancellet, G., Taupin, F., et al. (1998). Subtropical tropopause break as a possible stratospheric source of ozone in the tropical troposphere. Journal of Atmospheric and Solar-Terrestrial Physics, 60:27-36(10). doi:10.1016/S13646826(97)00116-8.

[Beekmann et al., 1994] Beekmann, M. et al. (1994). Climatology of tropospheric ozone in southern europe and its relation to potential vorticity. J. Geophys. Res., 99(D6):12,841-12,854.

[Bell and Geller, 2008] Bell, S. W. and Geller, M. A. (2008). Tropopause inversion layer: Seasonal and latitudinal variations and representation in standard radiosonde data and global models. J. Geophys. Res., 113. doi 10.1029/2007JD009022.

[Bethan et al., 1996] Bethan, S. et al. (1996). A comparison of ozone and thermal tropopause heights and the impact of tropopause definition on quantifying the ozone content of the troposphere. Q.J.R. Meteorol. Soc., 122, Issue 532:929-944.

[Birner, 2006] Birner, T. (2006). The fine scale structure of the extratropical tropopause region. J. Geophys. Res., 111. D04104 doi:10.1029/2005JD006301.

[Birner et al., 2002] Birner, T. et al. (2002). How sharp is the tropopause at midlatitude? Geophys. Res. Lett., 29(14). 1700, doi:10.1029/2002GL015142.

[Bischoff et al., 2007] Bischoff, S., Canziani, P., and Yuchechen, A. (2007). The tropopause at southern extratropical latitudes: Argentine operational rawinsonde climatology. International Journal of Climatology, 27:189-209. doi:10.1002/joc.1385.

[Cuevas and Rodríguez, 2001] Cuevas, E. and Rodríguez, J. (2001). Estadísticas de depresiones aisladas en niveles altos. In V Simposio Nacional de Predicción. INM, Madrid.

[Cuevas and Rodríguez, 2002] Cuevas, E. and Rodríguez, J. (2002). Caracterización del chorro subtropical. In $3^{a}$ Asamblea Hispano Portuguesa de Geodesia y Geofísica.

[Danielsen, 1968] Danielsen, E. (1968). Stratospheric-tropospheric exchange based on radioactivity, ozone and potential vorticity. J. Atmos. Sci., 25:502-518.

[Folkins and Appenzeller, 1996] Folkins, I. and Appenzeller, C. (1996). Ozone and potential vorticity at the subtropical tropopause break. J. Geophys. Res., 101:18,787-18,792. 
[Gettelman and de Forster, 2002] Gettelman, A. and de Forster, P. M. (2002). Definition and climatology of the tropical tropopause layer. Journal of the Meteorological Society of Japan, 80 (4B):911-924.

[Glickman, 2000] Glickman, T. S. (2000). Glossary of meteorology. American Meteorological Society, second edition.

[Haynes et al., 2001] Haynes, P., Scinocca, J., and Greenslade, M. (2001). Formation and maintenance of the extratropical tropopause by baroclinic eddies. Geophys. Res. Lett., 28(22):4,179- 4,182.

[Highwood and Hoskins, 1998] Highwood, E. J. and Hoskins, B. J. (1998). The tropical tropopause. Quarterly Journal of the Royal Meteorological Society, 124:1579-1604. doi 10.1256 /smsqj. 54910 .

[Hoerling et al., 1991] Hoerling, M. P., Schaak, T. D., and Lenzen, A. J. (1991). Global objective tropopause analysis. Monthly Weather Review, 119:1,816-1,831.

[Hoinka, 1997] Hoinka, K. (1997). The tropopause: Discovery, definition and demarcation. Meteorologische Zeitschrift, 6:281-303.

[Hoinka, 1998] Hoinka, K. (1998). Statistics of the global tropopause pressure. Mon. Wea. Rev, 126:3,303-3,325.

[Holton et al., 1995] Holton, J.R.; Haynes, P. et al. (1995). Stratosphere-troposphere exchange. Rev. Geophys., 33:403-439.

[Kahya et al., 2005] Kahya, C. et al. (2005). An examination of the laminae characteristics in ozone profiles in eastern and south eastern europe. International Journal of Remote Sensing, V26(N16):3455-3466.

[Kochanski, 1955] Kochanski, A. (1955). Cross sections of the mean zonal flow and temperature along $80^{\circ} \mathrm{W}$. J. Meteor., 12:95-106.

[Komhyr, 1969] Komhyr, W. D. (1969). Electrochemical cells for gas analysis. Ann. Geophys., 25.

[Komhyr, 1986] Komhyr, W. D. (1986). Operations handbook-ozone measurements to 40$\mathrm{km}$ altitude with model 4a electrochemical concentration cell (ecc) ozonesondes (used with 1680 mhz radiosondes). Technical report, NOAA Tech. Memo. ERL ARL-149, 49p.

[Komhyr and Harris, 1971] Komhyr, W. D. and Harris, T. B. (1971). Development of an ecc ozonesonde. Technical report, NOAA Tech. Rep. ERL 200, APCL 18.

[Logan, 1999] Logan, J. A. (1999). An analysis of ozonesonde data for the troposphere: Recommendations for testing 3-d models and development of a gridded climatology for tropospheric ozone. J. Geophys. Res., 104(D13):16,115-16,149.

[WMO, 1957] WMO (1957). Meteorology - A three-dimensional science: Second session of the Commission for Aerology. WMO Bulletin, vol. IV, no.4:134-138, Geneva, Switzerland.

[WMO, 1986] WMO (1986). Atmospheric ozone 1985, WMO Global Ozone Res. and Monit. Proj. Rep., 20. Geneva, Switzerland. 
[Pan et al., 2004] Pan, L.L.; Randel, W. J. et al. (2004). Definitions and sharpness of the extratropical tropopause: A trace gas perspective. J. Geophys. Res., Atmospheres, 109. D23103, doi:10.1029/2004JD004982.

[Randel et al., 2007] Randel, W. J., Seidel, D. J., and Pan, P. L. (2007). Observational characteristics of double tropopauses. J.Geophys.Res., 112. D07309, doi:10.1029/2006JD007904.

[Randel et al., 2007] Randel, W. J., Wu, F., and Forster, P. (2007). The extratropical tropopause inversion layer: Global observations with gps data, and a radiative forcing mechanism. Journal of the Atmospheric Sciences, 64(12):4,489-4,496.

[Ray et al., 2004] Ray, E. A., Rosenlof, K. H., Richard, E., Parrish, D., and Jakoubek, R. (2004). Distributions of ozone in the region of the subtropical jet: An analysis of in situ aircraft measurements. J. Geophys. Res., 109, D08106:18,787-18,792. doi:10.1029/2003JD004143.

[Reichler et al., 2003] Reichler, T., Dameris, M., and Sausen, R. (2003). Determination of tropopause heights from gridded data. Geophys. Res. Lett., 30(20). doi: 10.1029/2003GL018240.

[Sancho et al., 2001] Sancho, A. J. M., Afonso, G. S., and Cuevas, A. E. (2001). Programa de Ozonosondeos del Observatorio Atmosférico de Izaña. Technical Report 3, Instituto Nacional de Meteorología.

[Sancho and Romero, 2002] Sancho, A. J. M. and Romero, P. M. C. (2002). Programa de Ozonosondeos del Observatorio Atmosférico de Izaña: El ozono sobre Tenerife y su relación con la procedencia de las masas de aire. Technical Report 4, Instituto Nacional de Meteorología.

[Sausen and Santer, 2003] Sausen, R. and Santer, B. D. (2003). Use of changes in tropopause height to detect human influences on climate. Meteorologische Zeitschrift, 12, no3:131-136.

[Schneider, 2004] Schneider, T. (2004). The tropopause and the thermal stratification in the extratropics of a dry atmosphere. J. Atmos. Sci., 61:1,317-1,340.

[Seidel et al., 2001] Seidel, D. J., Ross, R. J., Angell, J. K., and Reid, G. C. (2001). Climatological characteristics of the tropical tropopause as revealed by radiosondes. J.Geophys.Res., 106, No.D8:7,857-7,878.

[Steinbrecht et al., 1998] Steinbrecht, W. H., Claude, U. K., and Hoinka, K. P. (1998). Correlations between tropopause height and total ozone: implications for long term changes. J. Geophys. Res., 103 (D04104):19,183-19,192. doi:10.1029/2005JD006301.

[Sun and Chawla, 2004] Sun, P. and Chawla, S. (2004). On local spatial outliers. In ICDM '04: Proceedings of the Fourth IEEE International Conference on Data Mining, pages 209-216, Washington, DC, USA. IEEE Computer Society.

[Thuburn and Craig, 1997] Thuburn, J. T. and Craig, G. C. (1997). Gcm tests of theories for the height of the tropopause. J. Atmos. Sci., 54:869-882. 
[Wei, 1987] Wei, M. (1987). A new formulation of the exchange of mass and trace constituents between the stratosphere and troposphere. Journal of the Atmospheric Sciences, 44, D20:3,079-3,086. doi:10.1175/1520-0469.

[Wirth, 1995] Wirth, V. (1995). Diabatic heating in an axisymmetric cut-off cyclone and related stratosphere-troposphere exchange. Q. J. R. Meteorol. Soc., 121:127-147.

[Wirth, 2001] Wirth, V. (2001). Cyclone-anticyclone asymmetry concerning the height of the thermal and the dynamical tropopause. J. Atmos. Sci., 58:26-37.

[Wirth, 2004] Wirth, V. (2004). A dynamical mechanism for tropopause sharpening. Met. Zeitschrift, 13:477-484.

[Zahn et al., 2004] Zahn, A. et al. (2004). Passenger aircraft project caribic 1997-2002, part I: the extratropical chemical tropopause. Atmos. Chem. Phys. Discuss., 4:1,091-1,117.

[Ziv and Paldor, 1998] Ziv, B. and Paldor, N. (1998). The divergence fields associated with time-dependent jet streams. American Meteorological Society, pages 1,843-1,857. 